\title{
Overview of Zoonotic Diseases in Turkey: The One Health Concept and Future Threats
}

\author{
Türkiye’de Zoonotik Hastalıklara Genel Bakış: Tek Sağlık Konsepti ve Gelecek Tehditler
}

\author{
Abdullah Inci ${ }^{1,2}$ (D), Mehmet Doğanay ${ }^{2,3}$ (D), Aykut Özdarendeli2,4 (D), Önder Düzlü ${ }^{1,2}$ (B), \\ Alparslan Yıldırım ${ }^{1,2}$
}

1Department of Parasitology, Erciyes University Faculty of Veterinary Medicine, Kayseri, Turkey

${ }^{2}$ Erciyes University Vectors and Vector Borne Diseases Implementation and Research Center, Kayseri, Turkey

${ }^{3}$ Department of Infectious Diseases and Clinical Microbiology, Erciyes University School of Medicine, Kayseri, Turkey

${ }^{4}$ Department of Microbiology, Erciyes University School of Medicine, Kayseri, Turkey

Cite this article as: Inci A, Doğanay M, Özdarendeli A, Düzlü Ö, Yıldırım A. Overview of Zoonotic Diseases in Turkey: The One Health Concept and Future Threats. Turkiye Parazitol Derg 2018; 42:39-80

\section{ABSTRACT}

Zoonotic infections are globally important diseases and lead to huge economic losses in both low- and middle-income and high-income countries. Global warming, environmental and ecological changes, illegal movement of animals and humans, regional civil wars, and poverty are predisposing factors for the emergence of zoonotic infections and their distribution worldwide; they are also a big threat for the future. In addition, environmental pollution and antimicrobial resistance are immense serious threats and dangers to prevent and control zoonotic infections. The natural location of Turkey allows many emerged or re-emerged infections with zoonotic characteristics by animal movements, such as bird immigrations, and by human movements due to civil wars as seen with regional refugees. Numerous zoonotic diseases, including 37 bacterial, 13 fungal, 29 viral, 28 parasitic ( 3 trematodes, 7 cestodes, 10 nematodes, and 8 protozoan), and totally 107 infections, have been reported from Turkey to date. Additionally, many ectoparasitic zoonoses within 15 different arthropod groups and one leech infestation have been reported from Turkey to date. The "One Health" initiative is particularly relevant for developing strategies to combat zoonotic diseases. In this article, we review the occurrence of zoonotic diseases in man and animals in Turkey in the light of the "One Health" perspective. Keywords: Zoonotic diseases, Turkey, one health concept, future threats Received: 31.10 .2017

Accepted: 01.02.2018

\section{öz}

Zoonotik enfeksiyonlar global öneme sahip olup gerek düşük ve orta gelirli ülkelerde gerekse geliri yüksek ülkelerde büyük ekonomik kayıplara neden olmaktadır. Küresel ısınma, çevresel ve ekolojik değişiklikler, yasadışı insan ve hayvan hareketleri, bölgesel sivil savaşlar ile fakirlik zoonotik enfeksiyonların ortaya çıkması ve dünya genelinde yayılmasında predispoze faktörler olup ayrıca gelecek için büyük tehdit oluşturmaktadırlar. Bununla birlikte, çevre kirliliği ve antimikrobiyel direnç zoonotik enfeksiyonların kontrolü ve önlenmesinde çok ciddi tehdit oluşturmaktadır. Doğal lokasyonu, sivil savaşlara bağlı bölgesel mülteci göçleri ve göçmen kuşlar gibi hayvan hareketleri dolayısıyla Türkiye birçok yeni ve tekraren ortaya çıkan zoonotik enfeksiyonlar açısından risk taşımaktadır. Türkiye'de bugüne kadar 37 bakteriyel, 13 mantar, 29 viral, 28 parazitik ( 3 trematod, 7 cestod, 10 nematod ve 8 protozoon) olmak üzere toplam 107 farklı zoonotik enfeksiyon bildirilmiştir. Buna ilaveten 15 farklı artropod grubu ve 1 sülük enfestasyonu olmak üzere birçok ektoparazitik zoonozlar da günümüze kadar Türkiye'den bildirilmiştir. "Tek Sağlık" konsepti, özellikle zoonotik enfeksiyonlarla mücadele stratejilerinin geliştirilmesinde uygun bir yaklaşımdır. Bu derlemede "Tek Sağlık" perspektifi ışı̆̆ında Türkiye'de insan ve hayvanlarda görülen zoonotik hastalıklar hakkında bilgi verilmiştir.

Anahtar sözcükler: Zoonotik hastalıklar, Türkiye, tek sağlık konsepti, gelecek tehditler

Geliş Tarihi: 31.10 .2017

Kabul Tarihi: 01.02.2018

Address for Correspondence / Yazışma Adresi: Abdullah Inci E.mail: ainci@erciyes.edu.tr DOI: 10.5152/tpd.2018.5701

CCopyright 2018 Turkish Society for Parasitology - Available online at www.turkiyeparazitolderg.org

(C)Telif hakkı 2018 Türkiye Parazitoloji Derneği - Makale metnine www.turkiyeparazitolderg.org web sayfasından ulaşılabilir. 


\section{INTRODUCTION}

Zoonotic diseases are contagious or non-contagious infections with emerging and/or re-emerging characteristics and naturally transmissible from vertebrate animals to humans and vice-versa via contact, food, water, and by vectors in the human and animal ecosystems; their increasing risks affect global health security (1-3). These infections are caused by all types of pathogens, including bacteria, fungi, parasites, viruses, and unconventional agents such as prions. Prior to the 20th century, the best known zoonoses were rabies, anthrax, glanders, tuberculosis, plague, yellow fever, influenza, and certain zoonotic parasitic diseases (4). Sixty percent of 300 infectious agents identified between 1940 and 2004 have been classified as zoonoses, and most of these infections belong to the neglected diseases $(5,6)$. More than 200 zoonoses have previously been described to date, and their epidemiological appearance and distributions occur in sporadic, endemic, epidemic, and pandemic forms in the world causing deaths among humans, livestock, as well as wildlife. Zoonotic infections also result in great economic losses $(5,7)$ and could be one of the major reasons of poverty (6-8). The public health impact and financial consequences of these diseases can devastate the already overburdened economic conditions in developing countries as well as in Turkey $(9,10)$. Over the last decade, the global economic impact of zoonotic diseases has been estimated as more than $\$ 220$ billion ( $\$ 20$ billion from direct costs and $\$ 200$ billion from indirect losses) $(11,12)$. In the second-half of the last century, the control and/or elimination of zoonotic diseases has been successful in several industrialized countries through expensive infrastructural investments and meticulous coordinated interventions, including "test and cull of animals," feed bans, mass vaccination of domestic animals and wildlife, health education, and milk pasteurization. Naturally, these highly effective methods for elimination of zoonotic diseases involve legal and financial collaterals. However, in most developing countries, livestock practices have primarily focused on implementing prevention and eradication measures with much less emphasis on the effect of mitigation (transmission control) strategies, considering the economic and development impacts at the macro (national economy and environment) or micro (health, livelihoods, and food security of smallholder farmers) levels. Thus, in most developing countries, the surveillance of zoonotic diseases is not recognized in the One Health context between veterinary medicine and human medicine. In addition, many countries lack diagnostic capacity and health infrastructure (7). Meanwhile, the global increase in zoonotic diseases was reported as 22\% in 1990-2000 and 21\% in 2000-2010 (13). The zoonotic infections that have emerged or re-emerged globally are Severe Acute Respiratory Syndrome (SARS) in 2003, Influenza A H1N5 (avian influenza) in 2003, Influenza A H1N1 (pandemic influenza or swine flu) in 2009-2010, Middle East Respiratory Syndrome (MERS) in 2012, Influenza A H7N9 in 2013, Ebola in 2014, and Zika virus in 2015-2016. To combat of zoonoses, the One Health concept has been defined by the World Health Organization (WHO) as a worldwide strategy that would expand interdisciplinary collaborations and communications in all aspects of health care for humans, animals, and environment (14).
Turkey is geographically located in Eurasia and represents a natural bridge for the transmission of many zoonotic infections that involve the movement of animals (particularly bird immigrations) and humans (illegal transport of humans or mass immigrations of populations) among the continents of Europe, Asia, and Africa. Turkey has a population of over 80 million and a livestock population of over 50 million, and its economic structure currently depends on a mix of industrial and agricultural products (10). Currently, Turkey has been affected from illegal animal and human movements. In particular, regional conflicts in the countries neighboring Turkey has led to massive refugee and illegal human movements during the past 30 years (15-17). In addition, Turkey has highly variable climatic conditions, vegetation structures, wildlife, and particularly many sanctuaries for immigrant birds. The geographic structure of Turkey also allows suitable habitats for various vector arthropods, such as bloodfeeding insects and ticks, throughout the four seasons of the year (10, 18-21). Thus, several zoonotic diseases are endemic throughout the country and affect humans and animals (22-24) with economic losses (25-30). In this review, an overview of the zoonotic diseases (Figure 1) in Turkey are described in the One Health concept and future threats perspectives.

\section{ZOONOTIC DISEASES IN TURKEY}

The dynamic interactions of zoonoses among humans, animals, and pathogens in the same environment could be evaluated within the "One World-One Health" concept with a holistic perspective. Actually, this approach dates back to the ancient periods of humankind (31). Prior to the discovery and application of sanitation and hygiene, particularly sterilization and antibiotics, bacterial zoonotic diseases, such as bovine tuberculosis, bubonic plague, and glanders, caused millions of human deaths in the world as well in Turkey (32). The discovery and application of insecticides and acaricides, and entomopathogens led to the reduction of vector-borne infections in the last century in Turkey as well globally (33). Effectively implemented control measures have resulted in a decrease in many community-acquired infections, including bacterial and parasitic diseases, such as tuberculosis and malaria, which constituted major public health problems until a few decades ago. Meanwhile, the frequent use of antibiotics in human medicine and veterinary purposes have led to the emergence of antimicrobial resistance in various nosocomial isolates of gram-positive and gram-negative bacteria. However, recent guidelines limiting antibiotic applications have been promising (34).

In addition, over 50 vector-borne infections (19 tick-borne diseases [TBDs]) caused by different pathogens have been reported in farm animals and humans $(20,21)$ and in cats and dogs $(35)$. A total of 47 tick species (38 ixodid and 9 argasid) have also been reported in the last century in Turkey (10), and these zoonotic diseases have a significant impact on the livestock industry of the country $(26,29,30)$.

Modes of transmission for zoonotic diseases between animals and humans involve several routes: (i) via blood-feeding arthropods, such as ticks, mites, fleas, biting midges, mosquitoes, and sand flies; (ii) via contaminated food (food-borne) and/or contaminated water (water-borne); (iii) via direct contact (ie, farmers, 


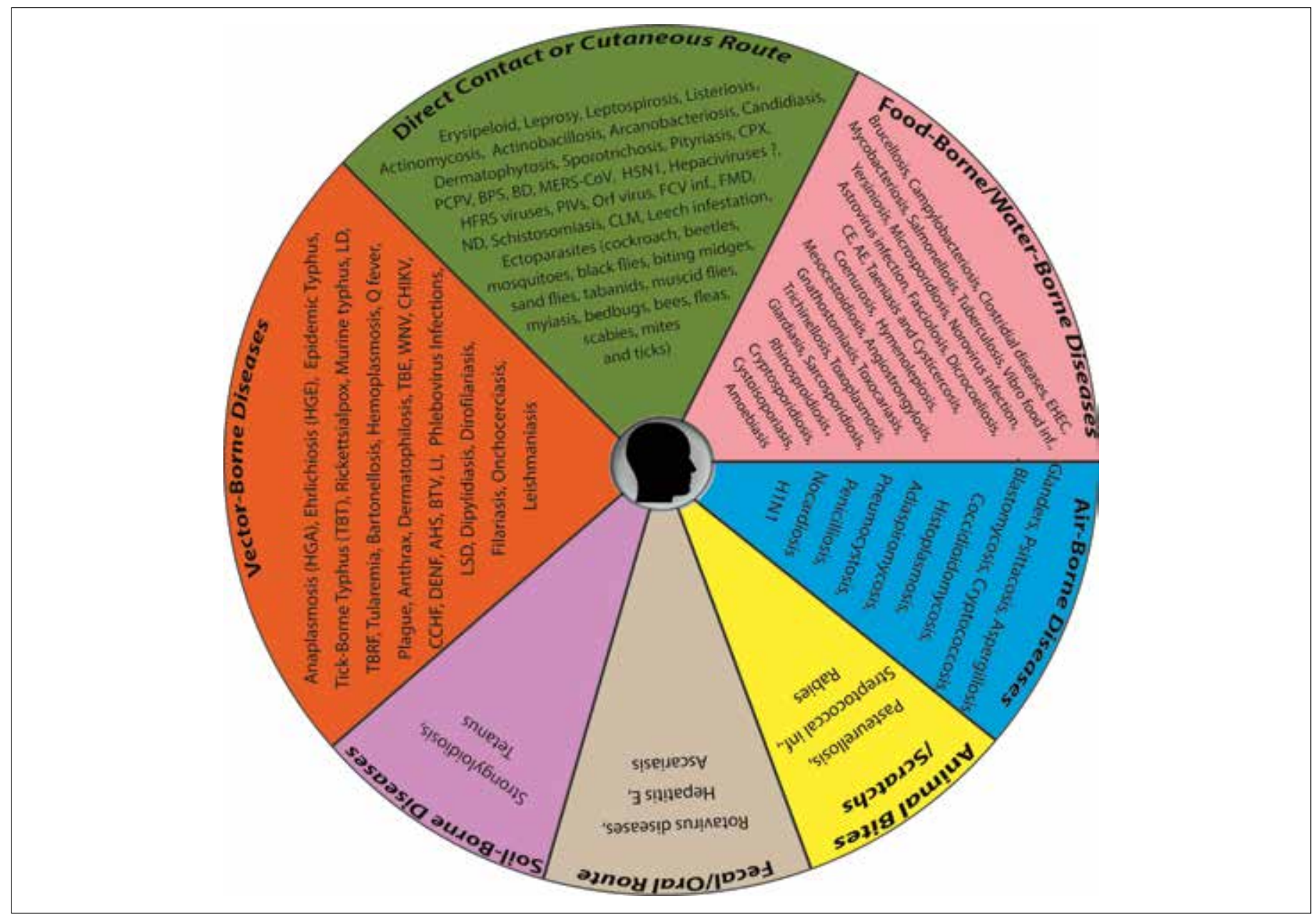

Figure 1. Overview of zoonotic diseases found in Turkey

workers, and veterinarians at increased risk to exposure with zoonotic agents); (iv) via soil contaminated with manure; (v) via animal bites and/or animal scratches; and (vi) invasion with active penetration (36). In addition, some zoonotic diseases can be transmitted from patients to health care workers and health professionals (physicians, nurses, and other health staffs) (37).

\section{Bacterial Zoonotic Diseases in Turkey}

Bacterial zoonoses are grouped based on the infection routes described above. Most of the vector-borne bacterial zoonotic diseases are classified depending on the biological vector involved in its transmission, such as tick-, mite-, flea-, and insectborne. In addition, mechanical transmission of some bacterial zoonoses are also possible by iatrogenic or by insects, whereas a few zoonotic bacterial pathogens can be transmitted by the ingestion of trematodes and caddishflies as well. Particularly, tick-borne bacterial zoonoses are complex and have been grouped as rickettsial (38) and non-rickettsial (39). The reported bacterial zoonotic diseases in Turkey are shown in Table 1.

Anaplasmosis is an opportunistic rickettsial vector-borne disease of humans and animals, caused by Anaplasma species including A. marginale, A. centrale, $A$. bovis, and $A$. ovis for ruminants; $A$. platys for canines; and A. pagacytophilum for human and domestic animals such as horses. The infection is widespread and transmitted iatrogenically and mainly intrastadially by male ticks; the disease is called Human Granulocytic Anaplasmosis or Human Granulocytic Ehrlichiosis (HGE) in man. The etiologic agent of HGE A. phagocytophilum is transmitted by Am. americanum ticks in endemic areas (40). A. phagocytophilum was determined in farm animals $(41,42)$ and in humans $(43,44)$ in Turkey. Additionally, A. phagocytophilum was detected in Ixodes ricinus ticks isolated from humans (45). A few bovine anaplasmosis outbreaks were also reported in cattle from some areas (35, 46-49) and one A. platys infection was reported in a dog in Turkey (50).

Ehrlichiosis is caused by A. phagocytophilum, Ehrlichia chaffeesis, and E. ewingii in humans and is called Human Monocytotropic Ehrlichiosis and by A. phagocytophilum and E. canis in dogs and is called Canine Monocytotropic Ehrlichiosis (CME). The diseases are transmitted by ixodid ticks and are of public health and veterinary importance (38). In Turkey, the studies on CME are very limited but few reports have documented seropositivity (51), clinical cases, treatment $(52)$, and molecular prevalence $(53,54)$.

Typhus (Epidemic Typhus) is an arthropod-transmitted infection in humans and animals caused by Rickettsia prowazekii. At least 
Table 1. Reports on zoonotic diseases in Turkey

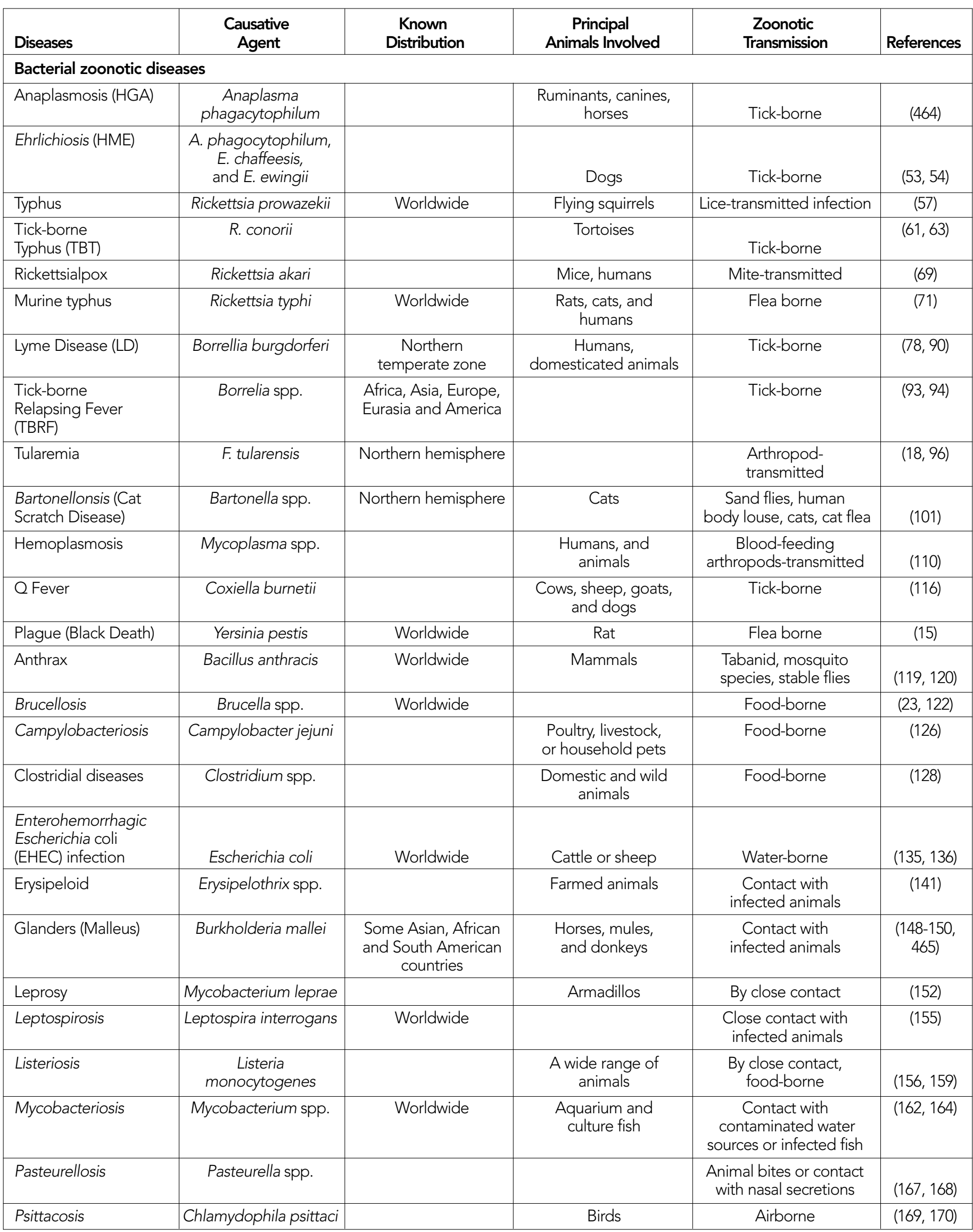




\begin{tabular}{|c|c|c|c|c|c|c|c|c|}
\hline \multicolumn{3}{|c|}{ Salmonellosis } & \multicolumn{2}{|c|}{ Salmonella enterica } & Worldwide & $\begin{array}{l}\text { Domestic and wild } \\
\quad \text { animals }\end{array}$ & Food-borne & $(172,175)$ \\
\hline \multicolumn{3}{|c|}{$\begin{array}{l}\text { Streptococcal } \\
\text { infections }\end{array}$} & \multicolumn{2}{|c|}{ Streptococcus spp. } & & $\begin{array}{l}\text { Dog and cat, } \\
\text { wild predatory animal }\end{array}$ & Dog and cat bites & $(181,182)$ \\
\hline \multicolumn{3}{|c|}{ Tetanus (lockjaw) } & \multicolumn{2}{|c|}{ Clostridium tetani } & $\begin{array}{l}\text { Many developing } \\
\text { countries }\end{array}$ & & Soil borne & (131) \\
\hline \multicolumn{3}{|c|}{ Tuberculosis } & \multicolumn{2}{|c|}{$\begin{array}{l}\text { Mycobacterium } \\
\text { tuberculosis }\end{array}$} & Worldwide & & By close conctact & (124) \\
\hline \multicolumn{3}{|c|}{ Vibrio Food Infection } & \multicolumn{2}{|c|}{ Vibrio spp. } & & & $\begin{array}{l}\text { Food-borne, } \\
\text { water-borne }\end{array}$ & (188) \\
\hline \multicolumn{3}{|c|}{ Yersiniosis } & \multicolumn{2}{|c|}{ Yersinia spp. } & & & Food-borne & $(189,191)$ \\
\hline \multicolumn{3}{|c|}{ Actinomycosis } & \multicolumn{2}{|c|}{ Actinomyces spp. } & & Cattle & $\begin{array}{l}\text { By contact with } \\
\text { infected animals }\end{array}$ & $(194,195)$ \\
\hline \multicolumn{3}{|c|}{ Actinobacillosis } & \multicolumn{2}{|c|}{ Actinobacillus lignieresii } & & Sheep and cattle & Cutaneous route & (194) \\
\hline \multicolumn{3}{|c|}{ Arcanobacteriosis } & \multicolumn{2}{|c|}{ Arcanobacterium spp. } & & Cattle and sheep & By close contact & $(200,201)$ \\
\hline \multicolumn{3}{|c|}{ Dermatophilosis } & \multicolumn{2}{|c|}{$\begin{array}{l}\text { Dermatophilus } \\
\text { congolensis }\end{array}$} & & $\begin{array}{l}\text { Horses, dogs, cats, } \\
\text { and ruminants }\end{array}$ & Vector-borne & $(202,203)$ \\
\hline \multicolumn{3}{|c|}{ Nocardiosis } & \multicolumn{2}{|c|}{ Nocardia asteriodes } & & Dog & $\begin{array}{l}\text { Ways such as inhalation, } \\
\text { traumatic inoculation }\end{array}$ & $(206,207)$ \\
\hline \multicolumn{9}{|c|}{ Fungal Zoonotic Diseases } \\
\hline \multicolumn{3}{|c|}{ Aspergillosis } & \multicolumn{2}{|c|}{ Aspergillus spp. } & & Birds, dogs, and horses & Airborne & $(213,214)$ \\
\hline \multicolumn{3}{|c|}{ Blastomycosis } & \multicolumn{2}{|c|}{ Blastomyces dermatitis } & North America & Humans and animals & Airborne & (216) \\
\hline \multicolumn{3}{|c|}{ Candidiasis } & \multicolumn{2}{|c|}{ Candida albicans } & & Humans and birds & Direct contact & (217) \\
\hline \multicolumn{3}{|c|}{ Coccidioidomycosis } & Cocc & dioides spp. & Western Hemisphere & $\begin{array}{l}\text { Cattle, cats, horses, } \\
\text { dogs, and wildlife }\end{array}$ & Airborne & (219) \\
\hline & yptococc & & & $\begin{array}{l}\text { otococcus } \\
\text { oformans }\end{array}$ & Worldwide & $\begin{array}{l}\text { Livestock animals, dogs, } \\
\text { cats, birds, and wild life }\end{array}$ & Airborne & (221) \\
\hline & istoplasm & & Histopla & ma capsulatum & Worldwide & $\begin{array}{l}\text { Dogs, cats, farm } \\
\text { animals, and other } \\
\text { wild mammalians }\end{array}$ & By inhalation of the spores & (223) \\
\hline & ermatoph & ytosis & Trich & phyton spp. & & Humans and animals & By direct contact & (225) \\
\hline & orotricho & & Sporc & hrix schenckii & Worldwide & Horses and cats & Contaminated environment & (228) \\
\hline & enicilliosis & & Per & cillium spp. & South Asia countries & Human & Still not known & (229) \\
\hline & neumocys & tosis & Pnes & nocytis spp. & & $\begin{array}{l}\text { Rodents, rabbits, } \\
\text { and humans }\end{array}$ & Airborne & (238) \\
\hline & $\begin{aligned} \text { alassezia } \\
\text { Pityriasi }\end{aligned}$ & nfection or & & $\begin{array}{l}\text { alassezia } \\
\text { hydermatis }\end{array}$ & & Humans and animals & Mechanically via hands & (235) \\
\hline & diaspirom & ycosis & Em & onsia spp. & Worldwide & Humans and animals & Airborne & (237) \\
\hline & icrosporic & iosis & $\begin{array}{r}\text { Encep } \\
\text { and }\end{array}$ & $\begin{array}{l}\text { alitozoon spp. } \\
\text { En. bieneusi }\end{array}$ & Worldwide & Humans and animals & $\begin{array}{l}\text { By ingestion or inhalation } \\
\text { of the spores }\end{array}$ & (244) \\
\hline & ral Zoonc & tic Disease & & & & & & \\
\hline 1 & & Rabies & & Lyssavirus & & Carnivores & Dog bites & (252) \\
\hline 2 & 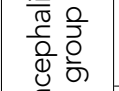 & $\begin{array}{l}\text { Tick-Borne } \\
\text { Encephaliti }\end{array}$ & is (TBE) & Flavivirus & Asia and Europe & & Tick-borne & (20) \\
\hline 3 & फ & $\begin{array}{l}\text { West Nile } \\
\text { (WNV) }\end{array}$ & & Flavivirus & Worldwide & Domestic animals & Mosquito-borne & (21) \\
\hline 4 & 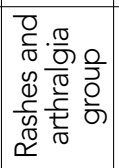 & $\begin{array}{l}\text { Chikungun } \\
\text { (CHIKV) }\end{array}$ & yya virus & Alphavirus & Africa and Asia & & Mosquito-borne & $(254,255)$ \\
\hline
\end{tabular}




\begin{tabular}{|c|c|c|c|c|c|c|c|}
\hline 6 & 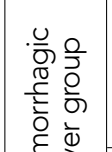 & $\mathrm{CCHF}$ & Nairovirus & $\begin{array}{c}\text { Sub-Saharan Africa, } \\
\text { Eastern Europe, Russia, } \\
\text { the Middle East, } \\
\text { West China }\end{array}$ & $\begin{array}{l}\text { Wild and } \\
\text { livestock animals }\end{array}$ & Tick-borne & (20) \\
\hline 7 & 可 & $\begin{array}{l}\text { Dengue fever } \\
\text { (DENF) }\end{array}$ & Flavivirus & Worldwide & & Mosquito-borne & (258) \\
\hline 8 & $\begin{array}{l}\text { 음 } \\
\text { 으 } \\
\text { の }\end{array}$ & $\begin{array}{l}\text { Middle East } \\
\text { Respiratory } \\
\text { Syndrome } \\
\text { Coronavirus }\end{array}$ & Coronavirus & Middle East countries & Bats, dromedary camel & By close contact & (263) \\
\hline 9 & $\frac{\sqrt{\bar{D}}}{\frac{.}{\Phi}}$ & $\begin{array}{l}\text { Avian Influenza } \\
\text { (H5N1) }\end{array}$ & Influenza A & Worldwide & Birds & By direct contact & (265) \\
\hline 10 & ய์ & $\begin{array}{l}\text { Swine Influenza } \\
\text { (H1N1) }\end{array}$ & Influenza A & Worldwide & Swine & Airborne & \\
\hline 12 & 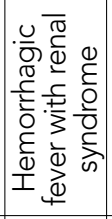 & $\begin{array}{l}\text { Hepatitis E } \\
\text { Parainfluenza viruses }\end{array}$ & $\begin{array}{l}\text { Hepatitis E virus } \\
\text { Paramyxovirus }\end{array}$ & Worldwide & Cattle & $\begin{array}{l}\text { Fecal/oral } \\
\text { Through direct contact }\end{array}$ & $\begin{array}{c}(269,270) \\
(273)\end{array}$ \\
\hline 13 & 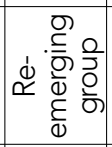 & $\begin{array}{l}\text { Orf virus infection } \\
\text { (Ecthyma } \\
\text { contagiosum) }\end{array}$ & Parapoxvirus & & $\begin{array}{c}\text { Wild and } \\
\text { domesticated } \\
\text { cattle, sheep, goats }\end{array}$ & $\begin{array}{l}\text { By direct or } \\
\text { indirect } \\
\text { contact }\end{array}$ & $(280,281)$ \\
\hline 14 & & $\begin{array}{l}\text { African Horse } \\
\text { Sickness (AHS) }\end{array}$ & Orbivirus & $\begin{array}{c}\text { Africa, Asia, and } \\
\text { Middle East, and Europe }\end{array}$ & Equids & Mosquito-borne & (283) \\
\hline 15 & & Bluetongue (BTV) & Orbivirus & Worldwide & Sheep, goats, and cattle & Mosquito-borne & $(286)$ \\
\hline 16 & & Borna Disease (BD) & Bornaviridae & & $\begin{array}{c}\text { Horses, sheep, cattle, } \mathbb{E} \\
\text { dogs, and cats }\end{array}$ & $\begin{array}{l}\text { Exposure to contaminated } \\
\text { saliva or nasal secretions }\end{array}$ & $(289,290)$ \\
\hline 17 & & $\begin{array}{l}\text { Feline Calicivirus } \\
\text { infection }\end{array}$ & Vesivirus & & Cats & Direct contact & (292) \\
\hline 18 & & $\begin{array}{l}\text { Foot and Mouth } \\
\text { Disease (FMD) }\end{array}$ & Aphthovirus & Worldwide & $\begin{array}{c}\text { Cattle, water buffalo, } \\
\text { sheep, goats, and pigs }\end{array}$ & By close contact & (297) \\
\hline 19 & 吾 $\frac{0}{5}$ & Louping ill (LI) & Flavivirus & Various European countries & Sheep and goats & Tick-borne & (10) \\
\hline 20 & 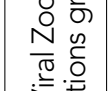 & $\begin{array}{l}\text { Newcastle Disease } \\
\text { (ND) }\end{array}$ & Avulavirus & Worldwide & Birds & By direct contact & $(300)$ \\
\hline 21 & 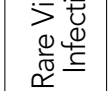 & Cowpox (CPX) & Orthopoxvirus & $\begin{array}{l}\text { European countries } \\
\text { and Eurasia }\end{array}$ & $\begin{array}{l}\text { Small mammals } \\
\text { and cattle }\end{array}$ & By direct contact & (303) \\
\hline 22 & & $\begin{array}{l}\text { Pseudocowpox } \\
\text { virus Infection }\end{array}$ & Parapoxvirus & Worldwide & Cows & By direct contact & (305) \\
\hline 23 & & $\begin{array}{l}\text { Bovine papular } \\
\text { stomatitis }\end{array}$ & Parapoxvirus & Worldwide & Cattle & $\begin{array}{l}\text { Through direct or } \\
\text { indirect contact }\end{array}$ & (308) \\
\hline 24 & & Rotavirus diseases & Rotavirus & Developing countries & Calves and foals & $\begin{array}{c}\text { Contact with } \\
\text { contaminated objects }\end{array}$ & (312) \\
\hline 25 & & Norovirus infection & Norovirus & & Calves & $\begin{array}{c}\text { Food or water-borne, } \\
\text { by contact and } \\
\text { aerosol route }\end{array}$ & $(315,316)$ \\
\hline 26 & . $\frac{0}{7}$ & Astrovirus infection & Astrovirus & & & Food and water-borne & (316) \\
\hline 27 & $\begin{array}{ll}+ & 0 \\
0 & 0 \\
0 & 0 \\
0 & n \\
0 & 0 \\
N & 0\end{array}$ & $\begin{array}{l}\text { Phlebovirus } \\
\text { Infections }\end{array}$ & Phlebovirus & $\begin{array}{l}\text { Mediterranean } \\
\text { Basin }\end{array}$ & Vector-borne & $(21)$ & \\
\hline 28 & 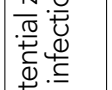 & $\begin{array}{l}\text { Lumpy Skin } \\
\text { Disease (LSD) }\end{array}$ & Capripoxvirus & & Cattle & $\begin{array}{l}\text { Blood-feeding } \\
\text { arthropods borne }\end{array}$ & $(20,75)$ \\
\hline 29 & $\therefore \frac{0}{\circ}$ & Hepaciviruses & Hepacivirus & & Domesticate cattle? & $?$ & (327) \\
\hline
\end{tabular}




\begin{tabular}{|c|c|c|c|c|c|c|c|}
\hline \multicolumn{8}{|c|}{ Parasitic Diseases with Zoonotic Characteristics } \\
\hline \multirow{3}{*}{\multicolumn{2}{|c|}{ 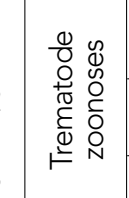 }} & Fascioliasis & $\begin{array}{c}\text { Fasciola } \\
\text { hepatica spp. }\end{array}$ & Worldwide & $\begin{array}{c}\text { Sheep, cattle, } \\
\text { ruminants, and humans }\end{array}$ & Food-borne & (334) \\
\hline & & Dicrocoeliosis & $\begin{array}{l}\text { Dicrocoellum } \\
\text { dentricum }\end{array}$ & Worldwide & Livestock, humans & Food-borne & (336) \\
\hline & & Schistosomiasis & Schistoma spp. & Worldwide & Humans & Water-borne & (338) \\
\hline \multirow[t]{2}{*}{4} & \multirow{7}{*}{ 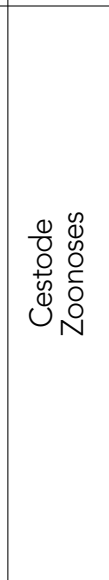 } & Echinococcosis & $\begin{array}{l}\text { Echinococcus } \\
\text { spp. }\end{array}$ & Worldwide & $\begin{array}{l}\text { Cattle, buffalo, sheep, } \\
\text { goat, pigs, dogs, } \\
\text { and humans }\end{array}$ & Food-borne & (343) \\
\hline & & Taeniasis & Taenia saginata & Worldwide & $\begin{array}{l}\text { Cattle, pigs, sheep, } \\
\text { and humans }\end{array}$ & Food-borne & (348) \\
\hline 6 & & Cysticercosis & & Worldwide & $\begin{array}{l}\text { Cattle, pigs, sheep, } \\
\text { and humans }\end{array}$ & Food-borne & (348) \\
\hline 7 & & Coenurosis & $\begin{array}{c}\text { Taenia } \\
\text { multiceps }\end{array}$ & Worldwide & $\begin{array}{c}\text { Small ruminants, sheep, } \\
\text { cattle, and humans }\end{array}$ & $\begin{array}{l}\text { Food-borne } \\
\text { Water-borne }\end{array}$ & (350) \\
\hline 8 & & Dipylidiasis & $\begin{array}{l}\text { Dipylidium } \\
\text { caninum }\end{array}$ & Worldwide & $\begin{array}{l}\text { Pet animals, dog, cats, } \\
\text { and humans }\end{array}$ & Food-borne & (353) \\
\hline 9 & & Hymenolepiasis & $\begin{array}{l}\text { Hymanolepis } \\
\text { spp. }\end{array}$ & Worldwide & Humans & $\begin{array}{l}\text { Food-borne, water- } \\
\text { borne, Poor sanitation }\end{array}$ & (355) \\
\hline 10 & & Mesocestoidiasis & $\begin{array}{l}\text { Mesocetoides } \\
\text { spp }\end{array}$ & Worldwide & Dogs and cats & Food-borne & $(357)$ \\
\hline 11 & \multirow{10}{*}{ 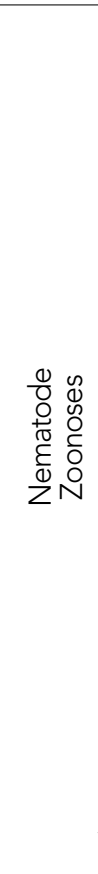 } & Angiostrongylosis & $\begin{array}{l}\text { Angiostrongylus } \\
\text { spp. }\end{array}$ & Worldwide & Humans and dogs & Food-borne & (358) \\
\hline 12 & & Ascariasis & $\begin{array}{c}\text { Ascaris } \\
\text { lumbricoides }\end{array}$ & Worldwide & Humans & Food-borne & (359) \\
\hline 13 & & $\begin{array}{l}\text { Cutaneous Larva } \\
\text { Migrans (CLM) }\end{array}$ & \begin{tabular}{|l|} 
Ancylostoma \\
spp. Necator \\
americanus, \\
Uncineria \\
stenocephala and \\
Bunostomum \\
phlebotomum \\
\end{tabular} & $\begin{array}{l}\text { Areas with moist and } \\
\text { warm climate }\end{array}$ & $\begin{array}{c}\text { Dogs, cats, wild animals, } \\
\text { and humans }\end{array}$ & $\begin{array}{l}\text { By walking barefoot on } \\
\text { sandy beaches or } \\
\text { contacting moist soft } \\
\text { soil, that have } \\
\text { contaminated with } \\
\text { animal feces }\end{array}$ & (362) \\
\hline 14 & & Dirofilariasis & Dirofilaria spp. & Worldwide & Dogs and humans & Mosquito-borne & (363) \\
\hline 15 & & Filariasis & $\begin{array}{l}\text { Wuchereria } \\
\text { bancrofti } \\
\text { Brugia spp. }\end{array}$ & Worldwide & $\begin{array}{l}\text { Humans, felines, } \\
\text { and monkeys }\end{array}$ & Mosquito-borne & (365) \\
\hline 16 & & Gnathostomiasis & Gnathostoma spp. & Worldwide & Humans & $\begin{array}{l}\text { Water-borne } \\
\text { Food-borne }\end{array}$ & (45) \\
\hline 17 & & Onchocerciasis & Onchocerca spp. & Worldwide & Humans and animals & Simulid-borne & $(367)$ \\
\hline 18 & & Strongyloidiasis & $\begin{array}{l}\text { Strongyloides } \\
\text { stercoralis }\end{array}$ & Worldwide & $\begin{array}{l}\text { Humans, dogs, } \\
\text { and cats }\end{array}$ & Soil-transmitted & (370) \\
\hline 19 & & Toxocariasis & Toxocara spp. & Worldwide & $\begin{array}{l}\text { Humans, dogs, } \\
\text { and cats }\end{array}$ & $\begin{array}{l}\text { Contaminated with dog } \\
\text { or cat feces, food-borne }\end{array}$ & (353) \\
\hline 20 & & Trichinellosis & Trichinella spp. & Worldwide & Humans and animals & Food-borne & (374) \\
\hline 21 & \multirow{8}{*}{ 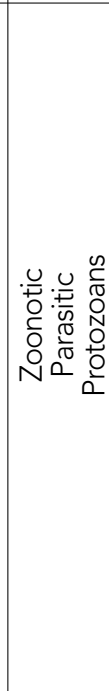 } & Leishmaniasis & Leishmania spp. & Mediterranean Basin & $\begin{array}{l}\text { Dogs, cats, cattle, } \\
\text { and equids }\end{array}$ & Vector-borne & $(21,454)$ \\
\hline 22 & & Toxoplasmosis & Toxoplasma gondii & Throughout the world & $\begin{array}{l}\text { Mammal and } \\
\text { bird species }\end{array}$ & $\begin{array}{c}\text { By congenital, carnivorism } \\
\text { and fecal-oral route }\end{array}$ & $(23,393)$ \\
\hline 23 & & Sarcosporidiosis & Sarcocystis spp. & Worldwide & $\begin{array}{l}\text { Some mammalians, } \\
\text { and in some avian }\end{array}$ & By oral route & (399) \\
\hline 24 & & Giardiasis & Giardia spp. & Worldwide & Domesticated animals & $\begin{array}{l}\text { Water, food borne, and } \\
\text { by direct physical contact }\end{array}$ & $(405,406)$ \\
\hline 25 & & $\begin{array}{l}\text { Amoebiasis or } \\
\text { Amoebic } \\
\text { Dysentery }\end{array}$ & $\begin{array}{l}\text { Entamoeba } \\
\text { histolytica }\end{array}$ & Worldwide & & Fecal-oral transmission & $(407,408)$ \\
\hline 26 & & Cryptosporidiosis & $\begin{array}{l}\text { Cryptosporidium } \\
\text { spp. }\end{array}$ & Globally & $\begin{array}{c}\text { Mammals, birds, reptiles, } \\
\text { amphibians, and fish }\end{array}$ & Water-borne & $(412,413)$ \\
\hline 27 & & Rhinosporidiosis & $\begin{array}{c}\text { Rhinosporidium } \\
\text { seeberi }\end{array}$ & & Fish and amphibians & By the contact & $(417)$ \\
\hline 28 & & Cystoisosporiasis & Cystoisospora belli & $\begin{array}{l}\text { Tropical and subtropical } \\
\text { regions in the world }\end{array}$ & $\begin{array}{l}\text { Monkey, dog, pig, rat, } \\
\text { mouse, Guinea pig, } \\
\text { and rabbit }\end{array}$ & Food/water-borne & $(419,420)$ \\
\hline
\end{tabular}


two strains of the agent can be distinguished by genetic analysis. One strain is found only in humans worldwide, while the other also occurs in flying squirrels (Glaucomys sabrinus and G. volans) in the USA (55). The primary vector of person-to-person transmission is the human body louse (Pediculus humanus corporis). Lice are infected when they feed on the blood of infected patients and excrete $R$. prowazekii in the feces as they feed on a new host. Transmission occurs when organisms in the louse feces are rubbed into the bite wound or other breaks in the skin (55). The rickettsia is also infectious by inhalation or contact with the mucous membranes of the mouth and eyes. In most parts of the world, humans are the only reservoir host for $R$. prowazekii. Infections can become latent and later recrudesce; humans with recrudescent typhus are capable of infecting lice and spreading the disease (56). It was reported that typhus epidemics were seen in Erzurum and nearby cities during the years of World War I in Turkey (57).

Tick-borne Typhus is one of the oldest rickettsial diseases also called Boutonneuse fever or Mediterranean Spotted Fever (MSF). In Turkey, several cases of MSF associated with $R$. conorii have been reported in humans (58-63). Recently, $R$. hoogstraali and two human pathogenic species ( $R$. aeschlimannii and $R$. slovaca) were detected in ixodid ticks in Turkey $(64,65)$. In addition, in the Thrace region of Turkey, $R$. conorii was also isolated from the skin lesions in three of 10 patients with MSF and was identified molecularly in the biopsy materials from 9 of 10 patients (66); Rickettsia spp. were found positive in the pools of ticks collected from tortoises (67).

Rickettsialpox is a mite-transmitted bacterial zoonotic disease. The causative agent is Rickettsia akari, a member of the spotted-fever group of rickettsiae. The disease causes mild, self-limited, febrile illness characterized by eschar formation at the mite bite site, followed by the onset of systemic symptoms and a more generalized papulovesicular rash. The pathogen is originally found in mice (usually the house mouse), and humans may be infected by the bite of an infected mite, Liponyssoides sanguineus (68). In Turkey, a clinical rickettsialpox case has been described in a 9-year-old boy from the Nevsehir province (69).

Murine typhus is a zoonotic infection in rats, cats, and humans caused by Rickettsia typhi and occurs worldwide. Recently, the infection is also described as a disease of travelers (70). The causal agent may be transmitted to humans by the bite of infected rodent fleas (Xenopsylla cheopis) and possibly cat fleas (Ctenocephalides felis). Two clinical cases of endemic or murine typhus were also reported in Istanbul, Turkey (71).

Wolbachia endobacteria are the most widespread intracellular endosymbiont of arthropods and nematodes. Their interactions with their hosts are often mutualistic rather than parasitic (72). Recently, the prevalence of Wolbachia endobacteria were determined via molecular techniques in the mosquito populations in Turkey $(73,74)$ and in the chewing lice species collected from the Angora goats (75).

Candidatus Rickettsia vini is a newly named rickettsial bacterium belonging to the spotted-fever group that has been molecularly detected in Ixodes arboricola ticks (76). In Turkey, Candidatus R. vini was detected in I. arboricola ticks collected from birds in the Kizilirmak Delta (77).

Lyme Disease (LD), the most common tick-borne zoonotic infection with clinical significance of humans and domesticated animals in the northern temperate zone, was first described in the USA in the late 1970s, and the causal agent was described as a tick-borne spirochete Borrellia burgdorferi in 1982. The environmental risk of LD is measured by the density of infected questing ticks and more specifically by the density of infected nymphs of genus lxodes, as nymphs appear to be the most important epidemiological stage (39). In Turkey, Lyme borreliosis is also one of the most important tick-borne zoonotic disease, and its causal agent Bor. burgdorferi was isolated from I. ricinus ticks collected from cattle in the Black Sea region in 1998 (78). The spirochetes of Borrelia were present in an unfed tick nymph (79). Meanwhile, some Bor. burgdorferi sensu lato strains were characterized molecularly (80), and a novel Borrelia sp. was also isolated from H. aegyptium ticks collected from tortoises (Testudo graeca) (81), and the spirochete was named as Bor. turcica sp. nov (82). A clinical Lyme case was observed in a dog in 2007 (83), and antiBor. burgdorferi antibodies were also detected in dogs and horses in Turkey (84). In contrast, a few reports on LD cases in humans have been documented in some parts of Turkey (85-88). The seropositivity rate was reported as $17 \%$ in the patients with a history of tick bite in Central Anatolia (89). However, a serological study showed that the seropositivity rate for LD was found to be $10 \%$ in 50 patients having symptoms compatible with LD at the Erciyes University Hospital in the Kayseri province (90). In the Marmara region, three LD cases have been confirmed serologically and by in vitro cultivation with two of the three cases detected in the residents of Istanbul, while the third was described in a tourist from the USA (88). Meanwhile, Bor. burgdorferi was also isolated from questing I. ricinus ticks sampled by flagging from parks and rural areas in the Thrace region of Turkey (44). In the same region of Turkey, another similar field study was performed on ticks, which were collected from tortoise and Rickettsia spp., and Bor. burgdorferi s.l. were molecularly detected in the tick pools (67). Meanwhile, another study was conducted to investigate the presence of Bor. burgdorferi in tick samples collected from humans, domestic and wild animals, and the ground as unfed (questing) in 12 different provinces, including Agri and Erzurum in Eastern Anatolia; Ankara, Cankiri, Yozgat, and Kirsehir in Central Anatolia; Artvin, Giresun, and Corum in the Black Sea Coast; Kocaeli and Bolu in Marmara; and Mardin in Southeastern Anatolia regions of Turkey. Bor. burgdorferi sensu stricto was also isolated from unusual tick species, such as $H$. marginatum, H. excavatum, Hae. parva, and nymphs of Hyalomma spp. (64). Epidemiologically, these results reveal that Turkey has a high-risk potential for zoonotic LD.

Tick-borne Relapsing Fever (TBRF) Can be either louse-borne (LBRF) or tick-borne (TBRF). LBRF is caused by a human-restricted pathogen, spirochete Borrelia recurrentis, and transmitted by the body louse Pediculus humanus, while TBRF is caused by Borrelia spp. and is associated with the bite or coxal fluid of argasid ticks of the genus Ornithodoros in a wider endemic geographic area of the world, spanning Africa, Asia, Europe, Eurasia, 
and the Americas with different Borrelia tick vector complexes implicated in the transmission in each area $(39,91,92)$. In Turkey, the presence of relapsing fever with a spirochete of the Crocidurae group Bor. crocidurae was shown in Ornithodoros erraticus ticks collected from rodent holes in the southeastern areas near the Syria border (93). During the Balkan War and the First World War, some outbreaks were noted among the Ottoman and Turkish army (94).

Tularemia is an important arthropod-transmitted zoonotic bacterial infection caused by the Francesilla tularensis and comprises a range of clinical syndromes ranging from mild to very severe intensity. The majority of cases occur in the northern hemisphere, particularly in the rural or semirural environments (39). In Turkey, tularemia is also an important disease, which has reemerged in 1988, and the first outbreak was recorded in 2005. Almost all cases were recorded as oropharyngeal tularemia due to the ingestion of contaminated food or water (95). The first case associated with the outbreak was diagnosed near Kayseri in 2009 in Central Anatolia, and the region was described as an endemic area for tularemia (96), but no positivity was detected using molecular techniques in the pools of mosquitoes and ticks collected near the Kayseri area (18).

Bartonellosis or Cat Scrath Disease is another zoonotic vector-borne infection of humans and animals that is caused by an excluded rickettsilaes bacteria Bartonella spp. The causal agents Bar. bacilliformis and Bar. quintana are transmitted by sand flies (Lutzomyia spp) and by the human body louse, respectively, while the other agent Bar. henselae is commonly transmitted to humans through the bite or saliva-contaminated scratch of cats that are the natural reservoirs for the bacteria (97). Bar. henselae has a large distribution in the northern hemisphere (98). Domestic cats represent the main reservoir of the pathogen, and the main vector of the infection is the cat flea (99). However, the trans-stadial transmission of Bar. henselae by 1 . ricinus ticks was also shown (100). In Turkey, a case of bartonellosis in a domestic cat was reported (101). However, the seropositivity rates of Bar. henselae were $18.6 \%$ in cats $(101), 6 \%$ in human blood donors (102), and $16.9 \%$ in kidney transplant patients (103) and $22.2 \%$ in cattle breeders and veterinarians (104), while the seroprevalence of Bar. vinsonii subsp. berkhoffii was recorded as $6.6 \%$ in dogs (105) in Turkey. In addition, the seropositivity rates of Bar. henselae in domestic cats varied in distinct provinces, such as Bursa, Adana, Aydin Burdur, Kayseri, and Istanbul, where they were $41.3 \%, 33.9 \%, 27.5 \%, 32.3 \%, 7.9 \%$, and $12.5 \%$, respectively; the average seropositivity of Bar. heselae in cats was found to be $27.9 \%$ in Turkey (106).

Hemoplasmosis is one of the bacterial infections of humans and animals caused by the Mycoplasma spp. (107). Although the infection is mainly described as vector-borne and transmitted by blood-feeding arthropods, such as ticks and fleas, the disease might also be transmitted through other routes, such as mechanically with contaminated operation tools or blood transfusions and vertically in the intrauterine period (108). Rhipicephalus appendiculatus transmits the infection to dogs by co-feeding (109). In Turkey, a clinical case of feline hemoplasmosis associated $M$. haemofelis was reported (110).
Q fever is caused by an excluded rickettsiales bacterium Coxiella burnetii. A number of hard and soft tick species, including Amblyomma, Dermacentor, Haemaphysalis, Hyalomma, Rhipicephalus, and Ornithodoros, have been documented to harbor the C. burnetii (111-113). Recent studies have shown that ticks harbor Coxiella-like bacteria, which are potentially tick-specific endosymbionts. For instance, Coxiella-like bacteria and possibly $C$. burnetii have been detected in the tick species Haemaphysalis bispinosa, Hae. hystricis, Dermacentor compactus, Der. steini, and Amblyomma sp., which were collected from wildlife and domesticated goats in different locations of Malaysia (114). $\mathrm{Q}$ fever is also an endemic and zoonotic infectious disease of humans and animals in Turkey. It was reported that cows, sheep, goats, and dogs might serve as reservoirs of $C$. burnetii, and Ornithodorus lahorensis ticks also harbor the agent; the disease is disseminated throughout Turkey, although the epidemics among humans are relatively rare (115). Recently, IgG seropositivity of $C$. burnetti in women with an abortion history and in women with healthy births in the central Black Sea region of Turkey was reported as $15.6 \%$ and $11.1 \%$, respectively, (116).

Plague or Black Death is another zoonotic bacterial disease transmitted from rodent to rodent and from rodent to man via flea bites. Humans can also be infected by direct contact with infected animal tissues. Pneumonic plague may result from direct human-to-human transmission. The causative agent of the disease is the bacterium Yersinia pestis. Urban plague describes the situation where plague circulates among wild rodents. The infection is maintained in the rat population by fleas, such as Xenopsylla cheopis (Asia, Africa, Europe, and the Americas), X. astia (southeast Asia), and X. brasiliensis (Africa, India, and South America). Rarely, plague is spread directly from person to person by fleas, such as Xenopsylla species and the so-called human flea Pulex irritans (117). The first recorded appearance of the plague in Europe was at Messina, Sicily, in the Middle Ages (October 1347). It is thought that it arrived on trading ships that likely came from the Black Sea, past Istanbul and through the Mediterranean. It is estimated that a quarter of the people living in Europe were killed from the Black Death at that time. Within the last decade, human plague cases have been reported from countries in Africa, America, and Asia. Between 1990 and 1996, there were 16,005 cases of plague and 1214 deaths (7.6\%) reported to the $\mathrm{WHO}(117)$. It is noted that the last plague outbreak involving 32 human cases in Turkey was recorded in 1947 in Akcakale, a town located on the Turkish-Syrian border (15). There is no official record of plague in Turkey since then.

Anthrax is an infection of humans and other mammals caused by the bacterium Bacillus anthracis, a Tier 1 biologic agent. Anthrax spores persist for a long time under changing environmental conditions and can be easily found in nature; they can also be produced in the laboratory. Although the vast majority of human cases are related to direct contact with infected carcasses or to handling of contaminated products from morbid animals, the transmission of the disease has been demonstrated by a wide variety of tabanid and mosquito species and with stable flies (Stomoxys spp) (118). The disease has wide distribution in the world and is also an endemic zoonosis in Turkey. A total of 967 (464 from animals and 503 from humans) anthrax 
cases were reported from Eastern Turkey between 1992 and 2004 (119). In contrast, a total of 26,954 human anthrax cases were recorded by the Turkish Ministry of Health between 1960 and 2005, with 6861 cases reported between 1990 and 2005 (120). Although the incidence rate of anthrax in humans is decreasing ( $\leq 150$ cases per year between 2011 and 2016) in Turkey, regional outbreaks still present a risk to human and animal health. The prominent clinical form recorded is cutaneous anthrax $(120,121)$. Recently, in April 2017, two pumas died at the Kayseri Zoo Park, and the etiologic agent was identified as $B$. anthracis by laboratory examination. The source of the infection was considered consumption of a carcass of cattle that had died of unknown reasons (personal communication with Professor M Doganay).

Brucellosis is a zoonotic infection with significant health and economic problems worldwide. The causal agents of the infection are Brucella abortus, B. melitensis, B. ovis, B. suis, and B. canis. The disease is mainly food-borne and is transmitted to humans through the consumption of unpasteurized/raw dairy products and rarely by eating undercooked meat. In addition, the bacteria may also enter the body by inhalation or by contact. In Turkey, brucellosis is a known disease since the First World War and its incidence has been increasing over the years. In 1999, 11,462 cases were notified to the Ministry of Health, with the incidence rate being 17.41/100,000. In the last decade, the annual recorded cases in human have been decreasing below 6,000. Predominant etiological agent is also B. melitensis (122). Although several control and eradication measures have been applied, brucellosis remains an endemic disease in many regions and leads to a large economic loss in cattle and in small ruminants with serious public health problems $(23,123)$. The prevalence of brucellosis was shown to be $32.9 \%$ in tested animals (124).

Campylobacteriosis is a common food-borne zoonotic infection of humans with gastroenteritis. The causal agent of the disease is most commonly Campylobacter jejuni. The agent is transmitted to humans by ingestion of contaminated food (usually unpasteurized/raw milk and undercooked poultry) and drinking of contaminated water (water-borne). The infection is also transmitted by contact with contaminated poultry, livestock, or household pets, particularly puppies (125). Meanwhile, animals farmed for meat are the major source of campylobacter enteritis. In Turkey, campylobacter gastroenteritis has been reported as a more common disease in children (126).

Clostridial diseases are caused by many clostridial bacteria both in humans and domestic animals, but these pathogens are seldom considered zoonotic agents. Clostridium botulinum and $C$. tetani lead neurotoxicoses in humans and domestic and wild animals, but there is no evidence for transmission among the species. C. septicum causes malignant edema in domestic animals and humans, and the signs and the lesions of infection are generally the same in both; however, there is no evidence for direct transmission between animals and humans. However, it was suggested that indirect transmission of entrotoxigenic $C$. peringes type $C$ and $C$. difficile is possible via foods (i.e., in retail meats) (127). In Turkey, limited C. difficile infection cases have been reported in the patients with antibiotic-associated bloody diarrhea in some provinces such as Kayseri (128), Bursa (129), and Istanbul (130).

Tetanus is also another clostridial disease characterized with muscle rigidity and spasms. The agent of infection is Clostridium tetani, which is generally found in soil, dust, and manure. The pathogens usually enter through a break in the skin, such as a cut or puncture wound by a dirty contaminated object. Tetanus in neonates is primarily related to insufficient sanitation and lack of hygiene. Neonatal tetanus is actually preventable by immunization in many developing countries, and it has already been eliminated in most of the developed countries. In Turkey, the incidence of tetanus cases in humans has been reduced by improving hygiene conditions and implementation of tetanus vaccine in the last decades $(131,132)$.

Enterohemorrhagic Escherichia coli (EHEC) infection is an important coliform water-borne zoonotic disease seen worldwide. Cattle are important reservoirs of Shiga-like toxin-producing Escherichia coli (SLTEC) 0157:H7 EHEC, which causes hemorrhagic colitis and hemolytic uremic syndrome in humans. The infected cattle can shed low levels of E. coli O157:H7 for a long term. The most important EHEC reservoir cattle can also carry unusual EHEC strains, such as EHEC O104:H4. Humans acquire EHEC by direct contact with carrier cattle or sheep, their feces, infected people, and contaminated soil or water or via the ingestion of undercooked meat, other animal products, contaminated vegetables and fruit, and other foods (133). In Turkey, limited data are available regarding EHEC 0157 in humans and animals. Although the incidence of $\mathrm{E}$. coli O157:H7 has been reported as varying up to $40 \%$ in gastroenteritisassociated children (134, 135), verocytotoxin producing $E$. coli 0157 was molecularly detected in only one case (136). In contrast, verocytotoxin producing $E$. coli $O 157$ was also isolated from clinically healthy cattle samples in the Hatay province of the Mediterranean region (137) and in the carcasses of cattle and abattoir environment in Istanbul in the Marmara area (138).

Erysipeloid is a rare skin bacterial infection of humans caused by Erysipelothrix rhusiopathiae and Ery. tonsillaru and occurs more commonly in individuals, who handle fish and raw meat. The disease has economic importance for farmed animals, including swine, turkeys, chickens, and sheep. People acquire the disease through contact with infected animals (particularly pigs), fish, or birds. The pathogen enters the body through existing skin wounds, such as cuts, scratches, punctures, or splinters. The infection does not spread from person to person (139). In Turkey, a few rare cases of erysipeloid in humans were reported $(140$, 141).

Glanders or Malleus is one of the oldest known, highly contagious and re-emerging infections and often causes fatal zoonotic disease in equids, such as horses, mules, and donkeys. These solidungulate animals serve as a natural reservoir role for the pathogen. The causal agent of the disease is Burkholderia mallei (formerly Pseudomonas mallei). It was reported that this bacterium has been listed as a potential agent for biological warfare and bioterrorism under Center of Diseases Controlcategory B (142). The pathogen organism is transmitted to the animals either directly or indirectly from secretions and excretions of 
infected animals. The infection occurs subclinically in horses, and the agent organisms are found in the lesions and discharges of the skin and nasal mucosa. Thus, chronic infected horses can serve a carrier role for the epidemiology of the disease. Mules and donkeys are acutely infected animals, and the organisms are excreted in feces, urine, saliva, and tears. The major mode of transmission among solipeds is the respiratory route and ingestion of feed and water contaminated by nasal discharge, or sputum of sick animals, or direct contact with fomites. Glanders has been eradicated from many countries by statutory testing, elimination of infected animals, and import restrictions. However, it persists in some Asian, African, and South American countries. The infection should be considered a re-emerging disease and may be imported by pet or racing equids into glanders-free areas (143). The transmission of $B$. mallei from infected equines to humans is uncommon, and the person-to-person transmission is also rare. The main routes of zoonotic transmission of $B$. mallei in humans involve direct invasion of a cut, abrasion, or laceration of the skin and; inhalation; and by attack to mucous membranes (144). The first zoonotic human case was reported in a French veterinarian in 1793 (142), and recently, a clinical glanders case was determined in a microbiologist at the U.S. Army in 2000 (145). Professionals who are in close contact with sick horse, such as veterinarians, farmers, horse traders/fanciers, laboratory workers, and other workers in slaughterhouses and horse stable and soldiers are at occupational exposure to glanders. In Turkey, glanders is one of the compulsory notifiable diseases. To control and eradicate glanders, a national project was conducted by the Ministry of Agriculture between 2000 and 2001. In the project scope, a total of 235,286 equines were screened for glanders, and 3509 were found positive. All of the positives were culled as compensation. The economic impact of the disease was devastating for Turkey. In same period, no clinical cases of glanders were observed in tested horses and mules, while only one glanders case was reported from a donkey with clinical sings. In recent years, approximately 10,000 pedigree horse sera were tested using the complement fixation test (CFT) and all of the tested sera were found negative for glanders (146). It was reported that the history of human cases of glanders goes back to 1890s when some army and civil veterinarians became sick during the struggle programs against glanders between 1901 and 1934 and died of the disease (147). In the following decades, limited human cases of glanders were also reported from some parts of Turkey (148-150).

Leprosy is a serious human disease caused by Mycobacterium leprae. The transmission of the disease from an infected person to others is possible by close contact. However, the transmission of animal leprosy to man may be possible with armadillos that are the only other known natural hosts of the pathogen organism. The disease was a serious health problem almost 60 years ago in Turkey (151), but no leprosy case is seen in the country today. The disease was eradicated with systemic surveillance and treatment, intensive control measures, improvement in general health conditions, and with good coordination of health institutions in Turkey (152).

Leptospirosis is a zoonotic disease caused by Leptospira interrogans and occurs worldwide. The infection predominantly affects some professionals who are in close contact with infected animals or their urine. The incidence of leptospirosis was found to be relatively high in humans $(153)$ as well in animals $(154,155)$ in Turkey.

Listeriosis is a sporadic bacterial zoonotic infection caused by Listeria monocytogenes and affects a wide range of animals, including man and birds. Encephalitis or meningencephalitis in adult ruminants is the most commonly recognized clinical form of the disease. The disease is primarily a winter-spring infection of feedlot or housed ruminants. Grazing animals ingest the organism and animal-to-animal transmission occurs via the fecaloral route. The transmission of listeriosis to man is possible by close contact or through handling of aborted material; nosocomial infection is also seen in hospitals. L. monocytogenes is an important cause of severe infection in patients with impaired cell-mediated immunity, neonates, pregnant women, the elderly, and transplant recipients. Human infection is generally observed as a food-borne disease. Various clinical forms, such as central nervous system infection, sepsis, endocarditis, gastroenteritis, and rarely other clinical forms, were reported in humans in Turkey (156). Several serosurveys indicate that seroprevalance of L. monocytogenes was relatively high in healthy animals and reported as $44.9 \%$ in cattle (157), 25.8\% in sheep (158), $40.29 \%$ in horses (159), and $22.3 \%$ in dogs (160) in different regions of Turkey. Meanwhile, it was declared that the prevalence of $L$. monocytogenes was $42.2 \%$ in slaughterhouse workers in Ankara (161).

Mycobacteriosis is a chronic or acute, systemic, granulomatous disease that occurs in aquarium and culture fish. Several species of Mycobacterium cause the infection. The two most important species in fish and humans are Mycobacterium marinum and $M$. fortuitum. The source of $M$. marinum infection is contaminated water. In the past, human outbreaks of $M$. marinum were sporadic and most commonly associated with swimming in contaminated pools. In humans, breaks in the skin serve as an entry point for the organism during contact with contaminated water sources or infected fish. In fish, transmission can occur by consumption of contaminated feed, cannibalism of infected fish or aquatic detritus, or by entry via injuries, skin abrasions, or external parasites. In Turkey, Mycobacterium spp. were detected in fish samples in the Mersin province (162). In contrast, avian mycobacteriosis is also an important disease that has been reported widely in pet birds, captive wild birds, as well as poultry and occurs worldwide (163). Recently, a case of avian mycobacteriosis was detected in a wild bird (Buteo rufinus) in the Kars province in Turkey (164).

Pasteurellosis is an important zoonotic disease caused by Pasteurella species, which are highly prevalent among animal populations where they are often found as part of the normal microbiota of the oral, nasopharyngeal, and upper respiratory tracts. Many Pasteurella species are opportunistic pathogens that can cause endemic disease and are associated increasingly with epizootic outbreaks. Zoonotic transmission to humans usually occurs through animal bites or contact with nasal secretions, with $P$. multocida being the most prevalent isolate observed in human infections (165). In Turkey, bovine pasteurellosis is one of 
the prevalent infections and leads to important economic losses (166). Meanwhile, cellulitis due to Pasteurella multocida in a 5-year-old girl bitten by a dog (167) and acute osteomyelitis due to $P$. multocida in a 70year-old diabetic man bitten by a cat have been reported (168).

Psittacosis is a zoonotic infectious disease of birds caused by Chlamydophila psittaci. The disease is also known as parrot fever or avian chlamydiosis. C. psittaci can be transmitted among birds by inhalation of infectious dust or airborne particles, such as feathers, and by ingestion of infectious material including carcasses. Humans usually get the infection by inhalation of contaminated dust, feathers, or aerosolized secretions and excretions. In Turkey, C. psittaci was detected in pet birds (169) and in some waterfowls in different zoos (170), while there is no official report on human chlamydiosis.

Salmonellosis is a widespread food-borne contagious zoonotic infection both humans and animals worldwide caused by Salmonella enterica subspecies enterica serovar Typhimurium. Domestic animals and wild animals may serve as carriers in the epidemiology of the disease. The disease is typically transmitted to humans by consumption of Salmonella-contaminated food, with eggs being the most blamed food (171). In Turkey, few studies have been performed on salmonellosis in dogs (172) and in poultry (173). Recently, different Salmonello serotyps were detected in turkey ground meat and meat parts, and S. corvallis was shown to be the predominant serotype in poultry meat in Turkey (174). Although salmonellosis is considered a threat for public health, limited reports on confirmed cases of human salmonellosis were documented in Turkey. In a study that was conducted to investigate surveillance of enteric pathogens of public health importance, a total of 177 Salmonella strains were isolated from different patients during the period between 2008 and 2011 in Ankara. Salmonella Enteritidis was found as the most frequent Salmonella serovar. Its prevalence was detected as $61.4 \%$ with one Salmonella typhi strain isolated (175). An outbreak of Salmonella Enteritidis due to consumption of contaminated patisserie products was reported in 433 persons in Kadirli county of Osmaniye province located in the Mediterranean region of Turkey in 2014 (176).

Streptococci are gram-positive and aerobic bacteria that cause several disorders, including pharyngitis, pneumonia, endocarditis, sepsis, and wound and skin infections. The wound and skin infections are seen in man and animals due to dog and cat bites or rarely wild predatory animal bites or rodent bites as well (177, 178). The numbers of bacterial isolates vary depending on the type of wound, which is commonly mixed as aerobic anaerobic infections (179). Streptococcus species are frequently isolated from dog bite wounds. Streptococcus mitis was found as the most common species among different members of the genus (180). In Turkey, the reports on the cases of wound and skin infections in animals and in man due to dog and cat bites are limited. In a retrospective study, 114 bite wounds were recorded in dogs and cats between 1999 and 2003 at small animal clinics of Veterinary Faculty of the Aydin province in the Aegean region of Turkey (181). Meanwhile, a total of 25,480 dog and cat bite cases were recorded in humans between 2005 and 2009 in Ankara
(182). Recently, the number of animal-inflicted human wound cases was reported as 205 between 2013 and 2014 in the Erzurum province in Eastern Anatolia, Turkey (183).

Tuberculosis (TB) is one of the most devastating and oldest known zoonotic disease in humans and occurs worldwide. The estimated global annual incidence rate of human TB is almost 128 new cases/100,000 populations (184). Although human TB is caused particularly by Mycobacterium tuberculosis, other major causative agents, such as $M$. bovis, $M$. caprae, $M$. avium, and $M$. marinum, can also cause human tuberculosis. $M$. bovis and to a lesser extent $M$. caprae are the main causative agents of bovine TB. These zoonotic pathogens are transmitted to humans by close contact with infected cattle or consumption of contaminated animal products, such as unpasteurized milk (185). In Turkey, the total number of human TB was reported as 16,551 while the rate of new cases of human TB was shown as 22/100,000 between 2005 and 2010 (186). Meanwhile, the prevalence of tuberculosis in cattle was reported as $0.38 \%-1.49 \%$ in Turkey (124).

Vibrio diseases may be mainly classified into two different infections groups: Vibrio cholera (caused by V. cholerae) and noncholera Vibrio (caused by V. parahaemolyticus or V. vulnificus). Most of these Vibrio infections are related to consumption of contaminated food or water and hence these infections are considered as food-borne or water-borne diseases. Poor sanitation and adverse environmental conditions after natural disasters, such as hurricane, earthquake, and tsunami, may also increase the risk of Vibrio infections. Humans can acquire Vibrio infections by ingestion of raw or undercooked shellfish. Vibriosis is also an economically important disease of cultured fishes, such as gilthead sea bream (Sparus aurata). Initial infection is probably water-borne; however, once established in fish, the infection spreads by contact. Some epizoitics can also be seen because of the use of infected marine fish in the feeds of healthy fish. The zoonotic transmission of fish vibriosis is possible by ingestion of infected fish tissues (187). In Turkey, studies on vibriosis are very limited. However, fish vibriosis was diagnosed in cultured gilthead sea bream in the Aegean Sea coast farms of Turkey (188). There is no official report on cases of human vibriosis in Turkey.

Yersiniosis is a food-borne zoonotic infection caused mostly by eating raw or undercooked contaminated foods with Yersinia enterocolitica. Y. enterocolitica and other Yersinia species were isolated from ground beef in Aydin (189). In another study that was conducted to investigate the incidence and pathogenicity of $Y$. enterocolitica in the Northeast Anatolia regions of Turkey (provinces of Kars, Igdir, and Ardahan), a total of 750 food samples, composed of ice cream, raw milk, feta cheese, chicken drumsticks, and minced meat were tested and 57 samples (7.6\%) were evaluated positive for Yersinia spp; 18 (2.4\%) of these isolated from 6 feta cheese, 4 ice cream, 2 chicken drumsticks, 4 minced meat, and 2 raw milk samples were determined as contaminated with pathogenic $Y$. enterocolitica (190). However, $Y$. enterocolitica and $Y$. pseudotuberculosis strains were isolated from humans in the Van province in East Anatolia, Turkey (191).

Actinomycosis is caused by anaerobic Actinomyces species $A$. israelii and $A$. bovis. The disease occurs rarely in humans, but 
frequently in cattle, and the infection is called "lumpy jaw" because of large abscesses seen on the necks of infected cattle. A. israelii and A. bovis are normal commensal species in humans and in cattle, respectively. The infection develops due to a predisposing factor in the buccal cavity, such as dental problem or periodontal disease (192). The rare zoonotic transmission of the disease may be seen by contact with infected animals (193). In Turkey, a total of 167 cattle with actinomycosis were treated at the surgical clinic of Veterinary Faculty between 1957 and 1971 in Ankara (194). However, a total of 50 A. israelii strain were isolated from cervico-vaginal regions of women who were introduced to gynecology clinics of Medicine School between 2002 and 2004 in the Van province in Eastern Anatolia (195).

Actinobacillosis is a bacterial zoonotic disease caused mostly by Actinobacillus lignieresii. The most common form of the disease occurs as mouth actinobacillosis in cattle and is called "wooden tongue." However, the infection affects sheep as well. Actually, the pathogen is considered a microorganism of normal rumen flora of sheep and cattle. The organism enters via damaged tissues in the mouth of ruminants. Cutaneous route was indicated for zoonotic transmission of the infection in humans (36). In Turkey, two cattle with clinical actinobacillosis were treated in Ankara (194), whereas there is no report on actinobacillosis in humans.

Arcanobacteriosis is a zoonotic infection characterized with granuloma caused by facultative anaerobic bacteria Arcanobacterium species, A. haemolyticum, and A. pyogenes. The infection can be transmitted by close contact from animal to animal, from animals to humans, or even from human to human $(36,196,197)$. A. pyogenes leads summer mastitis in cows with huge economic losses (197) and causes thoracic pyogranuloma formation in dogs (198), while causes endocarditis in man (196). However, the insect transmission of summer mastitis in cows at a cattle herd was successful experimentally via Hydrotaea irritans flies (199). In Turkey, a total of 51 A. pyogenes strains were identified from samples collected from cattle and sheep in the Konya province of Central Anatolia (200). Meanwhile, the prevalence of A. haemolyticum was reported as $2 \%$ in children with tonsillophargytis in Istanbul (201).

Dermatophilosis is a zoonotic bacterial infection caused by Dermatophilus congolensis. The infection is rare in humans but is frequent in horses, dogs, cats, and ruminants, particularly in cattle infested with ticks. In Turkey, a few cases of dermatophilosis in animals (202) and in humans have been reported (203).

Nocardiosis is a bacterial disease in immunocompromized hosts caused by opportunistic species belonging to the Nocardia asteriodes complex. The pathogens can be found in environment, such as soil, decomposing vegetation, and other organic matter as well as in fresh and salt water. People with cancer or people taking steroid treatments are at risk for nocardiosis, and the infection often happens via several ways, such as inhalation (pulmonary nocardiosis), traumatic inoculation (cutaneous nocardiosis), and hospital-acquired (extra pulmonary nocardiosis) (204-206). In Turkey, a solitary case with granulomatous nocardial pleurisy was documented in a dog in Ankara (207). However, a total of 53 cases with mostly pulmonary nocardiosis were report- ed in humans between 1997 and 2004 (208); recently, a few new cases with clinical nocardiosis were also diagnosed in man in distinct areas of Turkey $(209,210)$.

\section{Fungal Zoonotic Diseases in Turkey}

Fungal Zoonotic Diseases are significant health problems in man and in animals worldwide. Today, many fungal zoonotic diseases have been described in the world and some of them also occur in Turkey (Table 1).

Aspergillosis is a respiratory and non-contagious fungal infection caused by opportunistic Aspergillus species and occurs relatively rarely in humans, while it is a common and dangerous disease for birds. Although A. fumigatus is most common in humans, other common species, including $A$. flavus and A. niger, also cause problems in humans and in birds (211). Warm and moist environment, poor ventilation and insufficient sanitation, and long-term storage of feed, are predisposing conditions for aspergillosis and can increase the amount of the spores in the air. Spores often become airborne and spread to the environment by wind and can enter into the respiratory system by inhalation (212). In Turkey, aspergillosis has been detected predominantly in the homes of asthmatic patients $(213,214)$. Meanwhile, it was reported that aspergillosis is a prevalent fungi infection in pigeon herds, birds of zoo, geese, dogs, and horses (215).

Blastomycosis is a zoonotic fungal infection caused by Blastomyces dermatitis, and the disease occurs in several endemic geographical areas, such as North America. The fungus mainly thrives in moist soil and decomposed matters, such as wood and leaves. The infection is transmitted to humans and animals by inhalation the fungal spores via the airway from the environment or by contact with contaminated soils. In Turkey, a case of blastomycosis in a 47year-old female was reported (216).

Candidiasis is a zoonotic infection caused by particularly Candida albicans. Humans mainly serve as reservoirs, while animals only occasionally. Candida is present in the normal flora of humans and animals present on the skin, intestinal tract, and genital area of women; they generally do not cause any problems. However, the fungi sometimes lead to infections on the skin and in the mucous membrane of the mouth and the vagina. The transmission of disease is possibly via direct contact. In Turkey, Candida albicans was isolated from the fecal samples of cage birds in Istanbul (217). In contrast, different Candida species were isolated from the oral cavity of 65 of 125 healthy people between the ages 17 and 67 years in Istanbul, and the prevalence of C. albicans was found as $48 \%$ (218).

Coccidioidomycosis is a fungal infection caused by Coccidioides immitis and C. posadasii. The disease occurs in non-human mammals, such as cattle, cats, horses, dogs, and wildlife and is transmitted through environmental exposure. The causative pathogens of the disease are found particularly in warm, arid, and desert areas of the Western Hemisphere. The zoonotic transmission of the infection to humans has not been reported yet. However, any person who resides in or travels to the endemic area can become infected with Coccidioides spp. after inhalation of airborne arthroconidia (219). Recently, an imported coccidioidomycosis case has been detected in a 41-year-old other- 
wise healthy Turkish man who visited Texas area in the USA and returned to Turkey (220).

Cryptococcosis is a zoonotic and serious fungal disease worldwide caused by opportunistic Cryptococcus neoformans. The disease is considered to be acquired by inhalation of the infectious propagule from the environment in endemic areas and occurs in three forms in humans, such as cutaneous, pulmonary, and meningitis. Its prevalence has been increasing over the past 20 years for many reasons parallel to the increase in the incidence of acquired immunodeficiency syndrome (AIDS) and the expanded use of immunosuppressive drugs. The infection is also common in livestock animals, dogs, cats, birds, and wild life. Soil, fowl manure, and particularly dropping and nest of pigeons could be sources for disease. In Turkey, it was reported that the prevalence of C. neoformans varies between $1 \%$ and $35 \%$ in natural sources, and most of the human cases were clinically characterized with meningitis (221).

Histoplasmosis is a zoonotic fungal infection caused by Histoplasma capsulatum, and occurs worldwide in different forms, such as pulmonary and systemic infections in humans. The pathogen lives in the environment, mainly in the contaminated soil with fowl manure in the bat caves. Birds are not susceptible to the disease, but the pathogen causes infection in various animals, such as dogs, cats, farm animals, and other wild mammals besides humans. The causative agent is transmitted to the host by the inhalation of the spores (222). It was asserted that Turkey may be an endemic area for histoplasmosis by some earlier reports (223). Recently, a case report has been documented on histoplasmosis in humans (224).

Dermatophytosis is a widespread fungal infection of the skin caused by three types of fungi called trichophyton, microsporum, and epidermophyton, which infect both humans and animals. The infection on the skin clinically reflects typical enlarging raised rings called "ringworm." The spores of these fungi may survive for a long term in the soil. Humans and animals can acquire the infection by direct contact with contaminated soil, and the disease can also spread via contact with infected hosts. In an investigation conducted to determine the prevalence of dermatophytosis in the introduced patients in the dermatology clinic of Medical School in Elazig province in Eastern Anatolia, several fungi were isolated from 142 of 651 samples (21.8\%). The prevalence of Trichophyton rubrum, T. mentagrophytes, T. violaceum, T. tonsurans, Epidermophyton floccosum, and Microsporum canis in the isolates were diagnosed as $70.4 \%$, $15.4 \%, 2.11 \%, 0.7 \%, 2.8 \%$, and $4.2 \%$, respectively $(225)$. However, the prevalence of dermatophytosis in cattle, sheep, goats, and cat displayed in the Van province in the same region of Turkey were $33.3 \%, 18.1 \%, 33.3 \%$, and $47.1 \%$, respectively (226).

Sporotrichosis is an infection caused by the saprophytic fungus Sporothrix schenckii worldwide. It is characterized by skin, lung, and circulate types. The pathogen is present in the soil and on various plant matters, such as sphagnum moss, rose bushes, and hay. Humans can acquire the infection by contact with the spores of the fungus in the contaminated environment. The skin form of the disease is the most common and sometimes has been associated with cat scratches. Skin sporotrichosis is frequently seen in cats and horses, and infected cats can also play a role in zoonotic transmission of the infection. Hence, the disease is a major and close hazard for veterinarians. In Turkey, sporotrichosis is rare (227), but a few cases have been reported. A case of subcutaneous sporotrichosis was reported from a 48-year-old man in Kayseri in Central Anatolia (228). Sporothrix schenckii was isolated from a patient with nodular lymphangitic cutaneous sporotrichosis in the Edirne province of the Thrace region (227).

Penicilliosis is an emerging fungal zoonotic disease caused by Penicillium marneffei. P. marneffei has an enigmatic epidemiology, and more investigations are needed to understand its zoonotic or sapronotic transmission. This opportunistic fungus is generally seen in immunocompromized individuals, particularly in human immunodeficiency virus positives (229). The pathogen lives in the soil as its natural habitat and endemically occurs in south Asian countries. Bamboo rats and dogs can serve as reservoirs for the pathogen in endemic areas; important points about the zoonotic nature of its transmission is remains unknown (230). Penicillium spp was found as predominant allergen (46\%) in a study that was carried out to investigate fungus species at atmospheric air of elementary schools in the Denizli province of the Aegean region, Turkey (231).

Malassezia infection or Pityriasis is a fungal infection caused by Malassezia pachydermatis. The infection affects both humans and animals. Malassezia species can be involved in skin disorders, such as pityriasis versicolor, seborrheic dermatitis, atopic eczema, and folliculitis and occur at higher population densities on scalps with dandruff than on scalps without dandruff. The zoonotic transmission of pityriasis is possible mechanically through hands (232). Patients under total parenteral nutrition and immunocompromized patients with an increased length of stay in intensive care units are at risk for Malassezia infections. Dogs and cats become infected with $M$. pachydermatis that are normally present on their skin and in the ear canal (233). In Turkey, a limited number of studies on pityriasis have been performed to date (234-236)

Adiaspiromycosis is a rare chronic pulmonary disease caused by Emmonsia crescens, Emm. Parva, and Emm. pasteuriana and effects both humans and animals. The disease is mainly characterized by the presence of large adiaspores in the lungs of infected humans and animals. Among the etiologic agents, Emm. crescens is prevalent in continental Europe and England, whereas E. parva occurs in Asian, African, and American continents. Emmonsia species are environmental pathogens and their transmission to the host is possible by inhalation of their spores (230). In Turkey, some adiaspiromycosis cases were reported from several small wild mammals (237).

Pneumocystosis is a fungal disease caused by Pneumocystis jirovecii (previously known as Pneumocystis carinii) that primarily leads to pulmonary infection in AIDS or in immunocompromized patients $(238,239)$. The airborne transmission of Pneumocystis sp. from host-to-host has been demonstrated in rodent models (240). In Turkey, pneumocystis pneumonia due to $P$. carinii in AIDS patients was reported in 1990s $(241,242)$. The prevalence of $P$. jirovecii was also displayed as $54 \%$ in the respiratory samples introduced to the parasitology laboratory 
between 2003 and 2011 in the Samsun province of the Black Sea region (243).

Microsporidiosis is an opportunistic fungi infection of humans. The infection is caused by several microsporidian species, such as Encephalitozoon cuniculi, Enc. intestinalis, Enc. Hellem, and Enterocytozoon bieneusi. The infection occurs in immune-deficient individuals with persistent diarrhea. Microsporidial species also infect a wide range of animals, including birds, raising the concern for zoonotic transmission. Microsporidian spores are relatively resistant to harsh environmental conditions and exist in water sources. Humans and animals get the infection by ingestion or inhalation of the spores (244). A study in Turkey, which was conducted to investigate the prevalence of Enc. intestinalis and Ent. bieneusi in cancer patients under chemotherapy at the Erciyes University Hospital in Kayseri showed that 65 of 93 patients (69.9\%) with cancer were found positive; 43 (46.2\%) of the positive samples were identified as Enc. intestinalis, while the 9 were determined as (9.7\%) Ent. Bieneusi, and the other 13 (14\%) were diagnosed as mixed infections (245). However, a study was performed to investigate the molecular epidemiology of microsporidian infections in dogs around Kayseri in the Cappadocia region, and 41 of 282 stool samples (14.5\%) were found positive for microsporidiosis; 35 of 41 positive samples (85.3\%) were identified as Enc. intestinalis, while the reaming 6 (14.6\%) were detected as Enc. cuniculi. In the same study, three haplotypes that showed $99.4 \%$ identity to each other were characterized within the Enc. intestinalis isolates. However, only one haplotype was displayed in the sequences of Enc. cuniculi isolates and this haplotype was described as Enc. cuniculi Genotyp III (dog genotype), and no polymorphic region was found in the sequences of the Enc. cuniculi isolates (246). Furthermore, Enc. cuniculi and Ent. bieneusi were molecularly detected from household cats in the Samsun province of the Black Sea region (247).

\section{Viral Zoonotic Diseases in Turkey}

Globally, a total of 95 zoonotic viruses have been identified and listed under the entitled "spillover and pandemic properties of zoonotic viruses with high host plasticity" and their general transmission categories were also grouped (248). Several zoonotic viruses that are transmitted to humans by direct or indirect route cause severe infections in Turkey (Table 1) as well as globally. These infections were categorized according to their clinical manifestations and epidemiological characteristics, as indicated by Venkatesan et al. (249) into groups (i) encephalitis, (ii) rash and arthralgia, (iii) hemorrhagic fever, (iv) emerging, (v) re-emerging (vi), rare zoonotic, and (vii) potential zoonotic viral infections. The specific diagnosis of these infections generally involve virologic tests, such as virus neutralization test, complement fixation and hemagglutination-inhibition, enzyme-linked immunosorbent assays; further analysis is required for molecular detection and characterization of the causative viruses $(250,251)$. Vaccines are not available for the majority of these diseases. However, recent advances and intense investigations toward the development of new generation vaccines are encouraging for the future of control programs against viral infections. Currently, some measures, such as prophylactic and therapeutic, are available for the control of limited number of viral infections, whereas the implemen- tation of vector control programs are basically required for most of viral diseases.

Encephalitis group zoonotic viruses are RNA viruses of the Rhabdoviridae, Flaviviridae, Togoviridae, Reoviridae, and Bunyaviridae families and are transmitted to humans by mosquitoes and ticks, except rabies virus in Rhabdoviridae family, which is transmitted by the bite of an infected host. The symptoms of viral encephalitis are associated with clinical manifestations of neurological disorders, headache, fatigue, aches in muscles, fever, vomiting, double vision, confusion, and agitation or hallucinations. The reported viral zoonotic infections with encephalitis manifestation in Turkey are shown in Table 1.

Rabies is a lethal form of encephalitis caused by the Rabies lyssavirus belonging to the genus Lyssavirusvirus of the Rhabdoviridae family. The disease is still effective and has great zoonotic importance in Turkey. Confirmed 39 cases of human rabies were reported by the Ministry of Health in a 15-year period between 1992 and 2007. Of the cases, 29 (74\%) were related to dog bites, while the others were closely connected with wild animals (252).

Tick-Borne Encephalitis (TBE) is an important infection of humans caused by the tick-borne meningoencephalitis virus belonging to the genus Flavivirus in the family Flaviviridae. The infection is prevalent in a large endemic area of Asia and Europe, including Turkey. In Turkey, the seropositivity of the infection was reported in the range $1.4 \%-20.5 \%$ (10).

West Nile Virus (WNV) is an infection that has a worldwide distribution. The infection is mainly transmitted by mosquitoes. The virus has been isolated from several mosquito species. Especially Culex species have found to be infected with the virus. In 2010, the first outbreak of WNV infection, including 12 laboratory-confirmed and 35 suspected cases, were identified in Turkey. The patients were from different provinces, mainly located in the western part of the country (253). In Turkey, the seropositivity of the infection was reported in the range 1\%-16\% in humans, while $1 \%-37.7 \%$ in domestic animals $(35,254)$.

Rashes and arthralgia group viruses consist of a few viruses that belong to Alphavirus in Togaviridae family. Rashes and arthralgia are clinically seen in the virus-infected patients. In Turkey, the reported viral zoonotic infections causing rash and arthralgia are presented in Table 1.

Chikungunya virus (CHIKV) infection is a mosquito-borne zoonotic disease with rashes and arthralgia characteristics caused by CHIKV belonging to the genus Alphavirus of the Togoviridae family. The infection is prevalent in Africa and Asia. However, in Ankara, a case of CHIKV infection was diagnosed in a 55-yearold Turkish woman who had lived in India, New-Delhi, for 3 years (255). More recently, Alphavirus was also found by molecular assays in pools of mosquitoes collected from the Thrace region of Turkey (256).

Hemorrhagic fever group zoonotic viruses consist of 16 pathogens that belong to Arenaviridae, Bunyaviridae, Flaviridae, and Filoviridae families, causing infections generally associated with extensive bleeding. Most of viruses in this group are transmitted 
by vector arthropods, such as mosquitoes and ticks. In Turkey, the reported hemorrhagic fever viruses are shown in Table 1.

Crimean-Congo Hemorrhagic Fever (CCHF) is a tick-borne zoonotic contagious disease caused by a virus belonging genus Nairovirus in Bunyaviridae family, which is transmitted by tick species of the Ixodidae family. Wild and livestock animals serve as amplifiers of the CCHF virus in field conditions. The infection occurs in a large area of sub-Saharan Africa, Eastern Europe, Russia, the Middle East and western China. In Turkey, it was reported that the infection was first observed in 2002 in the Black Sea region and then spread to the rest of the country $(10,257)$.

Dengue fever (DENF) is a zoonotic infection caused by DENF virus (DEN-1, DEN-2, DEN-3, and DEN-4 serotypes) belonging to genus Flavivirus of the Flaviviridae family. The infection is transmitted to humans by Aedes aegypti mosquitoes and occurs worldwide. In Turkey, a case of DENF virus was diagnosed in a 40-year-old patient who has visited India and the virus was identified as DEN-3 serotype (258).

Emerging group zoonotic viruses: An emerging disease means previously unknown and newly identified infectious agent that causes public and animal health problems either locally or globally. This group has serious potential threats for human health with economic impacts, and their current trends have been going upwards. Thus, these viruses have been defined as "a zoonosis that is newly recognized or newly evolved or that has occurred previously but shows an increase in incidence or expansion in geographical, host or vector range" by the WHO/ Food and Agriculture Organization of the United Nations (FAO)/ World Organization for Animal Health (OIE) in Geneva (259). The last 30 years have seen a significant increase in emerging viral diseases in humans, and almost $70 \%$ of the infections were categorized as zoonotic infections $(2,260)$. The major source of emerging zoonotic viruses is increasing wildlife, particularly bats which play important epidemiologic roles for some viruses, such as Hendra and Nipah, SARS, and MERS virus. Toward the investigation of these viruses and to prevent current diseases (or possible infections), the One Health approach has been developed. In this scope, it was reported that a horse vaccine also called "One Health Vaccine" can be used to prevent the transmission of Hendra virus from horse to human (261). In Turkey, the reported emerging zoonotic viruses are shown in Table 1.

Middle East Respiratory Syndrome Coronavirus (MERS-CoV) is a zoonotic infectious disease caused by a virus belonging to genus Betacoronovirus in the subfamily Coronovirinae of the Coronaviridae family, and MERS-CoV was isolated from bats. Infected patients with MERS-CoV commonly have fever, cough and shortness of breath as clinical symptoms, and in most of the cases, gastrointestinal symptoms, such as diarrhea, have also reported. There is no vaccine or medication that protects against MERS-CoV (243), and close dromedary camel contact is a major risk for human infection (262). In 2015, 971 laboratory-confirmed cases of human infection with MERS-CoV were reported to $\mathrm{WHO}$, including at least 356 deaths. Most of these cases have been reported from several Middle East countries including Turkey (263).
Avian Influenza (H5N1) is a zoonotic infection caused by viruses adapted to birds that serve as a natural reservoir for the infection. Although influenza $A$ is adapted to birds, it can also stably adapt and sustain person-to person transmission. The transmission of the infection is mainly by contact between infected and healthy birds, although it can also be spread indirectly through contaminated equipment. The virus can be found in the secretions and droppings of the infected birds. A highly pathogenic infection is spread to people often through direct contact with infected poultry, such as during slaughter or plucking. The infection occurs as global avian influenza pandemics and cause big economic losses (261). The infection is also prevalent in Turkey, and its economic impact was reported at almost 7.5 million US dollars/per day and total loss was expressed as over 231 million US Dollars for 2 months in 2006 (264). A total of 625 patients with suspected $\mathrm{H} 5 \mathrm{~N} 1$ virus infection were treated at the University Hospital between 2005 and 2006 in the Van province, and eight of them were diagnosed as H5N1 positive. At the same period, additional four confirmed cases of $\mathrm{H} 5 \mathrm{~N} 1$ were reported from different areas of Turkey, including the Black Sea region and central, southeast, and eastern Anatolia (265).

Swine Influenza is a highly contagious respiratory zoonotic viral infection caused by influenza A viruses of the Orthomyxoviridae family. The most common subtypes of influenza virus in swine are H1N1, H1N2, and H3N2. The disease in swine occurs within a herd either as an epizootic or enzootic form, which infect the respiratory tract of pigs and result in a barking cough, decreased appetite, nasal secretions, and listless behavior; the virus can be transmitted to humans. Swine flu viruses may mutate so that they are easily transmissible among humans. Swine flu is transmitted from person to person by inhalation or ingestion of droplets containing virus from sneezing or coughing. In Turkey, a study was conducted to investigate the seroprevalence following the first wave of pandemic influenza $A(H 1 N 1)$ in 2009, the pandemic $\mathrm{H} 1 \mathrm{~N} 1$ seropositivity was found to be $24.1 \%$ for Ankara and $27.7 \%$ for Diyarbakir (266).

Hemorrhagic Fever with Renal Syndrome (HFRS) virus is a group of clinically similar diseases caused by various viruses, such as Hantaan, Dobrava, Saaremaa, Seoul, and Puumala, belonging to genus Hantavirus in Bunyaviridae family. HFRS comprises several diseases, such as Korean hemorrhagic fever, epidemic hemorrhagic fever, and nephropathia epidemica. Rodents are reservoirs for Hantaviruses, and humans can become infected by direct contact with infected rodents. Although individual transmission is possible, it is extremely rare. HFRS occurs commonly in a large area of Asia, Southeast Asia, and Europe (261). An outbreak of HFRS with 23 confirmed cases was reported as an emerging disease from Zonguldak and Bartin provinces in the Northwest part of Turkey in 2009 (267, 268).

Hepatitis $E$ is a liver disease caused by hepatitis $E$ virus, which is a small RNA virus with at least 4 genotypes. The transmission of the disease is possible by the fecal-oral route, principally via contaminated water. Hepatitis E virus occurs worldwide, although the prevalence is highest in East and South Asia (261). In Turkey, limited epidemiological studies on hepatitis virus have been conducted in children in various provinces. The seropositivity of 
hepatitis E virus was 2.1\% in Ankara of Central Anatolia (269), $12.4 \%$ in the Denizli province of the Agean region (270), and $4.2 \%$ in the Van province of Eastern Anatolia (271).

Parainfluenza viruses (PIVs) belong to the Paramyxoviridae family and have 5 subtypes, such as Parainfluenza 1, 2, 3, 4a, and 4b. Nosocomial infections are also common, particularly among young infants. Human parainfluenza viruses (hPIVs) can be transferred through direct person-to-person contact (with infected secretions) and via respiratory droplets (261). In Turkey, outbreaks were reported in children in the Izmir province between 2000 and 2005, and Parainfluenza type 3 was isolated from 96 of the 178 (53.9\%) viral specimens (272). In another study, the seropositivity of Parainfluenza 3 was found to be 18\% in 15 dairy cattle farms in East and Southeast Anatolia regions of Turkey (273).

Re-emerging group zoonotic viruses: Re-emerging infectious diseases include infectious agent that had fallen to such low levels that it was no longer considered a danger for public and animal health problem, but became reactive again and showed an upward trend in the incidence or prevalence in humans and animals both locally and worldwide. Re-emerging zoonotic viral infections can emerge when viruses expand their host range (for example monkey poxvirus and equine morbillivirus) or the disease can be a result of intrinsic properties of the virus itself, such as high mutation rate (ie, influenza $A$ virus and foot and mouth disease [FMD] virus) (274). Most re-emerging viral zoononeses involve infections with hemorrhagic and neuropathological viruses that are arthropod-borne (yellow fever virus; Zika virus) (275), by rodents (Hanta virus), or by nosocomial infections (Ebola virus). The re-emergence and increase of these group of infections are also a consequence of anthropogenic environmental changes, such as distortion of the ecological balance and major agricultural changes (276). Additionally, complex interactions among ecology, socioeconomic and demographic structures, health care, and human/animal behaviors also affect the re-emergence of zoonotic viral disease (249). The reported re-emerging viral zoonotic infections from Turkey are listed in Table 1.

Orf virus infection or Ecthyma contagiosum is one of the re-emerging zoonotic viral infections caused by a virus belonging to genus Parapoxvirus (PPV) in Chordopoxvirus subfamily of the Poxviridae family. The Orf virus often affects different hosts, such as wild and domesticated cattle, sheep, goats, and humans. The disease is transmitted to humans by direct or indirect contact with the infected material. The first case of Orf in humans was clinically manifested as solitary skin lesion in 1934 (277). In Turkey, the Orf virus infection has reemerged during the last two decades, and case reports and Orf outbreaks related to Orf in both animals and humans are available $(278,279)$. The human case of Orf virus infection with a pyoderma-like lesion on the left indicator finger was diagnosed in a 37-year-old man in 2011 in Ankara, and the virus was molecularly characterized (280). Later another case of Orf virus infection with similar manifestations on the right hand thumb was reported from a child (281).

Rare Viral Zoonotic Infections group: Various viral infections, which originate from animal pathogens, can sometimes cause nonspecific febrile illness in humans. The transmission of these diseases are commonly possible by contact with infected animal (FMD particularly serotype $\bigcirc$, buffalo pox), by handling of such organisms in laboratory conditions (bluetongue and Newcastle disease), by sexual contact (simian immune deficiency virus), by bite or scratch (monkey B virus), via vectors (semliki forest virus, African horse sickness, and louping ill [LI]), or through food or water (caliciviruses, such as swine vesicular exanthema, feline calicivirus, and rabbit hemorrhagic disease virus). Recently, it was reported that animal rotaviruses and the Eyach virus cause mild infections in humans (249). The reported rare viral zoonotic infections in Turkey are listed in Table 1.

African Horse Sickness (AHS) is a vector-borne and non-contagious disease of equids caused by the African horse sickness virus belonging to the genus Orbivirus within the Reoviridae family. The virus is transmitted to the hosts Culicoides species (282). The disease occurs in a large area of Africa, Asia, and Middle East region and has been reported in Europe (Iberian Peninsula). The infection was seen in a limited period between 1959 and 1966 in Turkey (283).

Bluetongue (BTV) is an insect-borne and non-contagious viral infection of ruminants caused by the Bluetongue virus (BTV) belonging to the genus Orbivirus of the Reoviridae family. The infection has a global distribution between latitudes of approximately $40-50^{\circ} \mathrm{N}$ and $35^{\circ} \mathrm{S}$ in Africa, Europe, Middle East, and the Mediterranean regions, Indian subcontinent, the Americas, and Asia (284). The global distribution and nature of BTV infection has changed significantly in recent years, and climate change, particularly global warming has been implicated as a potential cause of this dramatic event. BTV pandemics with devastating economic impact on the cattle industry have been especially seen due to the populations of different new Palearctic vectors, such as Culicoides chiopterus, C. dewulffi, C. obsoletus, C. scotius, and $C$. pulcaris, expanding their range in some parts of Europe (285). It was reported that BTV infection is a prevalent disease with almost $30 \%$ seropositivity among the herds of sheep, goats, and cattle in many parts of Turkey (286), but zoonotic transmission of the infection has not been recorded in the country until today.

Borna Disease $(B D)$ is a viral infection with neurological and psychiatric syndromes of animals and humans caused by BD viruses (BDV) 1 and 2 of the Bornaviridae family. BDVs have a wide host range and have been determined in some domesticated animals, such as horses, sheep, cattle, dogs, and cats as well as wild life. The transmission of these viruses is probably via intranasal exposure to contaminated saliva or nasal secretions (287). A correlation between BDV infection in animals and humans was demonstrated via autopsy in human brains (288). In Turkey, antibodies to BDV were first detected in the sera of 82 of 323 (25\%) clinically healthy horses in the Marmara region (289). Recently, the seropositivity of the infection in the distinct regions of Turkey was reported as $4.9 \%$ in horse, $12 \%$ in sheep, $4 \%$ in goats, $14 \%$ in cattle, and $6.6 \%$ in cats (290). There is no official report on the cases of human BDV infection in Turkey.

Feline Calicivirus (FCV) infection is a widespread respiratory disease of cats caused by a virus of the genus Vesivirus of Caliciviridae family. Cats can be infected after coming into con- 
tact with other infected cats in shelters. The disease can occur in cats of any age, but younger kittens under 6 weeks are most susceptible (291). In Istanbul, Turkey, FCV was detected in 17 of $220(8 \%)$ cats that had clinical oral lesions (292). There is no official report related to FCV infections in humans in Turkey.

Foot and Mouth Disease is a widespread and most contagious and notifiable disease of cattle, water buffalo, sheep, goats, and pigs caused by a virus (seven serotypes: O, A, C, SAT1, SAT2, SAT3, and Asia1) belonging to the genus Aphthovirus of the Picornaviridae family. The infection can be very rapidly spread among animals by aerosols of infected animals and contaminated equipment. The disease occurs worldwide as outbreaks and can occasionally be fatal and cause huge economic losses (293). Rare cases of human FMD may be observed due to close contact with infected animals. The highest risk to European Union countries is through legal and illegal imports of infected live animals and contaminated meat or dairy products from infected countries that are consumed by animals. International travelers bringing back food from endemic countries could also spread the disease. The FMDV can survive for long periods in a range of fresh, partially cooked, cured, and smoked meats and in inadequately pasteurized dairy products (294). The control program requires a close collaboration among veterinary office, health service, and local authorities. The control measures of FMD depend on restricting the movement of farm animals in the endemic region and immunization with vaccines in a vaccination regime. Several outbreaks of FMD have been reported in Turkey $(295,296)$. The official FMD status of Turkey has been shown in the list of OIE (297).

Louping III is a tick-borne infection of sheep and goats caused by the LI virus (LIV) belonging to the genus Flavivirus of the Flaviviridae family. The LIV characteristically causes encephalomyelitis of sheep. The epidemiological occurrence of the disease is closely related to the distribution of its primary vector tick Ixodes ricinus (298). The disease has been reported from various European countries, including England, Norway, Greece, and Bulgaria, as well as Turkey (10). There is no report human LIV infection cases in Turkey.

Newcastle Disease (ND) is a widespread, contagious, and notifiable infection of aves caused by a virulent strain of paramyxovirus type 1 (APMV-1) belonging to the genus Avulavirus of the Paramyxoviridae family. The transmission of the disease is possible by direct contact with affected birds and inhalation or ingestion of contaminated material. The virus survives in the environment, especially in the feces. It is an essential requirement for workers and staff to wear gloves, mask, and coveralls and to use of disinfected equipment and supplies to minimize the potential risk of zoonotic transmission of the disease. The infection occurs worldwide and causes devastating economic losses in the poultry sector (299). In Turkey, a total of 549 cases of ND in poultry have been reported from various regions between 2007 and 2014 (300). There is no report on the cases of human ND in Turkey.

Cowpox (CPX) is presently a rare zoonotic viral infection caused by Cowpox virus belonging to the genus Orthopoxvirus of the Poxviridae family. The zoonotic transferal of the infection is first seen in milkers, who touch the udders of infected cows. The infection is mostly restricted to small mammals rather than cattle (301). The transmission of the disease from pet rats to humans has also been observed in four different cases in France (302). It was reported that cases of cowpox are seen in European countries and also in Eurasia including Turkey (303).

Pseudocowpox virus (PCPV) Infection is a zoonotic viral skin disease caused by PCPV belonging to Parapoxvirus within the Chordopoxvirinae subfamily of the Poxviridae family. The virus is widespread worldwide and is transmitted to humans by direct contact with infected cows. The infection affects particularly milkers and farm workers. Clinically, the mild sores can be seen on udders and teats of the infected cows, and on hands of the infected milkers. Most recently, the isolation and identification of Pseudocowpox virus was performed from an infected Angus bull with lesions on the surface of the penis in Idaho, USA (304). In Turkey, PCPV was first isolated and characterized both from an infected cow and from a milker in a farm near the Milas district of Mugla (305).

Bovine papular stomatitis (BPS) is a zoonotic infection caused by Bovine popular stomatitis virus (BPSV) belonging to the genus Parapoxvirus of the Poxviridae family, and occurs worldwide in cattle. The infection has occupational zoonotic spreading among farmers, veterinarians, and butchers. The zoonotic transmission of the infection is through direct or indirect contact with infected animals (306). BPS virus infection is clinically seen with erosive lesions on the muzzle, lips, hard palate, oral mucosa, tongue, and esophagus in infected calves. In human, BPSV infection is often associated with nodules and pustules on the hands and rarely on the face (307). In Turkey, an outbreak of BPSV infection has been reported in a dairy herd in the town of Tire near Izmir (308).

Rotavirus diseases are epidemiologically important viral zoonotic infections for public health, particularly in children as well in calves and foals. Rotavirus infections are characterized by acute watery dehydrating diarrhea in various hosts, including birds and mammals. The infections are caused by different types of viruses belonging to the genus Rotavirus within the Reoviridae family. Rotaviruses are enteric pathogens that cause a large number of child deaths each year in developing countries, and rotavirus infections are mainly acquired by the fecaloral route, including fomites and person-to-person contact with contaminated objects (309). However, the cases of Rotavirus-associated enteritis are most frequently seen in calves and in foals, and to combat against Rotavirus infections, vaccines are available for infants and children $(310,311)$. In Turkey, a study was conducted to investigate the etiology of diarrhea cases between September 2004 and December 2005. At the end of the study, the prevalence of Rotavirus was determined as $39.7 \%$, and the serotype G1P of Rotaviruses was also found as dominant (312).

Norovirus infection is a very contagious disease caused by the Norwalk virus belonging to the genus Norovirus of the Caliciviridae family. Humans can be infected via different ways, such as contaminated food or water, or by touching contaminated surfaces, or by contact with an infected person who has norovirus illness, or by fecal-oral, or through aerosol route. The 
infection leads to acute gastroenteritis characterized by nausea, vomiting, watery diarrhea, and abdominal pain (313). In Turkey, norovirus was found positive in samples of mussels in the Izmir city of the Agean region (314) and in some samples of ready-toeat food items in Istanbul of the Marmara region (315). Additionally, a large multipathogenic gastroenteritis outbreak was reported from Erzurum located in the Eastern part of the country in 2012, and etiologic agents of the outbreak were identified as astrovirus, norovirus, Shigella sonnei, and E. coli (316). In contrast, bovine norovirus was detected through molecular techniques in calves (317).

Astrovirus infection is caused by a type virus belonging to the genera Astrovirus and Mamastrovirus in the family Astroviridae. The main mode of astrovirus transmission is by contaminated food and water, and it cause gastroenteritis in humans, particularly in children and the elderly individuals (318). In Turkey, astrovirus was identified as an agent in large multipathogenic outbreak, which was seen in Erzurum in 2012 (316).

Potential zoonotic viral infections group Expansions of human interest in nature damages the ecological balance among animal-human ecosystems. The emergence of zoonotic diseases due to changes in animal/human host interface is considered e a major threat for public health (319). The trend of increasing zoonotic virus emergence is expected to continue (259). In this scope, the foamy retroviruses of bovine, feline, and equine can be given as examples of potential viral zoonotic disease transmission to humans $(319,320)$. Moreover, a novel tick-borne phlebovirus with zoonotic potential was isolated from ticks in Australia and shown to be closely related to two other newly discovered zoonotic phleboviruses Severe Fever with Thrombocytopenia Syndrome Virus and Hunter Island Group Virus, which were responsible for severe disease and deaths in humans in four separate countries from Asia and North America (321). However, the zoonotic status of Lumpy Skin Disease (LSD) virus is still controversial. LSD was propounded as "potential for zoonotic spread to humans" (322), whereas the disease was shown as "not zoonose" in the list of EFSA $(323,324)$. The potential zoonotic viral diseases in Turkey are given in Table 1.

Hepaciviruses belong to the genus Hepacivirus in Flaviviridae family, and include hepatitis $C$ and hepatitis GB virus B ( $\mathrm{HCV}$ and GBV-B) types. Humans serve as natural hosts for these viruses. $\mathrm{HCV}$ is transmitted by infected blood transfusion between humans. HCV was also identified in domestic cattle from Germany (325). However, the zoonotic transmission of Hepaciviruses was investigated using Hepacivirus NS3/4A proteases (interfere with mitochondrial antiviral-signaling protein [MAVS] signaling) in both cognate animal hosts and humans. Human MAVS was found as susceptible to cleavage by these non-human viral proteases, indicating that it does not pose a barrier for zoonotic transmission to humans (326). In Turkey, the seropositivity of HCV was detected as $1.5 \%$ in sera collected from 1374 people who live in five distinct regions of the country (327).

Phlebovirus contains known disease agents of animals, including humans, that can be carried by different vectors (eg, phlebotomine sandflies, mosquitoes, and ticks) (328). Four serotypes of phleboviruses, sand fly Sicilian virus, sand fly Cyprus virus, sand fly Naples virus, and Toscana virus have been circulating in the Mediterranean Basin including Turkey (21).

Lumpy Skin Disease (LSD) is a pox disease of the cattle characterized with nodules on the skin and transmitted mechanically via blood-feeding arthropods, including some hard ticks. Rhipicephalus (Boophilus) decoloratus, Rhi. appendiculatus, and Amblyomma hebraeum ticks serve trasmitters in the epidemiology of LSD in the endemic areas (329). An LSD outbreak was first recognized in cattle associated with the nodular clinical symptoms in August 2013 in Turkey (330). In the following months, the infection has spread countrywide, and a total of 3504 LSD cases were recorded between August 2013 and December 2014 (331). Recently, an LSD outbreak with huge economic devastation has been reported by official government veterinarians in May and June of 2016 in the Aegean region of Turkey, and more than 500 cattle infected with LSD virus have been culled for the control of the disease (10).

\section{Parasitic Diseases with Zoonotic Characteristics in Turkey}

To date, various parasitic diseases with zoonotic characteristics caused by distinct parasite species of helminthes, protozoa, and arthropods have been reported from different regions subtropically located in Turkey (Table 1). These diseases can often cause serious public health problems and lead to greater economic devastation in livestock industry and may also promote poverty in some regions of Turkey as well throughout the world $(26,154)$. The life cycle of parasites is very complex, and it can be varied as monoxene and heteroxene. Combating parasitic zoonoses is also extremely difficult, and the control measures are mainly related to the management of livestock as indoor or outdoor, chemical usage, and vector control. Vaccines are not available for immunization against zoonotic parasitic disease in Turkey.

Trematode zoonoses are caused by mainly Fasciola spp and Schistosoma spp and to lesser extent by other trematode species, such as Dicrocoellium dentriticum that occur worldwide. Fascioliasis is a most prevalent parasitic disease of the liver in ruminants, sheep, and cattle caused by the common liver fluke Fasciola hepatica as well as by F. gigantica. The infection frequently occurs with acute and chronic forms in sheep and causes huge economic losses due to deaths and productivity losses (332), but also affects cattle. Humans are infected by eating some vegetables contaminated with the infective stage of metacercariae of the parasite. The $\mathrm{WHO}$ has accepted that fasciolosis is an important zoonotic infection of humans after 2,594 human cases were reported from 42 countries between 1970 and 1990 (333). In Turkey, 53 cases of human fascioliasis were reported from the Mediterranean region between 1998 and 2003 (334), and the seroprevalence of $F$. hepatica was detected as $5.6 \%$ in humans in the Van province in Eastern Anatolia (335). However, a case of human dicrocoeliosis caused by $D$. dentricum was reported from the eastern part of Turkey (336). Another important zoonotic disease is schistosomiasis caused by penetration of free-swimming larva form (cercariae), which is able to actively penetrate human skin. The disease is caused by five Schistoma species (S. mansoni, S. japonicum, S. mekongi, S. intercalatum, and $S$. haematobium). The disease causes global health problem 
and affects nearly 200 million people in the endemic areas of the world (337). In Turkey, a case of urinary schistosomiasis was detected in a man who had visited Nigeria (338). Briefly, cases of fasciolosis, dicrocoelliosis, and schistosomiasis in humans have been reported as zoonotic trematode infections from Turkey (Table 1).

Cestode Zoonoses can be grouped within two super families: Cyclophyllidea and Pseudophyllidea. Cyclophyllidea contains various species with zoonotic characteristics in different families, such as Taeniidae, Dipylidiidae, Hymenolepididae, and Mesocestoididiae, while Pseudophyllidea includes a few zoonotic species of the Diphyllobothriidae family. Taenia saginata, $T$. solium, T. multiceps, Echinococcus granulosus, and E. multilocilaris in Taeniidae; Dipylidium caninum in Dipylidiidae; Hymenolepis nana and $H$. diminata in Hymenolepididae; Mesocestoides linatus in Mesocestoididae; and Diphyllobothrium latum and Spirometra mansoni in Diphyllobothriidae are major and prevalent zoonotic species of cestodes in the world. The zoonotic cestodes belonging to family Taeniidae are of paramount importance in the economic structure of developing countries, including Turkey, and lead to huge losses (28). The animals, such as cattle, buffalo, sheep, goats, and pigs serve as intermediate hosts for Echinococcus granulosus. Humans get the echinococcosis after accidental consumption of foods contaminated with eggs of Echinococcus species that are shed in the feces of the definitive carnivorous host/animal. Taeniasis is another zoonotic infection for which pig and cattle are intermediate hosts for Taenia solium and Taenia saginata, respectively, and humans serve as definitive/final hosts. Neurocysticercosis, such as coenurosis, which is caused by T. multiceps, is one of the important neurological problems in animals, such as sheep and cattle, and this type of neurologic disorder can also occur in humans. Besides important animal and human health concern, particularly in sheep breeding, the economic losses arising due to these infections are enormous. Dipylidium infection is an ingested vector-borne zoonotic disease of dogs, cats, and humans. Dogs, cats, some wild carnivores, and humans can be infected by swallowing fleas (Ctenocephalides canis, C. felis and Pulex irritans) or by chewing lice (Trichodectes canis), which are infected with the larval form (cysticercoids) of a cyclophyllid cestode, D. caninum. The parasite mostly infects dogs and cats, but is occasionally found in humans, particularly young children. Hymenolepiasis caused by Hymenolepis nana and $H$. diminuta is actually classified as a neglected zoonotic disease. These worms thrive in the intestine of rats in warm climate conditions, and the eggs of these parasites can spread to the environment by feces of infected rats. The secondary host, which is an insect in the order of coleopteran, acquires the parasite from the contaminated environment and then the parasite develops as cysticercoid form within the insect. Humans and other animals are infected by eating foods or materials contaminated with infected insects. Humans can also acquire $H$. nana infection directly by ingesting the eggs of the parasite through contaminated food or water. In an infected person, it is possible for the worm to complete the entire lifecycle in the intestine (by autoinfection). Mesocestoidiasis is a zoonotic infection caused by Mesocestoides lineatus and $M$. variabilis. Mesocestoides spp. require a three-host life cycle to complete their development. The definitive hosts are primarily carnivores that become infected after eating meat contaminated with tetrathyridia of the parasite. Humans are not definitive hosts, but can serve as such after eating undercooked meat containing tetrathyridia of the parasite. In the case of human mesocestoidiasis, mild gastrointestinal symptoms, such as nausea, diarrhea, abdominal discomfort, and vomiting can be seen. M. lineatus infections are prevalent in a large area of Europe, Asia, Africa, and North America, whereas M. variabilis infections occur in North America. Other important parasitic zoononoses are pseudophyllid cestodes, such as Diphyllobothrium latum and Spirometra spp. Dogs and humans acquire the infection by eating raw or undercooked fish, which are infected with the third larval stage (plerocercoid) of the pseudophylliid cestode D. latum. Epidemiologically, diphyllobothriasis occurs worldwide in areas where raw fish is consumed. Sparganosis is a rare zoonotic cestode infection caused by Spirometra mansoni, S. ranarum, S. mansonoides, and S. erinacei. Dogs, cats, and other mammals are definitive hosts, while humans can play role of accidental host in the life cycle of the parasite. The infection is transmitted to humans by the ingestion of contaminated water or ingestion of a second intermediate host, such as a frog or a snake. The transmission of the infection is also possible by contact between a second intermediate host and an open wound or mucous membrane of the hosts. Once a human is infected, the sparganum (plerocercoid) migrates to various tissues and organs, such as brain and eyes. The subcutaneous location of the sparganum causes a painful nodule, while the migration to the brain results in cerebral sparganosis, and the migration to the eyes results in ocular sparganosis. Sparganosis is a frequently seen zoonotic disease in eastern Asia, but cases have also been reported from distinct areas of the world. To prevent the infection, interventions of public health must be focused on sanitation of water and dietary in parallel to education of the people in rural areas in endemic regions (339).

Echinococcosis is one of the most important parasitic zoonotic infections in Turkey of huge economic impact (30). The disease is seen in two forms: Cystic Echinococcosis (CE) and Alveolar Echinococcosis (AE). CE caused by Echinococcus granulosus sensu stricto is prevalent throughout the country (340), while AE caused by E. multilocilaris, occurs sporadically, and some human cases of $A E$ have been reported mostly from the Eastern Anatolia region of Turkey (341). Epidemiologically, the prevalence range of CE in domesticated animals varies between 3.5\% and $58.6 \%$, depending on intermediate hosts, such as sheep, goats, and cattle, and their managements and the different regions of Turkey (22). The prevalence can even reach $90 \%$ in sheep in some regions of the country (340). Although the present number of stray dogs and owned dogs, which are of critical importance for epidemiology of CE, is unknown in Turkey, the rising population of dogs is an increasing nuisance and seriously threatens both public health and the health of farm animals. The prevalence of CE in dogs has been reported widely to vary between $0.32 \%$ and $40 \%$ in different areas of Turkey. However, the regularly reported number of cases of CE in humans is 52,124 in the period of 16 years between 1990 and 2005 in Turkey. This official statistical data from Ministry of Health of 
Turkey reveals that 3,257 new CE cases are seen per year in humans. This incidence of CE in humans is very high and is a serious unacceptable threat for public health. The seroprevalence of CE in the Izmir area, which represents the western part of Turkey, has been reported as 291 per 100,000 inhabitants (22). In contrast, it was reported that most number of patients with complaints of CE were observed in the regional hospitals in the Northeastern part of the country, such as Ataturk University Hospital in the Erzurum province (342). A total of 304 CE cases in humans were treated surgically at the Ataturk University Hospital between 1981 and 1996 in Erzurum (343). In addition, 156 children with hydatid liver disease were also treated at the same hospital between 1994 and 2011 (344). At the same hospital in Erzurum, patients with AE were also operated for liver transplantation due to hepatic alveolar echinococcosis $(341,345)$. The recent epidemiological data on CE cases in humans were expressed as follows: the regional incidence of $\mathrm{CE}$ varied depending on epidemiological differences and ranged 0-79 per 100,000 population; the prevalence of CE was also reported as 50-400 cases per 100,000; the average incidence of CE in Turkey was given as 3.4 per 100,000 inhabitants (346).

Taeniasis and cysticercosis are important cestode zoonotic diseases. Especially, bovine cysticercosis is a prevalent infection of cattle caused by the larvae (cysticercosis) of Taenia saginata and leads to huge economic losses in developing and industrialized countries. Cattle acquire the infection through ingestion of eggs, while the zoonotic transmission of this cestode is possible by consuming the meat of cattle infected with the larval stage of T. saginata. Humans are the definitive host and the larva develop into adult form of the parasite in the intestines of the infected humans. The clinical manifestations of taeniasis in humans are characterized by symptoms that include pain, unexplained weight loss, blockage of the intestine, and digestive problems. Some people with taeniasis may also experience irritation due to the parasite in the perianal area. A person with taeniasis often becomes aware of the infection by seeing the segments or eggs of T. saginata in their stool. Naturally, infected cattle do not exhibit any clinical symptoms but they cause financial losses due to downgrading, condemnation, extra handling, refrigeration, and transport of the infected carcasses in cattle industry. The main intervention to control of bovine cysticercosis is meat inspection according to the legislation status. The current epidemiological situation of bovine cysticercosis in European countries, including Turkey, is based on the detection of cysticerci in the carcasses of bovine animals during meat inspection at the slaughterhouse. Official reports about the meat inspection are considered an underestimation of the real prevalence, as meat inspection has a low sensitivity for the detection of cysts in muscles. In Turkey, it was reported that the prevalence of bovine cysticercosis ranged from $0.3 \%$ to $30 \%$ between 1957 and 1990, while the current prevalence of infection was shown to be nearly $5 \%$ (347). However, in a study that investigated the status of taeniasis and bovine cysticercosis in the Burdur and Afyonkarahisar provinces between 2009 and 2011, the prevalence of bovine cysticercosis in 1684 carcasses examined was detected to be $0.24 \%$; the prevalence of taeniasis in humans in the examined 7644 stool samples was found as $0.1 \%$ (348).
Cerebral coenurosis is an important disease affecting small ruminants, particularly sheep, and causes significant economic losses in production. The infection is caused by larval stage (coenurus cerebralis) of Taenia multiceps and occurs worldwide. The life cycle of the parasite is commonly completed between host dogs and intermediate hosts, such as small ruminants. However, a rare case of cerebral coenurosis was seen in cattle and in humans (349). In Turkey, the prevalence of ovine coenurosis and bovine coenurosis was reported as $15.5 \%$ (350) and $0.47 \%$ (351), respectively. There is no official record on human coenurosis in Turkey.

Dipylidiasis is considered a potential risk for children and caregivers and companions living in the same houses. Definitely, pet animals, particularly dogs and cats are important companions in many households, contributing to the physical, social, and emotional development of children and the well-being of their owners. This close zoonotic potential threat should not be overlooked, and the possible flea infestations should be prevented on dogs and cats. In Turkey, the prevalence of Dipylidium caninum in stray dogs and in owned dogs was detected as $2.9 \%$ in the Afyonkarahisar province (352) and 2.8\% in the Kayseri area (353). There is no official record about the cases of $D$. caninum infections in humans in Turkey.

Hymenolepiasis is a most common cestode infection in humans living in environments with poor sanitation and insufficient hygienic conditions in the parts of the world. Actually, this infection was shown to be one of the diseases considered an indicator of the relationship between disease and extent of good sanitation in a habitat. Humans can become infected by ingestion of the eggs of the parasite in contaminated food, water, or feces (354). The geographic distribution and prevalence of Hymanolepis nana infections were reported from some parts of the world, including Turkey (355). Additionally, a rare case of $H$. dimunata infection in a child was also recorded from Turkey (356).

Mesocestoidiasis is a prevalent cestode infection of dogs and cats in Turkey as well in the world. Mesocetoides spp occasionally induce peritoneal cestodiasis, which results in death in infected dogs and cats. The definitive host ultimately becomes infected after eating meat contaminated with tetrathyridia. In Turkey, the prevalence of Mesocestoides lineatus in dogs was shown to range 1\%-19\% (357). There is no official report on the cases of mesocestoidiasis in humans in Turkey.

Zoonotic nematode infections are prevalent diseases in a large part of the world and affect millions of people. Zoonotic nematode diseases often may be classified as angiostrongylosis, anisakiasis, ascariasis, cutaneous larva migrans (CLM), dirofilariosis, filariasis, gnathostomiasis, onchoceriasis, strongyloidiasis, toxocariasis, trichinellosis, etc. The zoonotic nematode infections reported in Turkey are listed in Table 1.

Angiostrongylosis is an important nemadote disease caused by zoonotic Angiostrongylus species (A. cantonensis and A. costaricensis) within the Metastrongylidae family. The infection causes severe gastrointestinal or central nervous system disease in humans, depending on the species. A. cantonensis, the rat lungworm, is the most common cause of human eosinophilic menin- 
gitis in Southeast Asia, Africa, and America, while A. costaricensis is the causal agent of abdominal or intestinal angiostrongyliasis in humans and frequently occurs in Latin America. Humans can acquire the infection by eating raw or undercooked snails or slugs infected with the parasite. The third Angiostrongylus species $A$. vasorum causes canine angiostrongylosis in dogs, and it is not a zoonotic nematode. In Turkey, a case of canine angiostrongylosis in a dog in Ankara was diagnosed (358), while cases of zoonotic angiostrongylosis have been not reported officially until today.

Ascariasis is the most common helminthic disease caused by Ascaris lumbricoides, which is a soil-transmitted nematode. The infection with a global prevalence of $25 \%$ infects over 1 billion people. The transmission occurs through ingestion of excreted eggs of A. lumbricoides. Humans are infected mostly in regions with poor sanitation, where the environment is contaminated with human feces. Particularly, pediatric ascariasis frequently occurs in children with manifestations associated with permanent abdominal pain, growth retardation, pneumonitis, intestinal obstruction, or hepatobiliary and pancreatic injury. Zoonotic ascariasis may be associated with pigs and the use of hog manure, but in most endemic areas, it is most likely transmitted person-to-person. The prevalence can vary depending on geographic regions of Turkey, and was reported as $45 \%$ in schoolchildren in the Sanliurfa province in the Southeast part of the country (359).

Cutaneous Larva Migrans (CLM) is a zoonotic parasitic skin infection caused by larvae of hookworm species (Ancylostoma braziliense, A. caninum, A. duodenale, A. ceylanicum, A. tubaeforme, Necator americanus, Uncineria stenocephala, and Bunostomum phlebotomum) in the super family Ancylostomatoidea. The infection mostly occurs in areas with moist and warm climate. Normally, these parasites live in the intestines of definitive hosts, such as dogs, cats, wild animals; humans are not the final hosts. The infective larvae, which live in soil, can penetrate the human skin and cause CLM. Humans can be infected with the infective larvae by walking barefoot on sandy beaches or contacting moist soft soil contaminated with animal feces. Occasionally, A. caninum larvae may migrate to the human intestine, and lead to eosinophilic enteritis and cause unilateral sub-acute neuroretinitis (360). In Turkey, the parasitological prevalence of $A$. caninum in playgrounds in parks was found as $0.4 \%$ in the Kayseri area (361). However, a case of CLM was diagnosed in a 27-year-old Australian woman who has visited Brazil with a trip to the Amazon in 2009 (362).

Dirofilariasis is a mosquito-borne zoonotic nematode infection caused by Dirofilaria immitis, D. repens, and D. tenuis. The infection affects both dogs and humans throughout the world. The pathogens are transmitted to hosts through the mosquito bites. In dogs, the infection is called "heartworm disease" caused by $D$. immitis. The disease causes pulmonary artery blockage, cough, exhaustion upon exercise, fainting, coughing up blood, and severe weight loss. In individuals infected with $D$. immitis, the disease leads to pulmonary "dirofilariasis." In Turkey, a molecular study carried out to investigate the potential vectors and relative mosquito infection rates of $D$. immitis throughout two mosquito seasons (2008-2009) around Kayseri located in Central Anatolian showed that $9 / 312$ and 12/312 pools from Ae. vexans abdomens and thorax-heads were positive for filarial DNAs, respectively, whereas 3/241 pools of abdomens and thorax-heads from $C x$. pipiens were positive for D. immitis DNAs (137). In contrast, several dirofilariasis cases in humans have been reported from some parts of Turkey. In one case, a white-colored and motile nematode (D. conjunctivae) was removed via a surgical operation from a 44-year-old Turkish woman, who presented with a $1 \times 1.5 \mathrm{~cm}$ subcutaneous tumor in her occipital scalp (363). Recently, three ocular $D$. repens infection cases in humans were seen in June 2013 in the Marmara region, and the parasites were removed surgically, and antibiotic and anti-inflammatory therapies were applied post operatively (364).

Filariasis is a mosquito-borne lymphatic system disease of humans caused by several nematode species belonging to the genera Wuchereria and Brugia of the Onchocercidae family. The infection endemically occurs in many countries throughout the tropics and sub-tropics of Asia, Africa, the Western Pacific, and parts of the Caribbean and South America and affects over 120 million people. More than $90 \%$ of human infections are caused by Wuchereria bancrofti, and the remainder cases of filariasis are caused by Brugia spp. However, Brugia malayi can also cause infections in some animals, such as felines and monkeys. In Turkey, a case of filariasis was diagnosed in an 11-year-old girl patient who presented with swellings in both legs from Kozan, a town near the Adana province in the Mediterranean region of Turkey (365).

Gnathostomiasis is another zoonotic nematode infection in humans caused by the infective larvae of Gnathostoma spp ( $G$. spinigerum, G. binucleatum, G. doloresi, G. nippanicum, G. malaysiae, and G. hispidum) of the Gnathostomidae family. The disease, also known as larva migrans profunds or nodula migratory eosinophilic panniculitis, occurs worldwide. The common manifestations of the infection include epigastric pain, vomiting, fever, appetite loss, and migration in the subcutaneous tissues with painful and pruritic swellings (CLM), and migration to other tissues (visceral larva migrans) may result in cough, hematuria, meningitis and ocular gnathostomiasis. A large group of animals, such as freshwater fishes, frogs, snakes, poultry, birds, cats, dogs, and wild felids, serve as definitive hosts for gnathostomiasis, while the crustaceans of the genus Cyclops play a role as intermediate host. Zoonotic transmission of the infection is possible by consuming raw or undercooked final hosts, such as freshwater fishes, poultry, or frogs. In Turkey, a case report related to eosinophilic panniculitis in a 50-year-old male patient was recorded at the Erciyes University hospital in the Kayseri province of Central Anatolia (366).

Onchocerciasis is a simulid-borne zoonotic nematode infection caused by Onchocerca species. The infection is seen with manifestations of subcutaneous nodule formation, dermatitis, and blindness in humans and animals. In Turkey, cases of onchocerciasis in cattle $(367)$ and humans $(368,369)$ were reported.

Strongyloidiasis is a soil-transmitted zoonotic nematode disease caused by Strongyloides stercoralis. The infection occurs in humans, dogs, and cats worldwide. The hatching larvae in the 
soil or water molts to infective third stage. The latter infects the host through skin and migrates to the heart and lung and is finally swallowed back to cause intestinal infection. However, in some cases intense pulmonary manifestations may occur. Strongyloides stercoralis has a unique feature of molting from parasitic form to infective stage within the body, rather than having a free-living stage and causing autoinfection. This may lead to latent infection for indefinite period in an immunocompetent person but fatal hyper or disseminated infection in immunocompromized individuals, such as patients of AIDS, organ transplant recipients, and cancer and other patients put on immunosuppressive therapy, in whom it can involve any organ of the body (370). In Turkey, a case of strongyloidiasis was identified in a 50-year-old woman patient with gastric perforation in the Erzurum province in Eastern Anatolia (371). Later, another case of strongyloidiasis was diagnosed in a dog with clinical manifestations, including severe watery diarrhea, pain during defecation, intermittent cough, vomiting, and emaciation in the Samsun province in the Black Sea region (372).

Toxocariasis is an important zoonotic disease caused by the larva of the roundworms in the genus Toxocara within the Toxocaridae family. Of the disease agents, Toxocara canis infects dogs, while T. cati infects cats. The infected dogs and cats shed the eggs of the parasite to the environment. Humans become infected by ingestion of the embryonated eggs (containing infective larva at stage 2) in contaminated areas, such as parks for children and game lands. Although it is rare, humans may also be infected by eating undercooked meat containing Toxocara larvae. Many people, who are infected with Toxocara spp do not have any symptoms of the disease, while some manifestations characterized with ocular toxocariasis and/or visceral toxocariasis can be seen in the affected people. In Turkey, toxocariasis is a prevalent zoonotic infection. The coprological prevalence of $T$. canis in stray dogs and in owned dogs was found to be $4.8 \%$ in Kayseri (353). Furthermore, the molecular prevalence of T. canis, T. cati, and T. leonine in playgrounds in parks was detected as $12 \%, 3 \%$, and $7.5 \%$ in the Kayseri area, respectively (361). However, a case of visceral larva migrans with hypereosinophilia related to toxocariasis was determined in a 2.5-year-old child in Izmir province (373).

Trichinellosis (trichinosis) is the most prevalent zoonotic nematode disease caused by several species in the genus Trichinella of the Trichinellidae family. Trichinella spiralis, which is the classical agent of trichinellosis, is common in many carnivorus and omnivorus animals worldwide. The others, T. pseudospiralis, T. nativa, T. nelsoni, and T. britovi, have been recognized in mammals and birds worldwide, in Arctic bears, in African predators and scavengers and in carnivores of Europe and western Asia, respectively. Humans acquire trichinellosis by eating raw or undercooked meat infected with the Trichinella nematode, particularly pork or hunted wild animal meat. The zoonotic transmission is also possible even by tasting very small amounts of undercooked meat during preparation or cooking. Outbreaks of trichinellosis can be seen in areas, where multiple people consume the same Trichinella-infected meat. In Turkey, rare cases of trichinosis caused by T. spiralis were determined in domestic and wild pigs and in pork products (374). Later, several outbreaks of trichinellosis in humans have been reported from the Izmir province in the Aegean region (375-377) and from the Bursa province in the Marmara region (378). In recent years, the dramatic decrease in numbers of ruminants, particularly cattle and sheep population in Turkey, may be a predisposing factor for the outbreaks of trichinellosis, epidemiologically.

Leech infestations: Leeches are segmented worms belonging to the phylum Annelida and cause the parasitosis by blood feeding in animals and humans. However, some species within the subclass Hirudinea can be used for medical purposes in humans. Hirudo medicinalis is usually called the medical leech and has been used for medical purposes since ancient times, which is still used for some venous circulating problems in modern medicine. In the last decade, it has been used to follow-up some flab and re-implantation of graft after surgery by general surgeons to prevent venous congestion and maintain circulation (379). However, several important bacterial species belonging to the genus Aeromonas, which exist in the natural flora of the digestive tract of leeches, can cause infections in humans. Particularly, Aeromonas hydrophila, A. media, and A. veronii biovar sobria are known to be important pathogens for humans. These pathogens lead to pneumonia, sepsis, or gastroenteritis besides some tissue infections on skin and in some soft tissues. In addition, some leech species can play a vector role for some fungal, viral, and bacterial pathogens, such as Serratia marcescens, Pseudomonas spp, Vibrio fluvialis, Streptococcus spp, Clostridium tetani, classical swine fever virus, bovine parvovirus, feline calicivirus, equine arteritis virus, equine herpes virus type 1, Rickettsia spp, and Bartonella spp (380-382). Leeches can also transmit several Trypanosoma spp to fish (382). In Turkey, some cases of leech infestations were reported from humans and animals. It was reported that a total of 13 parasitic leech species ( 3 species from marine fish, 8 species from freshwater fish, 1 species from brackish water fish, and 1 species from aquarium fish) have been recorded in different parts of Turkey (383). A rare adverse effect caused by artificial infestation with about 14 leeches on both legs was diagnosed in a 42-year-old woman patient who was referred to the emergency service with painful and itchy lesions on her feet and legs in the Adiyaman province in southeastern Turkey (384). In another case of leech infestation, a leech with dark-brown color was removed by surgery from the floor of the mouth of a 10-year-old child, who was referred to the emergency service of the city hospital in Yozgat in Central Anatolia (385).

Zoonotic Parasitic Protozoans (Protozooses): A number of parasitic protozoa with zoonotic characteristics cause serious infections in humans and animals, and lead to economic losses in Turkey as well as globally. The reported zoonotic protozoan infections from Turkey are listed in Table 1.

Leishmaniasis is a most important vector-borne zoonotic disease caused by several Leishmania species in the Trypanosomatidae family. The infection mostly occurs in two clinical forms: visceral leishmanisis and cutaneous leishmanisis. The disease affects both humans and animals, such as dogs, cats, cattle, and equids. The transmission of the disease agents is through the bite of infected Phlebotomine sand flies in the Psychodidae family 
(386). Zoonotic visceral leishmaniasis ( $Z \mathrm{VL})$ is caused by Leishmania infantum and cutaneous leishmaniasis $(C L)$ is caused by $L$. tropica and $L$. infantum in Turkey (21). These diseases in humans are compulsory notifiable diseases in Turkey for years. The ZVL occurs in the Aegean and Mediterranean regions endemically. However, the infection has been reported sporadically in other regions of the country as well. It is consistent with Mediterranean type and mostly seen in infants. Leishmania strains isolated from human/dogs in different regions were identified as L. infantum MON-1 and MON-98 by multilocus enzyme electrophoresis, also known as zymodeme analysis. In Turkey, CL has been spreading from endemic regions to other regions because of different epidemiological factors. CL with different clinical types was reported from numerous provinces, but more than $90 \%$ of the cases were concentrated in the southeastern regions, eastern Mediterranean and Aegean of the country. According to Ministry of Health's official records, 46,003 new cases were reported between 1990 and 2010. Major migrations that have arisen due to the civil wars in Syria in recent years have made CL much more important for public health in Turkey. Twelve specific microsatellite markers have been identified in the analyses made on the isolates obtained from Turkish and Syrian patients in Sanliurfa region where $45 \%$ of the cases of $\mathrm{CL}$ detected in Turkey are seen (387). The result suggests that $L$. tropica is a more complicated zoonotic protozoan parasite than is suspected. This of course not only made the struggle more difficult, but also created a potential danger especially for the epidemiology of CL (387). Additionally, in a study performed to demonstrate the effects of Syrian civil war on the epidemiology of $\mathrm{CL}$ in the Gaziantep province in southeast part of Turkey, a total of 567 people were hospitalized with the suspicion of $\mathrm{CL}$, and 263 (46.4\%) of them were found positive by parasitological examination. Overall, 174 (66.15\%), 88 (33.46\%), and $1(0.38 \%)$ of the positive patients were grouped as Turkish, Syrians, and Afghan, respectively. Tissue samples on slides obtained from 34 $\mathrm{CL}$ suspected patients were also analyzed using polymerase chain reaction (PCR), and 20 of them were found positive. Eighteen ( 9 Turkish and 9 Syrians) of the PCR positive samples were identified as L. tropica, while two (1 Turkish and 1 Syrian) were L. infantum (388). These molecular epidemiological findings indicate that public health in Turkey and other European countries is under threat of new $L$. tropica and $L$. infantum strains. In contrast, Canine Leishmaniasis (CanL) is another serious form of the disease that occurs in dogs and wild canids. Dogs can be infected with several Leishmania species, but the most important clinical form of canine leishmaniasis is viscerocutaneous leishmaniasis caused by $L$. infantum. CanL mainly occurs in the Mediterranean Basin. The infection is also prevalent in dogs in Mediterranean and Aegean regions of Turkey. Another form of the infection is feline leishmaniosis caused by L. infantum, which sporadically occurs in domestic cats in various parts of the world. It was reported that a case of clinical feline leishmaniosis caused by L. infantum was seen in Agean region of Turkey (330).

Toxoplasmosis is the most prevalent zoonotic protozoan disease throughout the world caused by three infective forms (sporozoite, bradyzoite, and tachyzoite) of Toxoplasma gondii, which has 3 strain types (I, II, and III) in the Toxoplasmatinae subfamily. The infection could lead to serious global health problems in humans. The transmission of T. gondii is possible by congenital, carnivorism, and fecal-oral route. Toxoplasma gondii is a protozoan parasite that infects nearly all mammal and bird species worldwide. In the life cycle of T. gondii, all members of Felidae family serve as definitive hosts, while birds and all mammals, including man play a role as an intermediate host. Usually asymptomatic, toxoplasmosis can be severe and even fatal to many hosts, including people, particularly causing abortions in cattle and sheep that lead to huge economic losses in livestock industry (389). Elucidating the contribution of genetic variation among parasites to the patterns of disease transmission and manifestations has been the goal of many studies for the molecular epidemiology of toxoplasmosis. In a study that focused on the geographic variation of T. gondii strains, most genotypes of the parasite were detected as locale specific, but some were found conserved across continents and closely related to one other, indicating a recent radiation of a pandemic genotype (390). In Turkey, the seroprevalence of T. gondii was detected as $43 \%$ in domestic cats (391), $68.57 \%$ in dogs (392), $1.9 \%$ in horses (393), 66\% in cattle (23), 33.76\% in sheep (23), 63.2\% in goats (394), 1.66\% in domestic fowls (395), and $9.09 \%$ in prey birds (396). The general prevalence of toxoplasmosis ranged between $39.5 \%$ and $78 \%$ in animals (397). However, the prevalence of toxoplasmosis in different groups of humans, such as (i) hospital patients, (ii) people who are occupationally in close contact with animals or working in meat industry, (iii) apparently healthy people, and (iv) a special group that contains homosexuals and hemodialysis patients were reported as $13.9 \%-85.3 \%$; $20.7 \%-$ $57.6 \% ; 23.0 \%-43.7 \%$, and $16.3 \%-76.6 \%$, respectively (397).

Sarcosporidiosis is an important disease of animals and humans that occurs worldwide, and causes serious economic losses in livestock industry. Although the infection in humans is rare, it was reported that recent international attention on sarcocystosis has concentrated on recurrent outbreaks of muscular sarcocystosis among tourists visiting Malaysia (398). Animals and humans can be infected by the oral route with developmental stages of several Sarcocystis species. Sarcocystis species require both definitive and intermediate hosts to complete their life cycle. In the cases of intestinal sarcocystosis, humans can serve as definitive hosts for two species acquired from eating undercooked meat: S. hominis from beef and S. suihominis from pork. Clinical manifestations, such as nausea, stomachache, and diarrhea in humans with intestinal sarcocystosis, can be varied depending on the number of cysts ingested and appear more severe with pork than with beef. Humans can play a role as intermediate hosts for S. nesbitti, which is a species with reptilian definitive host. Humans can be infected by ingesting the sporocysts of the parasite from feces-contaminated food or water and the environment. In infected people, diagnosing the infection is difficult at the early phases, but some clinical signs, including fever, headache, and myalgia may be evident, and later, intramuscular cysts characterized with myositis can develop. Presumptive diagnosis related to travel history to tropical regions, elevated serum enzyme levels, and eosinophilia can be confirmed by finding sarcocystis in muscle biopsy material. There is no vaccine or 
confirmed effective antiparasitic drug for muscular sarcocystosis, but anti-inflammatory drugs may reduce the disease symptoms. Prevention strategies are also discussed (398). In Turkey, several Sarcocystis species have been detected in some mammalian intermediate hosts, such as sheep, goats, cattle, water buffaloes, horses, donkeys, and pigs and in some avian intermediate hosts, such as turkey and partridges, and some Sarcocystis species were also identified in definitive hosts, such as dogs and cats (399). There is no official report on cases of zoonotic sarcaoproidiosis in humans in Turkey.

Giardiasis is one of the most common zoonotic intestinal protozoan diseases caused by Giardia spp in the Giardiinae subfamily and occurs in humans and animals worldwide, particularly in developing countries; WHO has classified this infection as a neglected disease (400). One species in Giardia genus Giardia duodenalis (syn. Giardia lamblia and Giardia intestinalis) causes giardiasis in humans and domesticated animals, including livestock, dogs, cats, and wildlife; hence, giardiasis is considered a zoonotic disease $(401,402)$. Direct evidence that human giardiasis can be an example of a zoonosis, ie, a human infection acquired from non-human hosts under "natural" conditions (via ingestion of $G$. duodenalis cysts excreted by animals) is limited (403). Giardia cysts have environmental resistance and survive for a long time under natural conditions (over 65 days at $4^{\circ} \mathrm{C}$ ). After ingestion of the cysts by the host, primarily, the walls of cysts are broken down by bile salts, low $\mathrm{pH}$, stomach acids, and some other factors. After this excystation, the trophozoites are released in the duodenum, undergo repeated mitotic division, and finally develop into an environment resistant cyst form. These cysts can pass through the intestine via feces and spread to the environment by contaminated water, food, and fomites and by direct physical contact. The most important epidemiologic aspect for giardiasis is to understand the host range of different Giardia species and strains/genotypes (assemblages), the potential for cross-species transmission, and risk and environmental factors involved in the exposure to the pathogen. This is particularly important in determining the zoonotic potential of Giardia infections in domestic animals and in determining the human disease burden attributable to parasites of animal origin (402, 403). A significant association between the occurrence of Giardia infections in calves and calf handlers has been shown in a study in Bangladesh (404). In Turkey, G. intestinalis was identified in 5 of 30 small ruminants (19 kids and 11 lambs) with neonatal diarrhea at clinics of a veterinary faculty in the Burdur province of the Mediterranean region (405). However, changes in serum cytokine levels were determined in 92 giardiasic children infected with $G$. lamblia at a Medical Centre in the Malatya province located in the eastern part of the country, and all of the sick children were treated using metronidazole (406).

Amoebiasis or Amoebic Dysentery is an intestinal disease caused by an anaerobic parasitic amoebozoan protozoa, Entamoeba histolytica of the Entamoebidae family. The reservoir of $E$. histolytica is man. The infection is seen worldwide but often affects anyone, who lives in tropical regions with poor sanitary conditions. The disease causes mild to severe colitis and hepatic amoebiasis in infected individuals. The fecal-oral transmission of the infection is possible by ingestion of the infective cysts via contaminated water or food or flies or fomites. Workers or personnel at departments of laboratory animals may be infected from fecal matter contaminated on skin or on clothing. The disease also occurs clinically with chronic and mild colitis in animals, such as dogs and monkeys. E. histolytica can be found in the large intestine of rats as a commensal, but sometimes it can cause amoebic dysentery too. In Turkey, the disease is also a prevalent infection among humans. In a study, trichrome-stained 49 smear samples of 51 patients were found positive for E. histolytica/dispar at clinics of the Ege University Hospital in the Izmir province of the Aegean region, Turkey (407). A case of amoebic liver abscess caused by penetration of amoebic trophozoites of E. histolytica was diagnosed at the clinics of a university hospital in the Istanbul province (408).

Cryptosporidiosis is another important water-borne zoonotic protozoan disease caused by several apicomplexan parasites belonging the genus Cryptosoridium in the Cryptosporidiidae in the subphylum of Apicomplexa family and occurs globally with a devastating economic impact on the livestock industry. Cryptosporidium species infect both the gastrointestinal and respiratory tracts of a wide variety of animals (mammals, birds, reptiles, amphibians, and fish), including man. The infection is one of the major problems of farm animals, particularly C. parvum is seen as the most common entero-pathogen during the first weeks of life of newborn calves, lambs, goat kids, and piglets, and is thought to be a critical agent in the etiology of the "neonatal diarrhea syndrome" in newborns (409). The majority of human infections are caused by either $C$. hominis and/or C. parvum, and the disease mainly involves the infection of jejunum and ileum, resulting in a watery diarrhea. The infection may involve the biliary tract, stomach, and lungs in immunodeficient and immunosuppressed individuals (401). The persistent diarrhea and malabsorption can seriously threaten the life of the infected person, particularly in patients with AIDS (410). A significant association between the occurrence of Cryptosporidium infections in calves and calf handlers has been shown in a study in Bangladesh (404). A vaccine is not available for immunization against cryptosporidiosis, and an etiologic specific treatment option has also not been practiced for the infection. However, antidiarrheal medicine may be used to slow down the diarrhea. Actually, the major control measures of the infection are limited to sanitation, good hygienic conditions, and education. In Turkey, cryptosporidiosis is also a prevalent disease, and its prevalence in humans was reported in the range 4.9\%-39.08\% (22). In contrast, several molecular epidemiological studies have been performed for bovine cryptosporidiosis in the calves in different parts of Turkey. In one of these investigations, the molecular prevalence of crytospridiosis was found as $20.7 \%$ in neonatal calves with diarrhea in different localities of the Nevsehir province of the Capadoccia region, and C. parvum was detected as predominant species with a $15.3 \%$ prevalence (411). Another molecular study was conducted on cryptosporidiosis in cattle (up to 2 months calves with diarrhea and others) to investigate their reservoir importance for the epidemiology of disease in the Burdur area of the Mediterranean region, and C. parvum, C. ryanae and $C$. bovis parasites were identified related to bovine cryptosporidiosis and the total prevalence the disease was 
detected as $37.2 \%$, with $C$. parvum as the predominant parasite in the region (412). Conversely, in the Konya province of Central Anatolia, only C. parvum was detected molecularly related to bovine cryptosporidiosis in clinically diarrheic calves that were up to 2 months old (413).

Rhinosporidiosis is a chronic granulomatous infection of humans caused by a protist, Rhinosporidium seeberi, in Mesomycetozoea. The analysis of the aligned sequence and inference of phylogenetic relationships showed that $R$. seeberi is a protist from a novel clade of parasites that infect fish and amphibians. The disease usually manifests as vascular friable polyps that arise from the nasal mucosa or external structures of the eye in infected individual. The etiologic pathogen organism causes similar infections in amphibians and fish (414). Another molecular work has demonstrated evidence that $R$. seeberi may have host-specific strains (eg, human vs dog versus swan) (415). Humans generally acquire the infection by contact of the nasal mucosa with infectious material when bathing in ponds contaminated by animal feces (416). In Turkey, a case of cutaneous rhinosporidiosis localized in the nasal philtrum in a patient, who had a polyploid lesion was diagnosed at the clinics of the Akdeniz University Hospital in the Antalya province (417).

Cystoisosporiasis (formerly Isosporiasis or human cocciddiosis) is a food/water-borne intestinal infection of humans caused by the coccidian protozoan parasite Cystoisospora belli (formerly Isospora belli) in the Sarcocystidae family. The infection often occurs in the tropical and subtropical regions of the world. Humans are infected by ingestion of sporulated oocysts of the parasite via contaminated food and/or water. The infection clinically manifests as watery diarrhea in sick individuals. It was experimentally demonstrated that Isospora belli can cause infection in animals, such as monkey, dog, pig, rat, mouse, guinea pig, and rabbit (418). Hence, Cystoisospora belli may be regarded as a potential zoonotic coccidian pathogen. In Turkey, a few cases of cystoisosporiasis were reported in some immunosuppressed individuals $(419,420)$.

Arthropod zoonosis: Arthropods can be found on humans and/ or animals as ectoparasites and can adversely affect both humans and animals in several ways. They also live as urban pests (421). The ectoparasites or vectors can contaminate stored food and transmit many pathogens or introduce diseases in new and/or instable geographic areas epidemiologically. There are direct nonallergic effects, such as tissue damage due to stings and bites, as well as vesicating fluid exposure, and tissue infestation by the larval stages of the parasites themselves (e.g., myiasis). Additionally, some venoms produce necrosis in hosts tissues and some others can lead to neurological effects. Indirect effects on human and animal health comprise disease transmission (as a vector) and allergic reactions due to bites, irritations, and stings as well as reactions to some structures on arthropods, emanations, or secretions on arthropods (422). Basically, the attacks of arthropods on humans and animals could be classified as insect infestation or acar infestation, depending on the origin of the parasite. Besides being vectors for various diseases, the species of arthropods that have zoonotic importance in the orders of Blattaria, Coleoptera, Diptera, Hemiptera,
Hymenoptera, Lepidoptera, and Siphonaptera can cause direct infestations in humans and animals. The reported arthropod infestations in Turkey are as follows:

Bugs in Blattaria are commonly named as cockroaches. Cockroaches are the most important pests of the urban area and occur primarily in the tropical and subtropical regions of the world. Some cockroach species in the genera of Periplaneta and Blattella occur in caves and in animal barns, particularly in the animal feed deposits and feed with animal waste or organic matter. Cockroaches adversely affect human health via sometimes biting sleeping children, entering into ear canals of humans, and mechanical contamination of food with many pathogens (423). In Turkey, Blattella germanica was found to harbor intestinal parasites of public health importance (424).

Coleoptera (Beetles) have a very low medical and veterinary importance. However, some coprophagous and necrophagous species of beetles in the families of Dermestidae and Silphidae have been suspected of mechanically spreading the spores of Bacillus anthracis (423). Darkling beetles in Tenebrionidae family cause the infestation of feeds in chicken houses and may transmit Salmonella bacteria from infected chickens mechanically, leading to high economic losses in the poultry sector. Both larval and adult forms of the lesser mealworm beetle Alphitobius diaperinus may transmit Salmonella typhimurium and $S$. chester from infected chickens. In contrast, the small hive beetle, Aethina tumida of the Nitidulidae family causes severe infestation and leads to the destruction of honey bee colonies with huge economic losses. If the beetle infestation is sufficiently heavy in a honey bee colony, it may cause bees to abandon their hive. The presence of hive beetles can be an early marker in the detection of the Colony Collapse Disorder for honey bees. In addition, the beetles can also be a pest for stored combs with honey/without honey (425). In Turkey, there is no study related to beetles with medical and veterinary importance. However, in a study, several species of dung beetles in Scarabaeidae family have been reported from the Black Sea region of Turkey (426).

Diptera (true flies) is one of the largest insect orders in the world and includes many species, which have medical and veterinary importance in the Nematocera and Brachycera suborders. Most commonly, flies in this order cause serious infestations both in humans and in animals. Most of them also serve vectorial roles for the transmission of several diseases, which lead to huge economic losses in different regions of the world, particularly in the tropical and subtropical areas. Nematocera suborder contains many flies with conspicuously long antennae, such as mosquitoes, black flies, midges, and sand flies, while Brachycera include flies with short antennae, such as horse flies, deer flies, house flies, stable flies, and tsetse flies. Some flies of Diptera can also cause cases of myiasis via their maggot type larva both in humans and in animals (427).

Mosquitoes are one of the most important ectoparasitic flies in the Culicidae family and commonly cause serious infestations of both humans and animals. Particularly, they inflict more human suffering than other hosts. Mosquito bites can lead to severe skin irritation through an allergic reaction to the saliva of mosquitoes, which causes the red bump and itching on the skin of the 
infested individuals; additionally, severe mosquito infestations may lead to anemia and even deaths as seen in the old periods of human history. Every year nearly over one million people globally die from mosquito-borne infections. However, mosquitoes also transmit several pathogens, such as viruses and parasites, to some susceptible animals, such as dogs and horses. The mosquito-borne diseases include West Nile virus (WNV), Eastern equine encephalitis, dengue, encephalitis, yellow fever, chikungunya, St. Louis encephalitis, LaCrosse encephalitis, Western Equine encephalitis, Zika virus, human malaria, avian malaria, filariasis, and dirofilariasis. In Turkey, a total of 55 mosquito species have been reported (428). Recently, in a study conducted to investigate the potential vectors of Dirofilaria immitis using molecular techniques in Central Anatolia region of Turkey, Aedes vexans and Culex pipiens were detected as vectors in the Kayseri region of Central Anatolia (429). In another study performed to detect Culex pipiens biotypes in the Kayseri region using a real-time PCR technique, Cx. pipiens form pipiens, hybrids of $C x$. pipiens form pipiens, and Cx. pipiens form molestus were identified as biotypes among the genomic DNA isolates (430). However, in a study that was carried out via molecular techniques to investigate avian Plasmodium parasites and to determine the hemosporidian parasite lineages in mosquito samples in the Kayseri area of Central Anatolia region, Turkey, the samples of Cx. pipiens, Cx. theileri, Ae. Vexans, and Culiseta annulata were found positive for avian malaria and avian hemosporidian parasites, and Cx. pipiens was also shown as a major vector of avian Plasmodium parasites (431).

Black flies are small but powerful flies with autogenous and anautogenous characteristics in the Simuliidae family and can be formidable pests for humans, domestic animals, and wildlife, affecting virtually all facets of outdoor life. Black flies are distributed worldwide with the exception of Antartica and some oceanic islands. The black fly Simulium (Wilhelmia) lineatum is among the most widely distributed members of the Simuliidae family, ranging from the British Isles to eastern China $(432,433)$. Occasionally, some severe infestations of black flies at the level of disasters also lead to devastating economic losses in some countries. The public health importance of black flies is commonly related to the blood-seeking females and the disease agents they transmit. The females transmit the nematodes Onchocerca volvulus (river-blindness) and Mansonella ozzardi (mansonelliasis) to humans, and they are also suspected of the Altamira syndrome in humans in Brazil. However, black flies can transmit some other pathogens, such as Onchocerca lienalis and Leucocytozzoon spp to bovids and to birds, respectively. Black flies can also cause multideaths of animals, which are seen suddenly, particularly in cattle due to simulotoxicosis and toxic shock (434). In Turkey, some Simulium species have been reported, which showed pest characteristics and caused outbreaks $(432,433,435,436)$. In contrast, in a study that was performed for molecular detection of blood-feeding preferences of Simulium species in Central Kizilirmak Basin of Turkey, Onchocerca sp and Leucocytozoon sp were detected in the samples of Simulium spp. collected from the area (437). In last three decades, two cases of simulotoxicosis in cattle herds with over 100 sudden deaths were observed in the Erzurum province of eastern Turkey
(438). In a study, which was conducted to investigate the economic costs associated with a 2006-2007 outbreak of Simulium (Wilhelmia) spp. in the Cappadocia region of Turkey, the economic losses were calculated as US $\$ 5.45$ million according to 2013 prices (27).

Biting Midges are very small flies belonging to the Ceratopogonidae family and occur in the temperate and tropical areas of the world. Biting midges infest both humans and animals and cause discomfort. In addition, biting midges serve as vectors for a number of viruses, protozoans, and nematodes. Among the more important viral diseases are Oropouche fever in humans; bluetongue and epizootic hemorrhagic in ruminants; and African horsesickness in equines (439). In Turkey, a total of 57 Culicoides spp were reported from different localities in Marmara, Aegean, Mediterranean, Central Anatolia, and the Eastern and Southeastern Anatolia regions (440). In a different study conducted to investigate Culicoides spp by molecular techniques in the ecosystem of Sultan marshes near the Kayseri province in Central Anatolia, a total of 10 Culicoides spp were identified, and C. circumscriptus and C. nubeculosus complexes were found as the predominant species in the ecosystem (441).

Sand flies are an important hematophagous group belonging to the genera Phlebotomus and Lutzomyia of Phlebotominae subfamily in the Psychodidae family. During crepuscular time or at night, the females of sand flies feed on various mammals, reptiles, and birds. These bloodfeeding flies include the primary vectors of leishmaniasis, bartonellosis, and pappataci fever. In the old world, lesihmaniasis was transmitted to humans and animals by Plebotomus spp, while the Lutzomyia spp spread leishmaniasis in the new world (442). In Turkey, a total of 19 Phlebotomus spp were reported from distinct regions, such as Aegean, Mediterranean, Southeastern Anatolia, and Western Black Sea (443). Meanwhile, it was reported that four serotypes of phleboviruses, and phlebovirus RNA were determined in the Mediterranean region and around the Ankara province in Turkey, respectively (35).

Horse flies and deer flies belong to the Tabanidae family and attack humans and animals. They are large hematophagus and their adult feeding activity is diurnal, but occasionally crepuscular or nocturnal. In the most temperate areas, tabanids are primarily nuisance pests of humans. In this regard, they can pose economically significant problems for local tourism. Tabanids transmit some pathogens as biological (for Loa and Elaeophora schneideri) and mechanical (for Equine infectious anemia, bovine leukemia, hog cholera, Anaplasma marginale, Francisella tularensis, Bacillus anthracis, Besnoitia besnoiti, Trypanasoma evansi, and Try. vivax) vectors (439). In Turkey, a total of 161 species belonging to 11 genera of Tabanidae family were reported from different regions (444).

Muscid flies can be grouped ecologically as filth flies (house fly, stable fly, garbage fly, false stable fly, little house fly, and latrine fly), dung flies (horn fly and face fly), and sweat flies (sweat flies). Muscid flies also can be grouped depending on their mouthparts as biting (stable fly, Stomoxys calcitrans; Horn fly, Haematobia irritans; and Bufffalo fly Hae. irritans exgua) and nonbiting flies (house fly, Musca domestica; bazaar fly, M. sor- 
bens; bush fly $M$. vetustissima; face fly, M. autumnalis; false stable fly, Muscina stabulans; little house fly, Fannia canicularis; garbage fly, Hydrotaea spp.; sweat flies, Hydrotaea spp.), and all the important muscid flies are anautogenous that require proteins to complete their first gonotrophic cycle. Except for house fly, their seasonal patterns in abundance differ among the species, years, and locations. Most muscid flies of medical and veterinary importance are multivoltine, developing through two or more generations per breeding season. Adults of some important flies affect humans commonly as nuisance, occasionally as vector of several pathogens, and rarely as agents of myiasis. The cosmopolitan house fly and stable fly have more medical importance than others (445). In Turkey, a total of 11 species belonging to the Muscidae family have been reported from the Cukurova area (446).

Myiasis is the invasion of a living vertebrate animal by larvae of myiatic flies in the superfamilies Tipuloidea, Psychodoidea, Stratiomyoidea, Asiloidea, Platypezoidea, Syrphoidea, Tephritoidea, Ephydroidea, Carnoidea, Muscoidea, and Oestrroidea and are classified as accidental, facultative, obligatory, and emporary. Myiasis can also be categorized as gastrointestinal, urogenital, ocular, nasopharyngeal, auricular, and cutaneous depending on the site of larval invasion (447). In Turkey, several cases of myiasis in humans were reported from different regions (448-450)

Hemiptera are the kissing bugs and bed bugs, which are annoying nocturnal pests that feed on humans and animals by sucking blood. Kissing bugs in the Reduviidae family transmit Trypanosoma cruzi in some countries of Central and South America. The bed bugs Cimex lectularius of the Cimicidae family are external parasites of humans. In Turkey, actually, C. lectularius is one of the prevalent ectoparasites in houses and also in the coops for poultry, but its infestations were not documented sufficiently. However, a report related to C. lectularis infestation in a 46-year-old woman with poor personal hygiene was recorded in the Sakarya province of the Marmara region (451).

Hymenoptera order contains ants, bees, and wasps, and these insects are abundant throughout most of the world and constitute a significant proportion of all insects. A number of species of ants, bees, and wasps occasionally are harmful to humans and animals, and cause problematic cases, such as poisoning, allergies, and anaphylaxis (452). In Turkey, recently, a fatal case caused by massive honey bee stings on a 10 -year-old boy who was subjected to 5989 honey bee attacks was reported from the Erciyes University Hospital in the Kayseri province, and this case was also shown as the highest number of honey bee stings in the literature to date (453).

Lepidoptera order includes the species of moths and butterflies, which are recognized as economic pest of the cultivated plants on which their larvae feed. However, adult moths also can be a nuisance because of their attraction to lights and often entering homes at night, but butterflies are rare pests. In most cases of a medical-veterinary nature, it is the caterpillar larval stage that is involved. Some urticating caterpillars of the Limacodidae, Megalopygidae and Saturniidae families cause urticaria and moth dermatitis in humans, while the majority of caterpillars within the Lasiocampidae, Notodontidae, Thaumetopoidae, and Lymantriidae families induce abortions in pregnant mares and also in dromedary camels due to the ingestion of the larval forms during grazing in the infested areas (454). There is no official report on urticating caterpillar infestations in both humans and animals in Turkey.

Siphonaptera (fleas) are hematophagous and morphologically unique ectoparasites, and they feed by sucking blood on different warm-blooded hosts, including man, worldwide. Most fleas in the Pulicidae family, with other important fleas belonging to the Ceratophyllidae, Leptopsyllidae, or Vermipsyllidae have medical or veterinary importance. Occasionally, members of other families, notably the Hystrichopsyllidae and Rhopalopsyllidae, also feed on humans and domestic animals. Human flea (Pulex irritans), cat flea (Ctenocephalides felis), dog flea (Ctenocephalides canis), oriental rat flea (Xenopsylla cheopis), and chigoe (Tunga penetrans) can cause zoonotic infestations in both humans and animals. Fleas can cause considerable discomfort and occasionally lead to secondary infections of bite wounds. The bites of fleas can cause dermatitis and allergic reactions. In addition to the intense irritation, fleas transmit various diseases, such as myxomatosis, $\mathrm{Q}$ fever, tularemia, murine typhus, sylvatic epidemic typhus, plague, murine trypanosomiasis, rabbit trypanosomiasis, canine filariasis, double-pored tapeworm (Dipylidium caninum), rodent tapeworm (Hymenolepis diminuta), and Dwarf tapeworm (Hymenolepis nana) (455). In Turkey, in a study that was conducted to investigate the species of fleas around Ankara, 9 species of fleas belonging to 6 genera of 4 families were identified morphologically, and Pulex irritans, Ctenocephalides canis, Chaetopsylla globiceps, and Ctenocephalides felis were identified as prevalent species, with the prevalence of $31.91 \%, 29.79 \%, 23.89 \%$, and $11.92 \%$, respectively (456).

Zoonotic scabies is a rare form of canine scabies, also called pseudo scabies in humans. Sarcoptic mange in dogs is caused by Sarcoptes scabiei var. canis belonging to the Sarcoptidae family and affects body parts of dogs, which are devoid of hair, such as the head, chest, abdomen, neck, face, ears, elbow, and hocks. Basically, each species of the mite prefers one specific type of host, and it does not live long or reproduce away from the preferred host. However, occasionally humans can be infested with sarcoptic mange by close contact with infested dogs. Intense pruritis and irritation due to hypersensitivity reactions are seen as major clinical manifestations in infested individuals. The incubation period is shorter, the symptoms are transient, and the infestation is self-limiting. A case of a zoonotic sarcoptic mange caused by Sarcoptes scabiei var. canis in a 56-year-old man was reported from India (457). In Turkey, frequently cases of sarcoptic mange with manifested local or generalized forms in dogs are seen and treated with local or systemic acaricides (458). There is no official report on zoonotic mange in Turkey.

Ticks are obligate blood-sucking zoonotic ectoparasites belonging to the families Argasidae, Ixodidae, and Nuttalliellidae and are very important biological vectors for many pathogens of human and other animal diseases after mosquitoes (459). Ticks can cause serious direct damages to their hosts as well annoyance and "tick worry," skin lesions, predisposition for myiasis, 
loss of blood, tick paralysis, tick toxication, allergy, anaphylaxis, and meat allergy $(48,460)$. Tick infestations and TBDs of animals can cause huge economic losses, particularly in the cattle industry in many countries in the subtropical regions of the world, including Turkey $(9,459,461)$. The current status of tick species in Turkey showed 47 species ( 8 argasid and 39 ixodid) in the last century (10). In addition, almost 19 TBDs have been reported in animals and men, involving 4 protozoa (babesiosis, theileriosis, cytauxzoonosis, and hepatozoonosis), 1 filarial nematode (acanthocheilonemasis), 10 bacterial agents (anaplasmosis, ehrlichiosis, aegyptianellosis, TBT, Candidatus Rickettsia vini, Lyme borreliosis, TBRF, tularemia, bartonellosis, and hemoplasmosis), and 4 viral infections (TBE, Crimean-Congo Hemorrhagic Fever (CCHF), louping ill (LI), and LSD in Turkey (20).

Chiggers (larvae of Trombiculidae), bird and rodent mites (Dermanyssus gallinae and Lyponyssus bacoti), Cheyletiella spp, and house dust mites (Dermatophagoides spp) can cause rare zoonotic infestations, such as cutaneous reactions by close contact worldwide. Occasional asthma cases can be seen in children due to the inhalation of metabolites of house dust mites (462). In Turkey, a case of dermatosis caused by Cheyletiella sp. in a patient, who was a pet owner has been reported as a zoonotic mite infestation at the Sakarya University Hospital (463).

Unconventional zoonotic agents: The bovine spongiform encephalopathy (BSE) or "mad cow disease" and CreutzfeldtJakop disease (VCJD) are classified among unconventional zoonotic diseases by OIE and WHO. BSE is a central nervous disease caused by an agent named "prion" or "infectious protein." The infectious protein is transmitted to cattle via feeding of infected meat and/or bone meal, and then is found in the central nervous tissue, causing neurological disorders after an incubation period of 4-5 years ("mad cow"). The coincidence of the emergence of a variant form of VCJD in humans provides some evidence that the BSE agent might have crossed a species barrier. This is not scientifically proven but is the "precautionary principle" is suggested by OIE and WHO. There is no official report about both BSE and VCJD in Turkey.

\section{CONCLUSION}

In this review, we focused on the assessment of zoonotic infections in Turkey with a holistic approach. Turkey's natural conditions allow exposure to many diseases, including zoonotic infections in animals and humans in different regions $(10,48,441)$. Numerous zoonotic diseases, including 37 bacterial, 13 fungal, 29 viral, 28 parasitic (3 trematodes, 7 cestodes, 10 nematodes, and 8 protozoan) totaling to 107 infections have been reported in Turkey to date, almost one-half of the zoonotic diseases described in the world. Sixteen of these infections $(9$ bacterial (tuberculosis, E. coli infection, salmonellosis, brucellosis, leptospirosis, chlamydiosis, anthrax, Q fever, and campylobacteriosis), 3 viral (hepatitis E virus, rabies, and CCHF), and 4 parasitic (cryptosporidiosis, leishmaniosis, echinococcosis, and cysticercosis) diseases) have also been evaluated as among the most important infections for Europe and are among the 21 zoonotic diseases, which were high priority in Europe as determined and listed by the experts of Discontools (464-466). Additionally, many ectoparasitic zoonoses within 15 different arthropod groups have also been reported in Turkey. The main zoonotic transmission routes of the reported diseases and ectoparasites from Turkey are shown in Fig 1. Obviously, this high zoonotic burden found in Turkey is an important problem and a major threat to both public health and animal health. In addition, these diseases are a threat to the country's economic welfare when it is evaluated within the scope of the current understanding of "diseases are both the cause of poverty and the consequences of poverty." The severity and extent of the threat and danger can be better understood in light of the large migrations that Turkey has faced on regional basis in recent years. However, the same zoonotic dangers pose a threat to the rest of the world, especially for other European countries. It is unavoidable that hunger and misery dominates when the demographic and socioeconomic structures change dramatically at times of major migrations as we observed in the last decade. These conditions further promote poverty and poor hygiene and provide a rich environment for the parasitic, bacterial, vector-borne, and zoonotic diseases to flourish. Therefore, Turkey and the European countries are facing an increasing threat of various zoonotic pathogens today.

The epidemiological characteristics of many diseases are known on a molecular basis, allowing the capability to develop new and much more effective strategies in combat. Successful results can be obtained by using new generation drugs, such as antibiotics, antifungals, and antiparasitic preparations, in the treatment of many bacterial, fungal, and parasitic diseases, particularly in animals and humans. In addition, many viral diseases can be controlled with developed vaccines, and vaccine development studies are continuing for some viral diseases such as CCHF. Conversely, great success has been achieved by the usage of various acaricides and insecticides in the control of many vectors and thus vector-borne diseases. Unfortunately, resistance against these chemicals in vectors has developed due to the widespread usage of the chemicals thus leading to a new problem. In addition, the usage of intensive insecticide and acaricide caused environmental pollution and the death of non-target living creatures, such as bees, fish, and others. Today, we are faced with another serious problem, Antimicrobial Resistance (AMR). AMR and drug-resistant infections are now one of the biggest health threats that mankind faces in the coming decades. Considering the current adverse conditions, the health of the people, the animals, and the safe environment are facing danger (467). Therefore, the solution of the problem requires the new global approaches.

It may be useful to investigate the historical interactions of human populations and zoonotic diseases and to recall all the devastating consequences of economic losses.

In the early periods of history, high death and birth rates have had enormous impact on the demographics of populations, often leading to distributions shaped like a pyramid. Many children were born but few reached to adulthood. This meant that a large portion of the population depended on relatively few. Resources per capita were few; the population was poor because people were dying of disease, and few were working and producing. Under these conditions, deaths caused poverty, but according to Malthusian doctrine, poverty causes deaths. In 
this category, poor living and working conditions, which might give rise to low resistance to disease as well as more obvious factors, such as disease itself, wars, and famine directly affect the life of the people. Essentially, inadequate food supplies by themselves do not cause massive die-offs. High death rates during famines are typically caused by people migrating to where they perceive food is in greater abundance. In this situation, the congregation of a large numbers of people spread infectious diseases; particularly, during famines and wars people typically died from infections, such as typhus, cholera, typhoid fever, diarrheal diseases, influenza, and other infections. Any increased morbidity that accompanies the disease environment also will has negative effects on productivity. This situation will exacerbate the effects of the disease and increase poverty. It is true that inadequate nutrition may reduce the effectiveness of the immune system in combating disease; as a consequence, those who already have compromised immune systems, such as the infirm, the elderly, and the very young individuals are disproportionately likely to die (468). In modern times, a concept has been accepted that diseases, including zoonotic infectious diseases can be a reason and also a consequence of poverty, as mentioned above. However, in the same period, the close interest of people caused the imbalance in nature. A consistent theme that arises across studies of emerging zoonoses is the anthropogenic nature of identified risk factors. Homo sapiens has dramatically altered the ecological landscape in which other species and their pathogens function. It is accepted that almost four-thirds of the diseases that arise are acquired from animals. Actually, this situation shows us how artificial the separation is between the human species and the rest of the natural world. The growing understanding of the links between environmental disturbances and disease may require an extension of the "One Medicine" concept to include not only animal and human health, but planetary health as well (319). Particularly, global warming affects the behaviors of vector arthropods and causes a generation of aggressive insect populations as seen in simuliids (435) or biting midges (439). Similarly, ticks cause a global challenge $(20,48,459,469,470)$. Current local potential arthropod vectors, which have existed in the region for a long time and have been adapted to the region, are ready for the transmission of pathogens among humans, livestock, and wild animals. Naturally, increasing populations of vector arthropods can lead to increasing spread of zoonotic vector-borne diseases among animals and humans living in these tropical and subtropical areas (471).

Advanced information related to parasites and pathogens, sanitation, and hygiene (354) and the progress made in integrated economy and new biological views introduce new perspectives into the historical development of humanity and economies. Hence, in the last two decades, WHO has generated a new concept based on One Health for combating infectious, particularly zoonotic diseases (14). In this scope, WHO has purposed to generate "Healthier livestock and Wealthier People in a Reliable Ecosystem." For this aim, primarily, to prevent and control many infectious diseases and ectoparasites, including vectors, have been re-evaluated by the international coordination of the FAO, the OIE, and WHO. Following this initiative, a network named "Global Early Warning System (GLEWS)" has been established by WHO, OIE, and FAO for combating major animal diseases, including zoonoses (472). This network also is linked with national stakeholders to assist in early warning, prevention, and control of animal diseases and their zoonotic threats, and the International Food Safety Authorities Network to ensure food safety. Early warning of outbreaks and the prediction of their spreading capacity to new areas, particularly to the enzootic instable regions, is an essential principle for the control of endemic diseases. This principle is a fundamental and indispensable rule in international animal trade. Early warning and response is based on the concept that dealing with a disease epidemic in its early stages is easier and more economical than having to deal with it once it is widespread. The major mission of GLEWS is to provide multidisciplinary risk assessment for a zoonotic disease globally. For instance, for public health, an early warning for any outbreak with a known zoonotic potential will give adequate time to enable control measures that can prevent human morbidity and mortality, and as well economic losses. Also, this system gives an opportunity to discovery of new previously unknown human infectious diseases, which have emerged and will continue to emerge from the animal reservoir. However, both global warming and deterioration of the balance of the nature are essentially a management error. These negativities that are created as a result of over-demand all over the world will be corrected with the right decisions. While struggling at an international level against "global warming" at the global level, a number of additional social projects to prevent "environmental changes" can be required. At this point, for example, concurrent support from international sports organizations and their national partners can be provided. In this framework, messages about the dramatic destruction created by environmental changes to the masses of the people around the world can be provided in several types of international sporting events, such as the World Soccer Championship and so on. It should not be forgotten that all projects owned by the people can reach success. The positive impact of these projects will also have a widespread impact on the global scale. In this framework, the notion of "respect for nature" can be included among the concepts, such as "respect" and "enjoy responsibility," which are widely used in every step of the global scale sports in recent years, and the "environmental changes" can be noted and some urges can be achieved urgently. Moreover, at this point, it is at least reminded that what they do to administrators and politicians is not true.

From a public health and animal health perspective, prevention and control of diseases, including zoonotic infections, which have been reported from Turkey, should be realized with the coordination of national and international stakeholders based on the One Health concept. In accordance with the One Health concept, the development of advanced research projects for controlling zoonotic diseases by expert researchers from all related scientific disciplines should be top priority. In addition, the administrative and political decisions that impact climate change, urbanization, land use, and industrial and agricultural pollution should be consistent with ecological and epidemiological findings on diseases, 
including zoonoses, in Turkey. We also suggest that a regional program utilizing the One Health Concept that considers an interdisciplinary approach would be imperative to combat zoonotic infections given that country borders are insignificant for disease transmission. Turkey should provide leadership to bring together the agencies and appropriate researchers under the auspices of international organizations to help shape a global policy for zoonotic diseases control in the region.

Peer-review: Externally peer-reviewed.

Author Contributions: Concept - A.I.; Design - A.I., A.Y., Ö.D.; Supervision - M.D., A.Ö.; Resources - A.I., Ö.D.; Materials - A.I.; Data Collection and/or Processing - A.i.; Analysis and/or Interpretation - A.I., M.D., A.Ö., Ö.D., A.Y.; Literature Search - A.I., M.D., A.Ö., Ö.D., A.Y.; Writing Manuscript - A.I., M.D.; Critical Review - A.I., M.D., A.Ö., Ö.D., A.Y.; Other - A.I., M.D., A.Ö.

Acknowledgements: We thank Dr. Serap Aksoy of Yale School of Public Health for her editorial assistance with the manuscript.

Conflict of Interest: No conflict of interest was declared by the authors.

Financial Disclosure: The authors declared that this study has received no financial support.

Hakem Değerlendirmesi: Dış bağımsız.

Yazar Katkıları: Fikir - A.I.; Tasarım - A.I., A.Y., Ö.D.; Denetleme - M.D., A.Ö.; Kaynaklar - A.I., Ö.D.; Malzemeler - A.I.; Veri Toplanması ve/veya İşlemesi - A.I.; Analiz ve/veya Yorum - A.I., M.D., A.Ö., Ö.D., A.Y.; Literatür Taraması - A.I., M.D., A.Ö., Ö.D., A.Y.; Yazıyı Yazan - A.I., M.D.; Eleştirel İnceleme - A.I., M.D., A.Ö., Ö.D., A.Y.; Diğer - A.I., M.D., A.Ö.

Teşekkür: Editöryal yardımları için Yale Üniversitesi Halk Sağlığı bölümünden Dr. Serap Aksoy'a teşekkür ederiz.

Çıkar Çatışması: Yazarlar çıkar çatışması bildirmemişlerdir.

Finansal Destek: Yazarlar bu çalışma için finansal destek almadıklarını beyan etmişlerdir.

\section{REFERENCES}

1. Aksoy S. Transgenesis and the management of vector-borne disease. New York: Springer Science+Business Media; 2008.

2. Jones KE, Patel NG, Levy MA, Storeygard A, Balk D, Gittleman JL, et al. Global trends in emerging infectious diseases. Nature 2008; 451: 990-3. [CrossRef]

3. Lambertini E, Buchanan RL, Narrod C, Pradhan AK. Transmission of Bacterial Zoonotic Pathogens between Pets and Humans: The Role of Pet Food. Crit Rev Food Sci 2016; 56: 364-418. [CrossRef]

4. Blancou J, Meslin FX. (Brief review of the history of zoonoses). Rev Sci Tech OIE 2000; 19: 15-22. [CrossRef]

5. Budke CM, Deplazes P, Torgerson PR. Global socioeconomic impact of cystic echinococcosis. Emerg Infect Dis 2006; 12: 296-303. [CrossRef]

6. WHO. Zoonoses 2008 (Available from: http://www.who.int/topics/ zoonoses/en/.

7. Narrod C, Zinsstag J, Tiongco M. A One Health Framework for Estimating the Economic Costs of Zoonotic Diseases on Society. Ecohealth 2012; 9: 150-62. [CrossRef]

8. Pendell DL, Lusk JL, Marsh TL, Coble KH, Szmania SC. Economic Assessment of Zoonotic Diseases: An Illustrative Study of Rift Valley Fever in the United States. Transbound Emerg Dis 2016; 63: 203-14. [CrossRef]
9. Inci A, Ica A, Yildirim A, Vatansever Z, Cakmak A, Albasan H, et al. Economical impact of tropical theileriosis in the Cappadocia region of Turkey. Parasitol Res 2007; 101(Suppl 2): S171-4.

10. Inci A, Yildirim A, Duzlu O, Doganay M, Aksoy S. Tick-Borne Diseases in Turkey: A Review Based on One Health Perspective. Plos Neglect Trop D 2016; 10: e0005021.

11. Bank. W. People, Pathogens and Our Plant: Report 50833-GLB; 2010.

12. Bank W. People, pathogens and our planet Report No. 69145-GLB ; 2012.

13. Smith KF, Goldberg M, Rosenthal S, Carlson L, Chen J, Chen C, et al. Global rise in human infectious disease outbreaks. J Roy Soc Interface 2014; 11: 20140950. [CrossRef]

14. Kaplan B, Kahn LH, Monath TP. The brewing storm. Vet Ital 2009; 45 : 9-18.

15. Doganay M, Demiraslan H. Refugees of the Syrian Civil War: Impact on Reemerging Infections, Health Services, and Biosecurity in Turkey. Health Secur 2016; 14: 220-5. [CrossRef]

16. Karakus M, Nasereddin A, Onay H, Karaca E, Özkeklikçi A, Jaffe CL, et al. Epidemiological analysis of Leishmania tropica strains and giemsa-stained smears from Syrian and Turkish leishmaniasis patients using multilocus microsatellite typing (MLMT). Plos Neglect Trop D 2017; 11: e0005538.

17. Özkeklikçi A, Karakus M, Özbel Y, Töz S. The new situation of cutaneous leishmaniasis after Syrian civil war in Gaziantep city, Southeastern region of Turkey. Acta Tropica 2017; 166: 35-8. [CrossRef]

18. Duzlu O, Yildirim A, Inci A, Gumussoy KS, Ciloglu A, Onder Z. Molecular Investigation of Francisella-Like Endosymbiont in Ticks and Francisella tularensis in Ixodid Ticks and Mosquitoes in Turkey. Vector-Borne Zoonot 2016; 16: 26-32. [CrossRef]

19. Inci A, Düzlü, Ö. Vectors and Vector-Borne Diseases. ERU Vet Fak Derg 2009; 6: 53-63.

20. Inci A, Yildirim A, Duzlu O. The Current Status of Ticks in Turkey: A 100-Year Period Review from 1916 to 2016. Turkiye Parazitol Derg 2016; 40: 152-7. [CrossRef]

21. Inci A, Yazar S, Tuncbilek A, Canhilal R, Doganay M, Aydin L, et al. Vectors and Vector-Borne Diseases in Turkey. Ankara Univ Vet Fak Derg 2013; 60: 281-96.

22. Altintas N. Parasitic zoonotic diseases in Turkey. Vet Ital 2008; 44 633-46.

23. Inci A, Aydin N, Babur C, Cam Y, Akdogan C, Kuzan S. Seroepidemiological studies on toxoplasmosis and brucellosis in cattle and sheep around Kayseri. Pendik Vet Mikrobiyol Derg 1999; 1: 41-6.

24. Izgur M, Doganay M. Zoonozların Önemi ve Genel Bakış. In: Doganay M, Altintas N, editors. Zoonozlar Hayvanlardan Insanlara Bulasan Enfeksiyonlar. Ankara: Bilimsel Tıp; 2009. p. 21-32.

25. Gunes $V$, Inci A, Uyanik F, Yildirim A, Altuğ N, Eren $M$, et al. The Effect of Oxfendazole+Oxyclozanide Paste and Tablet Formulations on Parasite Burden and Metabolic Status of Sheep. J Anim Vet Adv 2008; 7: 589-94.

26. Sariozkan S. Evaluating the losses due to parasitic diseass in Turkish livestock: An economic perspective. Proceedings days of veterinary Medicine, 7th International scientific Meeting; 22-24 September; Struga-Mecadonia 2016. p. 61.

27. Sariozkan S, Inci A, Yildirim A, Duzlu O, Gray EW, Adler PH Economic losses during an outbreak of Simulium (Wilhelmia) species (Diptera: Simuliidae) in the Cappadocia region of Turkey. Turkiye Parazitol Derg 2014; 38: 116-9. [CrossRef]

28. Sariozkan S, Yalcin C. Estimating the production losses due to cystic echinococcosis in ruminants in Turkey. Vet Parasitol 2009; 163: 330-4. [CrossRef] 
29. Yildirim A, Gunes V, Ica A, Sariozkan S, Duzlu O, Inci A, et al. Koyunlarda Mide-Bağırsak Nematodlarına Karşı Oxfendazole + Oxyclozanide'nin Tablet ve Pasta Formülasyonlarının Kısa Süreli Etkinliğinin Araştırılması. Turkiye Parazitol Derg 2008; 32: 134-8.

30. Yildirim A, Ica A, Sariozkan S, Duzlu O, Inci A. Kayseri Yöresi Koyun ve Sığırlarında Cystic Echinococcosis'In Yaygınlığı ve Meydana Gelen Ekonomik Kayıplar. 16 Ulusal Parazitoloji Kongresi; 1-7 Kasım; Adana 2009.

31. Calistri P, lannetti S, Danzetta ML, Narcisi V, Cito F, Sabatino DD, et al. The components of 'One World - One Health' approach. Transbound Emerg Dis 2013; 60(Suppl 2): 4-13.

32. Cantas L, Suer K. Review: The important bacterial zoonoses in "one health" concept. Frontiers in Public Health 2014; 2: 144. [CrossRef]

33. Inci $A$, Kilic $E$, Canhilal R. Entomopathogens in control of urban pests. Ankara Univ Vet Fak Derg 2014; 61: 155-60.

34. Erdem $\mathrm{H}$, Akova M. Leading infectious diseases problems in Turkey. Eur J Clin Microbiol 2012; 18: 1056-67. [CrossRef]

35. Inci A. Kedi ve Köpeklerin Vektör-Borne Hastalıkları. Uluslararası Katılımlı 10 Ulusal Veteriner Iç Hastalıkları Kongresi; 27-30 Haziran; Türkiye 2013. p. 57-8.

36. McDaniel CJ, Cardwell DM, Moeller RB, Jr., Gray GC. Humans and cattle: A review of bovine zoonoses. Vector-Borne Zoonot 2014; 14: 1-19. [CrossRef]

37. Celikbas AK, Dokuzoguz B, Baykam N, Gok SE, Eroglu MN, Midilli $K$, et al. Crimean-Congo hemorrhagic fever among health care workers, Turkey. Emerg Infect Dis 2014; 20: 477-9. [CrossRef]

38. Gaff HD, Kocan KM, Sonenshine DE. Tick-borne Rickettsioses II (Anaplasmataceae). In: Sonenshine DE, Roe RM, editors. Biology of ticks Volume 2 Second edition ed. New York : Oxford University Press, 2014. p. 251-77.

39. Ogden NH, Artsob H, Margos G, Tsao J. Non-rickettsial tick-borne bacteria and the diseases they cause. In: Sonenshine DE, Roe RM, editors. Biology of ticks Vol 2. New York : Oxford University Press 2014. p. 278-312.

40. Kocan KM, de la Fuente J, Blouin EF, Coetzee JF, Ewing SA. The natural history of Anaplasma marginale. Vet Parasitol 2010; 167: 95-107. [CrossRef]

41. Gokce HI, Genc O, Akca A, Vatansever Z, Unver A, Erdogan HM. Molecular and serological evidence of Anaplasma phagocytophilum infection of farm animals in the Black Sea Region of Turkey. Acta Vet Hung 2008; 56: 281-92. [CrossRef]

42. Öter K, Çetinkaya H, Vuruşaner C, Toparlak M, Ergunay K. Molecular Detection and Typing of Anaplasma Species in Small Ruminants in Thrace Region of Turkey. Kafkas Univ Vet Fak Derg 2016; 22: 133-8.

43. Gunes $T$, Poyraz $O$, Atas M, Turgut NH. The seroprevalence of Anaplasma phagocytophilum in humans from two different climatic regions of Turkey and its co-seroprevalence rate with Borrelia burgdorferi. Turk J Med Sci 2011; 41: 903-8.

44. Sen E, Uchishima Y, Okamoto Y, Fukui T, Masuzawa T, Kadosaka T, et al. Molecular detection of Anaplasma phagocytophilum and Borrelia burgdorferi in Ixodes ricinus ticks from Istanbul metropolitan area and rural Trakya (Thrace) region of north-western Turkey. Ticks Tick-Borne Dis 2011; 2: 94-8. [CrossRef]

45. Aktas M, Vatansever Z, Altay K, Aydin MF, Dumanli N. Molecular evidence for Anaplasma phagocytophilum in Ixodes ricinus from Turkey. Trans R Soc Trop Med Hyg 2010; 104: 10-5. [CrossRef]

46. Aktas M, Altay K, Dumanli N. Molecular detection and identification of Anaplasma and Ehrlichia species in cattle from Turkey. Ticks TickBorne Dis 2011; 2: 62-5. [CrossRef]

47. Birdane FM, Sevinc F, Derinbay $O$. Anaplasma marginale infections in dairy cattle: clinical disease with high seroprevalence. Bull Vet Inst Pulawy 2006; 50: 467-70.
48. Inci A, Yildirim A, Duzlu O. Kenelerin Medikal ve Veteriner Önemleri. Inci A, editor. Kayseri: Erciyes Üniversitesi Yayınlarl; 2016.

49. Ozlem MB, Karaer Z, Turgut K, Eren H, Irmak K, Inci A. Efficacy of long-acting oxytetracycline on bovine anaplasmosis. Ank Univ Vet Fak Derg 1988; 35: 1-5.

50. Ulutas B, Bayramli G, Karagenc T. First Case of Anaplasma (Ehrlichia) platys Infection in a Dog in Turkey. Turk J Vet Anim Sci 2007; 31: 279-82.

51. Sari B, Taşkın Taşçi G, Kiliç Y. Seroprevalence of Dirofilaria immitis, Ehrlichia canis and Borrelia burgdorferi in Dogs in Iğdır Province, Turkey. Kafkas Univ Vet Fak Derg 2013; 19: 735-9. [CrossRef]

52. Aysul N, Ural K, Cetinkaya H, Kuşkucu M, Toros G, Eren, et al. Doxycycline-Chloroquine Combination for the Treatment of Canine Monocytic Ehrlichiosis. Acta Sci Vet 2012; 40: 1031.

53. Duzlu O, Inci A, Yildirim A, Onder Z, Ciloglu A. Köpeklerde kene kaynaklı bazı protozoon ve rickettsial enfeksiyonların Real Time PCR ile araştırılması ve saptanan izolatların moleküler karakterizasyonları. Ankara Univ Vet Fak Derg 2014; 61: 275-82.

54. Unver A, Rikihisa Y, Borku K, Ozkanlar Y, Hanedan B. Molecular detection and characterization of Ehrlichia canis from dogs in Turkey. Berliner und Munchener Tierarztliche Wochenschrift 2005; 118: 300-4.

55. Anon. Rickettsia prowazekii Infections Epidemic typhus, Typhus fever, Louse-borne typhus fever, Typhus exanthematicus, Classical typhus fever, Sylvatic typhus, European typhus, Brill-Zinsser disease, Jail fever. The Center For Food Security and Public Health, lowa State University. 2017, 1-5. Available from: http://www.cfsph.iastate. edu/Factsheets/pdfs/typhus_fever.pdf (Accessed 09.10.2017).

56. Azad A. Rickettsial Pathogens and Their Arthropod Vectors. Emerg Infect Dis 1998; 4: 179-86. [CrossRef]

57. Karatepe M. The role of Turkish physicians in the vaccination against typhus during the years of World War I. Mikrobiyoloji Bülteni 2008; 42: 301-13.

58. Coskun D, Ozyurek S, Goktas P. Bir Akdeniz benekli ates vakasi. Flora. 1999; 4: 72.

59. Erten N, Karan MA, Tascioglu C, Yurci A, Dilmener M, Kaysi A. Rickettsia conorii Infeksiyonu: Olgu Sunusu. Klimik Derg 2000; 13: 36-8.

60. Gunes T, Poyraz O, Atas M, Turgut NH. The seroprevalence of Rickettsia conorii in humans living in villages of Tokat Province in Turkey, where Crimean-Congo hemorrhagic fever virus is endemic, and epidemiological similarities of both infectious agents. Turk $J$ Med Sci 2012; 42: 441-8.

61. Mert A, Tabak F, Dumankar A, Eroglu C, Ozturk R, Aktuglu Y. Dört Marsilya hummasi olgusu. Klimik Derg 1997; 10: 146-8.

62. Ozgunes N, Ergen P, Yazici S, Aksoy Y, Bekler G, Sargin F. Yirmi Riketsiyoz Vakası. Klimik Derg 2001; 14: 91-22.

63. Seber E, Yaflar AY, Cetin BD, Sucu R. Riketsiyoz: bes vaka. VI Turk Klinik Mikrobiyoloji ve Infeksiyon Hastaliklari Kongresi; 15-17 Eylul; Trabzon1992. p. 44.

64. Orkun O, Karaer Z, Cakmak A, Nalbantoglu S. Spotted fever group rickettsiae in ticks in Turkey. Ticks Tick-Borne Dis 2014; 5: 213-8. [CrossRef]

65. Orkun Ö, Karaer Z, Çakmak A, Nalbantoğlu S. Identification of TickBorne Pathogens in Ticks Feeding on Humans in Turkey. Plos Neglect Trop D 2014; 8: e3067.

66. Kuloglu F, Rolain JM, Fournier PE, Akata F, Tugrul M, Raoult D. First isolation of Rickettsia conorii from humans in the Trakya (European) region of Turkey. Eur J Clin Microbiol 2004; 23: 609-14. [CrossRef]

67. Kar S, Yllmazer N, Midilli K, Ergin S, Alp H, Gargili A. Presence of the Zoonotic Borrelia burgdorferi sl. and Rickettsia spp. in the Ticks from Wild Tortoises and Hedgehogs. MÜSBED 2011; 1: 166-70.

68. Service MW. Mites (Prostigmata and Mesostigmata). In: Service MW, editor. The Encyclopedia of Artropod-Transmitted Infections. Oxfordshire, UK: CABI Publishing; 2006. p. 340-3. 
69. Ozturk MK, Gunes T, Kose M, Coker C, Radulovic S. Rickettsial pox in Turkey. Emerg Infect Dis 2003; 9: 1498-9. [CrossRef]

70. Angelakis E, Botelho E, Socolovschi C, Sobas CR, Piketty C, Parola $P$, et al. Murine typhus as a cause of Fever in travelers from Tunisia and mediterranean areas. J Travel Med 2010; 17: 310-5. [CrossRef]

71. Serefettin O. Murlne Typhus at Istanbul. Bulletin de la Société de Pathologie Exotique 1934; 27: 831-3.

72. Comandatore F, Cordaux R, Bandi C, Blaxter M, Darby A, Makepeace $B L$, et al. Supergroup C Wolbachia, mutualist symbionts of filarial nematodes, have a distinct genome structure. Open Biol 2015; 5: 150099. [CrossRef]

73. Yıldırım A, Incı A, Duzlu O, Onder Z, Cıloglu A. Detection and molecular characterization of the Wolbachia endobacteria in the Culex pipiens (Diptera: Culicidae) specimens collected from Kayseri province of Turkey. Ankara Univ Vet Fak Derg 2013; 60: 189-94.

74. Yetismis G. Investigation of Wolbachia endobacteria in mosquito species in Kayseri province by PCR and molecular genotyping of the isolates (Yuksek Lisans Tezi): Erciyes Üniversitesi; 2015.

75. Inci A, Dik B, Mumcuoglu KY, Yildirim A, Duzlu O, Ciloglu A, et al. Detection and molecular characterization of the Wolbachia endobacteria in chewing lice species collected from the Angora goats in Central Anatolia region of Turkey. 5th International Conference on Phthiraptera; 2-7 Ağustos; Utah, USA 2014. p. 76.

76. Novakova M, Costa FB, Krause F, Literak I, Labruna MB. Rickettsia vini n. sp. (Rickettsiaceae) infecting the tick Ixodes arboricola (Acari: Ixodidae). Parasite Vector 2016; 9: 469. [CrossRef]

77. Keskin A, Koprulu TK, Bursali A, Ozsemir AC, Yavuz KE, Tekin S. First record of Ixodes arboricola (Ixodida: Ixodidae) from Turkey with presence of Candidatus Rickettsia vini (Rickettsiales: Rickettsiaceae). J Med Entomol 2014; 51: 864-7. [CrossRef]

78. Polat E, Calisir B, Yucel A, Tuzer E. Turkiye'de Ixodes ricinus'lardan ilk defa ayrilan ve uretilen iki Borrelia kokeni. Turkiye Parazitol Derg 1998; 22: 167-73.

79. Çalisir B, Polat E, Güney G, Gönenc L. Investigation on the species composition of the Ixodid ticks from Belgrade forest in Istanbul and their role as vectors of Borrelia burgdorferi. Acta Zool Bulgar 2000; 52: 23-8.

80. Guner ES, Hashimoto N, Takada N, Kaneda K, Imai Y, Masuzawa T. First isolation and characterization of Borrelia burgdorferi sensu lato strains from Ixodes ricinus ticks in Turkey. J Med Microbiol 2003; 52: 807-13. [CrossRef]

81. Guner ES, Hashimoto N, Kadosaka T, Imai Y, Masuzawa T. A novel, fast-growing Borrelia sp. isolated from the hard tick Hyalomma aegyptium in Turkey. Microbiol 2003; 149: 2539-44. [CrossRef]

82. Guner ES, Watanabe M, Hashimoto N, Kadosaka T, Kawamura Y, Ezaki $T$, et al. Borrelia turcica sp. nov., isolated from the hard tick Hyalomma aegyptium in Turkey. Int J Syst Evol Microbiol 2004; 54 : 1649-52. [CrossRef]

83. Gulanber EG, Gulanber A, Albayrak R. Lyme Disease (Borreliosis) in a Saint Bernard Dog: First Clinical Case in Turkey. J Vet Anim Sci 2007; 31: 367-9.

84. Bhide M, Yilmaz Z, Golcu E, Torun S, Mikula I. Seroprevalence of anti-Borrelia burgdorferi antibodies in dogs and horses in Turkey. Ann Agric Environ Med 2008; 15: 85-90.

85. Bulut C, Tufan ZK, Altun S, Altinel E, Kinikli S, Demiroz AP. An overlooked disease of tick bites: Lyme disease. Mikrobiyoloji Bulteni 2009; 43: 487-92.

86. Eroglu C, Esen S, Hokelek M, Sunbul M, Sencan I, Ozturk R, et al. A case of lyme meningitis characterized with meningitis and encephalitis findings. Infeks Derg 2002; 16: 225-8.

87. Koc F, Bozdemir H, Pekoz T, Aksu HS, Ozcan S, Kurdak H. Lyme disease presenting as subacute transverse myelitis. Acta Neurol Belg 2009; 109: 326-9.
88. Polat E, Turhan V, Aslan M, Musellim B, Onem Y, Ertugrul B. First report of three culture confirmed human Lyme cases in Turkey. Mikrobiyoloji Bulteni 2010; 44: 133-9.

89. Demirci M, Yorgancigil B, Tahan V, Arda M. The lyme disease seropositivity in Isparta province in those with a history of tick-bite. Infeks Derg 2001; 15: 17-20.

90. Utas S, Kardas Y, Doganay M. The evaluation of Lyme serology in patients with symptoms which may be related with Borrelia burgdorferi. Mikrobiol Bul 1994; 28: 106-12.

91. Assous MV, Wilamowski A. Relapsing fever borreliosis in Eurasiaforgotten, but certainly not gone! Eur J Clin Microbiol Infect Dis 2009; 15: 407-14.

92. Rebaudet S, Parola P. Epidemiology of relapsing fever borreliosis in Europe. FEMS Immunol Med Microbiol 2006; 48: 11-5. [CrossRef]

93. Ozsan K, Akyay N. Relapsing fever in Turkey; presence in the South (Turko-Syrian border) of Ornithodorus erraticus infected with a spirochete of the Crocidurae group. Bull Soc Pathol Exo 1954; 47: 501 3.

94. Onul B. Infeksiyon Hastalıkları. Ankara Universitesi Tıp Fakültesi Yayını 1971; 252: 774-82.

95. Kilic S. Francisella tularensis ve Turkiye'de tularemi epidemiyolojisine genel bir bakış. Flora 2010; 15: 37-58.

96. Ulu-Kilic A, Doganay M. An overview: Tularemia and travel medicine. Travel Med Infect Dis 2014; 12: 609-16. [CrossRef]

97. Ramirez-Puebla ST, Servin-Garciduenas LE, Ormeno-Orrillo E, VeraPonce de Leon A, Rosenblueth $M$, Delaye $L$, et al. Species in Wolbachia? Proposal for the designation of 'Candidatus Wolbachia bourtzisii', 'Candidatus Wolbachia onchocercicola', 'Candidatus Wolbachia blaxteri', 'Candidatus Wolbachiabrugii', 'Candidatus Wolbachia taylori', 'Candidatus Wolbachia collembolicola' and'Candidatus Wolbachia multihospitum' for the different species within Wolbachia supergroups. Syst Appl Microbiol 2015; 38: 390-9. [CrossRef]

98. Chomel BB, Kasten RW. Bartonellosis, an increasingly recognized zoonosis. J Appl Microbiol 2010; 109: 743-50. [CrossRef]

99. Chomel BB, Chang C. Cat-scratch and other related Bartonella infections. In: Service MW, editor. The Encyclopedia of Arthropodtransmitted Infections of Man and Domesticated Animals. UK: CABI Publishing; 2006. p. 107-10.

100. Cotté V, Bonnet S, Le Rhun D, Le Naour E, Chauvin A, Boulouis HJ, et al. Transmission of Bartonella henselae by Ixodes ricinus. Emerg Infect Dis 2008; 14: 1074. [CrossRef]

101. Celebi B, Kilic S, Aydin N, Tarhan G, Carhan A, Babur C. Investigation of Bartonella henselae in cats in Ankara, Turkey. Zoonoses Public Health 2009; 56: 169-75. [CrossRef]

102. Yilmaz C, Ergin C, Kaleli I. Investigation of Bartonella henselae seroprevalence and related risk factors in blood donors admitted to Pamukkale University Blood Center. Mikrobiyoloji Bulteni 2009; 43: 391-401.

103. Kiris Satilmis O, Akkaya Y, Ergin C, Kaleli I, Dursun B, Aydin C. Investigation of Bartonella henselae antibodies in serum and plasma samples of kidney transplant patients. Mikrobiyoloji Bulteni 2012; 46: 568-74.

104. Sayin-Kutlu S, Ergin C, Kutlu M, Akkaya Y, Akalin S. Bartonella henselae seroprevalence in cattle breeders and veterinarians in the rural areas of Aydin and Denizli, Turkey. Zoonoses Public Health 2012; 59: 445-9. [CrossRef]

105. Çelebi B, Taylan A, Kilic S, Akca A, Koenhemsi L, Pasa S, et al. Seroprevalence of Bartonella vinsonii subsp berkhoffii in Urban and Rural Dogs in Turkey. J Vet Med Sci 2010; 72: 1491-4. [CrossRef]

106. Guzel M, Celebi B, Yalcin E, Koenhemsi L, Mamak N, Pasa S, et al. A serological investigation of Bartonella henselae infection in cats in Turkey. J Vet Med Sci 2011; 73: 1513-6. [CrossRef] 
107. Willi B, Boretti FS, Tasker S, Meli ML, Wengi N, Reusch CE, et al. From Haemobartonella to Hemoplasma: Molecular methods provide new insights. Vet Microbiol 2007; 125: 197-209. [CrossRef]

108. Messick JB. Hemotrophic mycoplasmas (hemoplasmas): A review and new insights into pathogenic potential. Vet Clin Pathol 2004; 33: 2-13. [CrossRef]

109. Maggi RG, Compton SM, Trull CL, Mascarelli PE, Mozayeni BR, Breitschwerdt EB. Infection with hemotropic Mycoplasma species in patients with or without extensive arthropod or animal contact. Eur J Clin Microbiol Infect Dis 2013; 51: 3237-41. [CrossRef]

110. Tuzer E, Goksu K, Bilal T, Yesildere T. A case of haemobartonellosis in a cat in Istanbul. J Protozool Res 1993; 3: 69-70.

111. Cooper A, Stephens J, Ketheesan N, Govan B. Detection of Coxiella burnetii DNA in wildlife and ticks in northern Queensland, Australia. Vector Borne Zoonotic Dis 2013; 13: 12-6. [CrossRef]

112. Mediannikov O, Fenollar F, Socolovschi C, Diatta G, Bassene H, Molez JF, et al. Coxiella burnetii in humans and ticks in rural Senegal. PLoS Negl Trop Dis 2010; 4: e654.

113. Spitalska E, Kocianova E. Detection of Coxiella burnetii in ticks collected in Slovakia and Hungary. Eur J Epidemiol 2003; 18: 263-6. [CrossRef]

114. Khoo JJ, Lim FS, Chen F, Phoon WH, Khor CS, Pike BL, et al. Coxiella Detection in Ticks from Wildlife and Livestock in Malaysia. Vector Borne Zoonotic Dis 2016; 16: 744-51. [CrossRef]

115. Payzin S. Epidemiological investigations on $\mathrm{Q}$ fever in Turkey. Bull World Health Organ 1953; 9: 553-8.

116. Günal Ö, Demirtürk F, Barut Ş, Kılıç S, Erkorkmaz U, Tekin FY, et al. A preliminary report of relationship between abortion and $\mathrm{Q}$ fever in Central Black Sea Region Turkish woman. Cumhuriyet Med J 2014; 36: 337-43. [CrossRef]

117. Butler T. Plauge. In: Service MW, editor. The Encyclopedia of Artropod-Transmitted Infections. Oxfordshire, UK: CABI Publishing; 2006. p. 401-8.

118. Dragon DC. Anthrax. In: Service MV, editor. The Encyclopedia of Artropod-Transmitted Infections. Oxfordshire, UK: CABI Publishing: 2006. p. 46-8.

119. Ozkurt Z, Parlak M, Tastan R, Dinler U, Saglam YS, Ozyurek SF. Anthrax in eastern Turkey, 1992-2004. Emerg Infect Dis 2005; 11: 1939-41. [CrossRef]

120. Doganay M, Metan G. Human anthrax in Turkey from 1990 to 2007. Vector Borne Zoonotic Dis 2009; 9: 131-40. [CrossRef]

121. Demiraslan H, Borlu A, Sahin S, Buyuk F, Karadag Y, Doganay M, et al. The epidemiological investigation and control of an anthrax outbreak in a village in Central Anatolia, Turkey. Pathog Glob Health 2017; 111: 206-11. [CrossRef]

122. Doganay M, Aygen B. Human brucellosis: an overview. Int J Infect Dis 2003; 7: 173-82. [CrossRef]

123. Yumuk Z, O'Callaghan D. Brucellosis in Turkey-an overview. Int J Infect Dis 2012; 16: e228-35.

124. Ertan D. AB Üyelik Sürecinde Türkiye'de Sığırlarda Görülen Şap, Tüberküloz ve Bruselloz Hastalıklarının Kontrolü ve Eradikasyonu: Yöntemler ve Maliyet Analizi (AB Uzmanlık Tezi). Ankara 2015.

125. Damborg P, Broens EM, Chomel BB, Guenther S, Pasmans F, Wagenaar JA, et al. Bacterial Zoonoses Transmitted by Household Pets: State-of-the-Art and Future Perspectives for Targeted Research and Policy Actions. J Comp Pathol 2016; 155(Suppl 1): S27-40.

126. Hascelik G, Akyon Y, Diker S, Berkman E. Campylobacter enteritis among Turkish Children. Med J Islamic World Acad Sci 1989; 2: 2013.

127. Songer JG. Clostridia as agents of zoonotic disease. Vet Microbiol 2010; 140: 399-404. [CrossRef]

128. Gursoy S, Guven K, Arikan T, Yurci A, Torun E, Baskol M, et al Clostridium difficile infection frequency in patients with nosocomial infections or using antibiotics. Hepato-Gastroenterology 2007; 54: $1720-4$

129. Ergen EK, Akalin H, Yilmaz E, Sinirtas M, Alver O, Heper $Y$, et al Nosocomial diarrhea and Clostridium difficile associated diarrhea in a Turkish University Hospital. Med Mal Infect 2009; 39: 382-7. [CrossRef]

130. Yilmaz M, Bilir YA, Aygun G, Erzin Y, Ozturk R, Celik AF. Prospective observational study on antibiotic-associated bloody diarrhea: Report of 21 cases with a long-term follow-up from Turkey. Eur J Gastroenterol Hepatol 2012; 24: 688-94. [CrossRef]

131. Dikici B, Uzun H, Yilmaz-Keskin E, Tas T, Gunes A, Kocamaz H, et al. Neonatal tetanus in Turkey; what has changed in the last decade? BMC Infect Dis 2008; 8: 112

132. Gurkan F, Bosnak M, Dikici B, Bosnak V, Tas MA, Haspolat K, et al. Neonatal tetanus: a continuing challenge in the southeast of Turkey: Risk factors, clinical features and prognostic factors. Eur J Epidemiol 1999; 15: 171-4. [CrossRef]

133. Anon. Enterohemorrhagic Escherichia coli and Other E. coli causing Hemolytic Uremic Syndrome The Center for Food Security and Public Health 2016 (Available from: http://www.cfsph.iastate.edu/ Factsheets/pdfs/e_coli.pdf

134. Erdogan H, Erdogan A, LeventB, Kayali R, Arslan H. Enterohemorrhagic Escherichia coli O157:H7: case report. Turk J Pediatr 2008; 50: 488-91.

135. Hascelik G, Akan OA, Diker S, Baykal M. Campylobacter and enterohaemorrhagic Escherichia coli (EHEC) associated gastroenteritis in Turkish children. J Health Popul Nutr 1991; 9: 315-7.

136. Tolun V, Ang-Kucuker M, Diren S, Ang O. Detection verotoxigenic Escherichia coli (VTEC) in stool samples of patients with diarrhea by PCR. Turk Mikrobiyol Cem Derg 2001; 31: 174-7.

137. Aslantas O, Erdogan S, Cantekin Z, Gulacti I, Evrendilek GA Isolation and characterization of verocytotoxin-producing Escherichia coli $\mathrm{O} 157$ from Turkish cattle. Int J Food Microbiol 2006; 106: 338-42. [CrossRef]

138. Yilmaz A, Gun $H$, Ugur M, Turan N, Yilmaz $H$. Detection and frequency of VT1, VT2 and eaeA genes in Escherichia coli O157 and O157:H7 strains isolated from cattle, cattle carcasses and abattoir environment in Istanbul. Int J Food Microbiol 2006; 106: 213-7. [CrossRef]

139. Brooke CJ, Riley TV. Erysipelothrix rhusiopathiae: Bacteriology, epidemiology and clinical manifestations of an occupational pathogen J Med Microbiol 1999; 48: 789-99. [CrossRef]

140. Meric M, Ozcan SK. Erysipelothrix rhusiopathiae pneumonia in an immunocompetent patient. J Med Microbiol 2012; 61: 450-1. [CrossRef]

141. Ozdemir M, Cimen K, Mevlitoglu I. Post-traumatic erysipeloid cutaneous leishmaniasis. Int J Dermatol 2007; 46: 1292-3. [CrossRef]

142. Verma A, Saminathan M, Neha, Tiwari R, Dhama K, Singh S. Glanders-A re-emerging zoonotic disease: A review. J Biol Sci 2014; 14: 38-51. [CrossRef]

143. OIE. Glanders. Manual IOT, editor. Paris: OIE; 2008

144. Van Zandt KE, Greer MT, Gelhaus HC. Glanders: an overview of infection in humans. Orphanet J Rare Dis 2013; 8: 131. [CrossRef]

145. Srinivasan A, Kraus CN, DeShazer D, Becker PM, Dick JD, Spacek L, et al. Glanders in a military research microbiologist. N Engl J Med 2001; 345: 256-8. [CrossRef]

146. Akcay E. Glanders in Turkey, eradication and control 2008 (Available from: http://mitos.tagem.gov.tr/fulltext.php?yayin=689\&id=fulltext/ tagem/689.doc.

147. Osmanağaoğlu Ş, Melikoğlu B. Türkiye'de Ruam hastalığı eradikasyon çalışmalarına tarihsel bir bakış açısı. Kafkas Univ Vet Fak Derg 2009; 15: 331-7.

148. Akman M. A glanders case in man, which has been treated with auromycine and streptomycine. Turk Hij Den Biyol Derg 1953; 13: 277 
149. Babacan M. A case of chronic glanders in man. Bullet Microbiol 1968; 2: 28-34.

150. Selvi N, Paykoc Z. A vase of acute farcy treated with streptomycine. Turk Hij Den Biyol Derg 1949; 9: 9-16.

151. Richter R, Tat L. Leprosy Problems in Turkey. Int J Lepr 1958; 26: 134 43.

152. Aytekin AH, Saylan T. Leprosy in Turkey. Leprosy review 1988; 59: 231-4.

153. Polat E, Aygun G, Ozdemir V, Ozdemir S, Altas K, editors. Leptospirozis tanisinda karanlik alan, kultur ve lam aglutinasyon yontemlerinin degerlendirilmesi. Klimik XI, Turk Klinik Mikrobiyoloji ve Infeksiyon Hastalıkları Kongresi; 200430 Mart- 3 Nisan; Istanbul.

154. Kenar B, Ozdemir V. The seroprevalence of leptospirosis in Anatolian buffaloes in Turkey. Revue Med Vet 2013; 164: 331-5.

155. Ozdemir V, Diker KS. Köpek serumlarının leptospirosis yönünden Mikroskopik Aglutinasyon Testi ve ELISA ile incelenmesi. Etlik Vet Mikrob Derg 1999; 10: 1-17.

156. Doganay M. Listeriosis: clinical presentation. FEMS Immunol Med Microbiol 2003; 35: 173-5. [CrossRef]

157. Sahal M, Gazyagci S, Ural K, Babur C, Kilic S, editors. Seroprevalance of antibodies to Listeria monocytogenes in cattle with and without clinical suspicious for listeriosis in Ankara in Turkey. XXII World Buiatrics Congress; 2002 18-23, August; Hannover-Germany.

158. Kennerman E, Erdogan HM, Senturk S, Golcu E. Bursa bölgesindeki koyunlarda listeriosisin ELISA ile serolojik tanısı. Vet Cerrahi Derg 2000; 6: 22-5.

159. Inci A, Babur C, Aydin N, Cam Y. The investigation on the seroprevalence of Toxoplasma gondii (Nicolle and Manceaux, 1908) and Listeria monocytogenes in equids around Kayseri. Firat Univ Sag Bil Vet Der 2002; 16: 181-5.

160. Gicik Y, Sari B, Babur C, Celebi B. The seropositivity of Toxoplasma gondii and Listeria monocytogenes in the dogs of Kars and vicinity. Turkiye Parazitol Derg 2010; 34: 86-90.

161. Aktepe OC, editor. Ülkemizde listeriyozun insanlardaki durumu. 1 Ulusal Zoonoz Kongresi; 2007 3-6, Aralık; Erzurum, Türkiye.

162. Sevim P, Ozer S, Rad F. First isolation of Mycobacterium spp. in Mullus spp. in Turkey. IJVR 2015; 16: 144-9.

163. Tell LA, Woods L, Cromie RL. Mycobacteriosis in birds. Revue scientifique et technique (International Office of Epizootics) 2001; 20: 180-203. [CrossRef]

164. Ozen H, Karaman M, Dag S, Karakurt E, Akbulut Y. A case of tuberculosis in a free-living Long-legged buzzard (Buteo rufinus). Kafkas Univ Vet Fak Derg 2016; 22: 473-6.

165. Wilson BA, Ho M. Pasteurella multocida: from zoonosis to cellular microbiology. Clin Microbiol Rev 2013; 26: 631-55. [CrossRef]

166. Ulker H, Kucuk D, Cantekin Z, Solmaz H. Hatay Yöresinde Kesimhanede Kesilen Sığır Akciğerlerinden Pasteurella multocida ve Mannheimia haemolytica İzolasyonu ve Antibiyotiklere Duyarlılığı. AVKAE Derg 2012; 2: 10-4.

167. Aygen B, Doganay M, Ustunbas HB. Cellulitis due to Pasteurella multocida. Turk J Infect 1991; 5: 135-9.

168. Balci U, Seyman D, Ozen NS, Inan D. Kedi Isııı̆ı Sonrası Gelişen Pasteurella multocida'ya Bağlı Osteomyelit Olgusu. Turk Mikrobiyol Cem Derg 2011; 41: 46-8.

169. Celebi BS, Ak S. A comparative study of detecting Chlamydophila psittaci in pet birds using isolation in embryonated egg and polymerase chain reaction. Avian diseases 2006; 50: 489-93. [CrossRef]

170. Karakuzulu H. Türkiye'deki önemli hayvanat bahçelerinde bulunan su kuşları ve bakıcılarında Chlamydia psittaci prevelansının belirlenmesi (Doktora Tezi). Bursa 2003.

171. D'Aoust JY, Maurer J. Salmonella species In: Doyle MP, Beuchat LR, editors. Food microbiology fundamentals and frontiers. Washington, D.C: ASM Press; 2007. p. 187-236.
172. Kocabiyik AL, Cetin C, Dedicova D. Detection of Salmonella spp. in stray dogs in Bursa Province, Turkey: first isolation of Salmonella corvallis from dogs. J Vet Med B Infect Dis Vet Public Health 2006; 53: 194-6. [CrossRef]

173. Sırıken B, Türk H. Poultry Meat and Salmonellosis. Animal Health Prod and Hyg 2013; 2: 174-82.

174. Erol I, Goncuoglu M, Ayaz ND, Ellerbroek L, Ormanci FS, Kangal OI. Serotype distribution of Salmonella isolates from turkey ground meat and meat parts. Biomed Res Int 2013; 281591

175. Gülmez D, Gür D, Hasçelik G, Güleşen R, Levent B. Ulusal Enterik Patojenler Laboratuvar Sürveyans Ağına (UEPLA) Dâhil Olan Bir Üniversite Hastanesinin Deneyimleri: Dört Yıllık Salmonella, Shigella ve Campylobacter Verileri. Turk Mikrobiyol Cem Derg 2012; 42: 85-92.

176. Karakus N, Ata N, Goktepe A, Temel F, Tunckol K, Levent B, et al., editors. Osmaniye ili, Kadirli ilçesi gıda kaynaklı Salmonella enteritidis Salgını. XVII KLIMIK Kongresi; 2015.

177. Elliott SP. Rat Bite Fever and Streptobacillus moniliformis. Clin Microbiol Rev 2007; 20: 13-22. [CrossRef]

178. Gaastra W, Boot R, Ho HTK, Lipman LJA. Rat Bite Fever. Vet microbiol 2008; 133: 211-28. [CrossRef]

179. Abrahamian FM, Goldstein EJ. Microbiology of animal bite wound infections. Clin Microbiol Rev 2011; 24: 231-46. [CrossRef]

180. Talan DA, Citron DM, Abrahamian FM, Moran GJ, Goldstein EJ. Bacteriologic analysis of infected dog and cat bites. Emergency Medicine Animal Bite Infection Study Group. N Engl J Med 1999; 340: 85-92. [CrossRef]

181. Kılıç N, Sarıerler M. Dog bite wounds: A retrospective study (114 Cases). YYÜ Vet Fak Derg 2003; 14: 86-8.

182. Aksoy M, Demirbaş B, Maden F, Şimşek C, Özlü A, Kaya M, et al., editors. Ankara ilinde 2005-2009 yılları arasında görülen şüpheli ısırıkların ve kuduz aşılamasının degerlendirilmesi. 3 EKMUD Kongresi; 2010 12-16 Mayıs; Ankara.

183. Sezgin B, Ljohiy M, Akgol Gur ST. Animal-inflicted open wounds in rural Turkey: lessons learned and a proposed treatment algorithm for uncertain scenarios. Int Wound J 2016; 13: 1282-8. [CrossRef]

184. WHO. Global tuberculosis control report 2011. Available from: http://apps.who.int/iris/bitstream/10665/44728/1/9789241564380_ eng.pdf

185. Ayele WY, Neill SD, Zinsstag J, Weiss MG, Pavlik I. Bovine tuberculosis: an old disease but a new threat to Africa. Int J Tuberc Lung Dis 2004; 8: 924-37.

186. WHO. Global tuberculosis control report 2015. Available from: http://apps.who.int/iris/bitstream/10665/191102/1/9789241565059_ eng.pdf

187. Paperna I, Colorni A, Gordin H, Kissil GW. Diseases of Sparus aurata in marine culture at Elat. Aquaculture 1977; 10: 195-213. [CrossRef]

188. Akaylı T, Timur G. A diagnostic study on vibriosis cultured gilt-head sea bream ( $S$. aurata) in the Aegean Sea coast farms of Turkey. J Fish Aquat Sci 2004; 18: 43-54.

189. Sirıken B. The Presence of Yersinia enterocolitica and other Yersinia species in ground beef in Aydin, Turkey. Turk J Vet Anim Sci 2004; 28: 489-95.

190. Güven A, Sezer Ç, Duman Aydin B, Bilge N, Vatansever L. Incidence and Pathogenicity of Yersinia enterocolitica Isolates from Foods in Turkey. Kafkas Univ Vet Fak Derg 2010; 16: S107-S12.

191. Berktas M, Kurtoglu MG, Bozkurt H, Guducuoglu H, Bayram Y, Kutluay N. Yersinia enterocolitica ve Yersinia pseudotuberculosis'in çeşitli infeksiyonlardaki rolü ve antimikrobial ilaçlara duyarlılıkları. Infeksiyon Derg 2003; 17: 259-64.

192. Valour F, Senechal A, Dupieux C, Karsenty J, Lustig S, Breton P, et al. Actinomycosis: etiology, clinical features, diagnosis, treatment, and management. Infect Drug Resist 2014; 7: 183-97. 
193. Steele JH. Zoonoses. In: Merck and Co EE, editor. The Merck Veterinary Manual. USA1999. p. 2161-85.

194. Oktem B, Anteplioglu H. The treatment of actinomycosis in cattle. Ankara Univ Vet Fak Derg 1972; 19: 53-62.

195. Çakır N, BerktaŞ M, Yaman G, I. A, Özer TT. Servikal örneklerden Actinomyces israelii izolasyonu ve antibiyotiklere direnç oranın incelenmesi. Van Tip Derg 2011; 18: 197-200.

196. Levy CE, Pedro RJ, Von Nowakonski A, Holanda LM, Brocchi M, Ramo MC. Arcanobacterium pyogenes sepsis in farmer, Brazil. Emerg Infect Dis 2009; 15: 1131-2. [CrossRef]

197. Turner MM, Deperno CS, Conner MC, Eyler TB, Lancia RA, Klaver RW, et al. Habitat, wildlife, and one health: Arcanobacterium pyogenes in Maryland and Upper Eastern Shore white-tailed deer populations. Infect Ecol Epidemiol 2013; 3: DOI: DOI: 10.3402/iee. v3i0.19175. [CrossRef]

198. Sivacolundhu RK, O'Hara AJ, Read RA. Thoracic actinomycosis (arcanobacteriosis) or nocardiosis causing thoracic pyogranuloma formation in three dogs. Aust Vet J 2001; 79: 398-402. [CrossRef]

199. Chirico J, Jonsson P, Kjellberg S, Thomas G. Summer mastitis experimentally induced by Hydrotaea irritans exposed to bacteria. Med Vet Entomol 1997; 11: 187-92. [CrossRef]

200. Hadımlı HH, Erganıs O, Kav K, Sayın Z. Koyun ve Sığır örneklerinden Arcanobacterium pyogenes izolasyonu ve polimeraz zincir reaksiyonu ile identifikasyonu. Kafkas Univ Vet Fak Derg 2010; 16: 611-6.

201. Balikci A, Topkaya AE, Belas Z. A frequently overlooked bacteria in clinical microbiology laboratories: Arcanobacterium haemolyticum. Mikrobiyoloji Bulteni 2011; 45: 535-40.

202. Oruc E, Aktas MS, Aydin H. Dermatophilosis in a Simmental calf. Lucrari Stiintifice-Medicina Veterinara Universitatea de Stiinte Agricole si Medicina Veterinara "Ion Ionescu de la Brad" Iasi 2014; 57: 283-7.

203. Harman M, Sekin S, Akdeniz S. Human dermatophilosis mimicking ringworm. Br J Dermatol 2001; 145: 170-1. [CrossRef]

204. Wilson JW. Nocardiosis: updates and clinical overview. Mayo Clinic proceedings 2012; 87: 403-7. [CrossRef]

205. Yildiz O, Alp E, Tokgoz B, Tucer B, Aygen B, Sumerkan B, et al. Nocardiosis in a teaching hospital in the Central Anatolia region of Turkey: treatment and outcome. Eur J Clin Microbiol Infect Dis 2005; 11: 495-9. [CrossRef]

206. Yildiz O, Doganay M. Actinomycoses and Nocardia pulmonary infections. Curr Opin Pulm Med 2006; 12: 228-34. [CrossRef]

207. Milli UH, Kokuuslu C, Berkin S. Bir Köpekte Nokardial Plörizi Olgusu. Ankara Univ Vet Fak Derg 1986; 33: 171-8.

208. Avci M. 2012. Available from: http://www.klimik.org.tr/wp-content/ uploads/2012/02/1082011115038-a8IRpLTqPAiE.pdf

209. Ozdemir L, Ozdemir B, Temelli M, Hatipoglu ON. Pulmonary Nocardiosis Induced by Long-Term Use of Steroids on a Bronchiectasis Backgroung. Medical Bull Haseki 2015; 53: 88-91. [CrossRef]

210. Aydoslu B, Tugrul HM. Trakya Universitesi Tip Fakültesi Hastanesinde bagisiklik sistemi baskilanmis hastalardan izole edilen Nocardia turleri ve antibiyotiklere duyarliliklari. Mikrobiyoloji Bulteni 2007; 41: 529-35.

211. Beernaert LA, Pasmans F, Van Waeyenberghe L, Haesebrouck F, Martel A. Aspergillus infections in birds: A review. Avian Pathol 2010; 39: 325-31. [CrossRef]

212. VandenBergh MF, Verweij PE, Voss A. Epidemiology of nosocomial fungal infections: invasive aspergillosis and the environment. Diagn Microbiol Infect Dis 1999; 34: 221-7. [CrossRef]

213. Ceylan E, Ozkutuk A, Ergor G, Yucesoy M, Itil O, Caymaz S, et al. Fungi and indoor conditions in asthma patients. J Asthma 2006; 43 : 789-94. [CrossRef]

214. Unlu M, Ergin C, Cirit M, Sahin U, Akkaya A. Molds in the homes of asthmatic patients in Isparta, Turkey. Asian Pac J Allergy Immunol 2003; $21: 21-4$.
215. Hizlisoy H, Kilic H. Evcil hayvanlarda Aspergillus spp. kaynaklı enfeksiyonlar ve teşhisinde kullanılan galaktomannan antijenleri. Erciyes Univ Vet Fak Derg 2011; 8: 111-8.

216. Durdu M, Baba M, Koca A, Demiroglu YZ, Seckin D. A quarter age delayed diagnosis: blastomycosis: case report. Turkiye Klinikleri Dermatol Derg 2009; 19: 35-9.

217. Baydas B, Ikiz S, Ilgaz A. Kafes kuşlarının gaitalarında Candida türlerinin araştırılması. J Fac Vet Med Istanbul Univ 2013; 39: 113-20.

218. Genc GE, Ozel S, Erturan Z. Sağlıklı kişilerde oral candida kolonizasyonu sıklığının araştıııması. ANKEM Derg 2014; 28: 26-31.

219. Brown J, Benedict K, Park BJ, Thompson GR. Coccidioidomycosis: epidemiology. Clinic epidemiol 2013; 5: 185-97.

220. Kantarcioglu AS, Sandoval-Denis M, Aygun G, Kiraz N, Akman C, Apaydin $\mathrm{H}$, et al. First imported coccidioidomycosis in Turkey: A potential health risk for laboratory workers outside endemic areas. Med Mycol Case Rep 2014; 3: 20-5. [CrossRef]

221. Kantarcioglu AS, Yucel A. Epidemiology of human cryptococcosis in Turkey (1953-2003). Cerrahpasa J Med 2003; 34: 95-109.

222. Allocati N, Petrucci AG, Di Giovanni P, Masulli M, Di llio C, De Laurenzi V. Bat-man disease transmission: Zoonotic pathogens from wildlife reservoirs to human populations. Cell Death Discovery 2016; 2: 16048. [CrossRef]

223. Turhan V. Histoplasmosis story from Tennessee, U.S.A. to Turkey. Mikrobiyoloji bulteni 2009; 43: 339-51.

224. Turhan U, Aydoğan M, Özkısa T, Karslıoğlu Y, Gümüş S. A Rare Case in Turkey: Pulmonary Histoplasmosis. Eurasian J Pulmonol 2016; 18: 116-8.

225. Dilek N, Saral Y, Yucel AY, Toraman ZA, Dilek AR. Firat Universitesi Hastanesi dermatoloji klinigi'ne basvuran hastalardaki dermatofitoz etkenleri. Turk Dermatoloji Derg 2009; 3: 27-31.

226. Illhan Z. Isolation of dermatophytes from cattle, sheep, goats and Van cats in Van and its around. Van Vet J 2015; 26: 1-5.

227. Gurcan S, Konuk E, Kilic H, Otkun M, Ener B. Sporotrichosis, a disease rarely reported from Turkey, and an overview of Turkish literature. Mycoses-Berlin 2007; 50: 426-9. [CrossRef]

228. Koc AN, Uksal U, Oymak O. Case Report. Successfully treated subcutaneous infection with Sporothrix schenckii in Turkey. MycosesBerlin 2001; 44: 330-3. [CrossRef]

229. Vanittanakom N, Cooper CR, Jr., Fisher MC, Sirisanthana T. Penicillium marneffei infection and recent advances in the epidemiology and molecular biology aspects. Clin Microbiol Rev 2006; 19 : 95-110. [CrossRef]

230. Seyedmousavi S, Guillot J, Tolooe A, Verweij PE, de Hoog GS. Neglected fungal zoonoses: hidden threats to man and animals. Eur J Clin Microbiol Infect Dis 2015; 21: 416-25. [CrossRef]

231. Ovet H. Denizli il merkezinde bulunan ilkogretim okullarının hava örneklerinde kuf mantarlarının araştırılması ve serumda alerjen spesifik lgE ölçümlerinin değerlendirilmesi (Uzmanlik Tezi). Denizli 2010.

232. Morris DO. Malassezia pachydermatis carriage in dog owners. Emergg Infect Dis 2005; 11: 83-8. [CrossRef]

233. Velegraki A, Cafarchia C, Gaitanis G, latta R, Boekhout T. Malassezia infections in humans and animals: Pathophysiology, detection, and treatment. PLoS Pathogens 2015; 11: e1004523.

234. Celik E, Ilkit M, Tanir F. Prevalence and causative agents of superficial mycoses in a textile factory in Adana, Turkey. Mycoses 2003; 46: 329-33. [CrossRef]

235. Gulec AT, Demirbilek M, Seckin D, Can F, Saray Y, Sarifakioglu E, et al. Superficial fungal infections in 102 renal transplant recipients: A case-control study. J Am Acad Dermatol 2003; 49: 187-92. [CrossRef]

236. Uremek H, Surucuoglu S, Turker M, Kipici A. The evaluation of pityriasis versicolor cases and the comparison of direct microscopy and culture. Turk J Infect 1997; 11: 67-9. 
237. Boisseau-Lebreuil M, Orhan V. First cases of adiaspiromycosis observed in small wild Mammals in Turkey. Three new host species. Bull Soc Pathol Exot 1985; 78: 31-6.

238. Bernard EM, Sepkowitz KA, Telzak EE, Armstrong D. Pneumocystosis. Med Clin North Am 1992; 76: 107-19. [CrossRef]

239. Singhal R, Mirdha BR, Guleria R. Human pneumocystosis. Indian J Chest Dis Allied Sci 2005; 47: 273-83.

240. Nevez G, Chabe M, Rabodonirina M, Virmaux M, Dei-Cas E, Hauser $\mathrm{PM}$, et al. Nosocomial Pneumocystis jirovecii infections. Parasite 2008; 15: 359-65. [CrossRef]

241. Aygen B, Sumerkan B, Inan M, Kandemir O, Doganay M, Ozesmi M, et al. Pneumocystis carinii pneumonia: Report of three cases. Mikrobiyoloji Bulteni 1994; 28: 385-91.

242. Alp E, Bozkurt I, Doganay M. Epidemiological and clinical characteristics of HIV/AIDS patients followed-up in Cappadocia region: 18 years experience. Mikrobiyoloji Bulteni 2011; 45: 125-36.

243. Yanik K, Karadag A, Usta E, Unal N, Yilmaz H, Hokelek M. Pneumocystis jirovecii pnomonisi şüphesi ile 2003-2011 yılları arasında Ondokuz Mayıs Üniversitesi Tip Fakültesi Parazitoloji Laboratuvarına gönderilen solunum yolu örneklerinde direkt floresans antikor test sonuçlarının değerlendirilmesi. Turk Mikrobiyol Cem Derg 2012; 42: 132-6. [CrossRef]

244. Didier ES, Stovall ME, Green LC, Brindley PJ, Sestak K, Didier PJ. Epidemiology of microsporidiosis: Sources and modes of transmission. Vet Parasitol 2004; 126: 145-66. [CrossRef]

245. Hamamci B, Cetinkaya U, Berk V, Kaynar L, Kuk S, Yazar S. Prevalence of Encephalitozoon intestinalis and Enterocytozoon bieneusi in cancer patients under chemotherapy. Mikrobiyoloji Bulteni 2015; 49: 105-13. [CrossRef]

246. Inci A, Yildirim A, Duzlu O, Onder Z, Ciloglu A. Kopeklerde Encephalitozoon cuniculi'nin molekuler prevalansi ve genetik karakterizasyonu. Erciyes Universitesi Bilimsel Arastirma Projesi (TSA2015-5742), 2016.

247. Pekmezci ZG. Senegal'den ithal edilen Senegal barbunu (Pseudupeneus prayensis), antenli mercan (Pagrus caeruleostictus) ve dülger balığında (Zeus faber) zoonoz Anisakis larvalarının varlığının tüketicilere olan riskinin ortaya konulması. 20. Ulusal Parazitoloji Kongresi (Uluslararası Katılımlı), 25-29 Eylül 2017, Eskişehir, ss, 381-2.

248. Johnson CK, Hitchens PL, Evans TS, Goldstein T, Thomas K, Clements $A$, et al. Spillover and pandemic properties of zoonotic viruses with high host plasticity. Scientific Reports 2015; 5: 14830. [CrossRef]

249. Venkatesan G, Balamuruga V, Gandhale PN, Singh RK, Bhanupraka V. Viral Zoonosis: A Comprehensive Review. Asian J Anim Vet 2010; 5: 77-92. [CrossRef]

250. Heeney JL. Zoonotic viral diseases and the frontier of early diagnosis, control and prevention. J Intern Med 2006; 260: 399-408. [CrossRef]

251. OIE. Manual of Diagnostic Tests and Vaccines for Terrestrial Animals Paris: OIE; 2016 Available from: http://www.oie.int/en/international-standard-setting/terrestrial-manual/access-online/

252. Buzgan T, Irmak H, Torunoglu MA, Yilmaz GR, Safran A. Epidemiology of human rabies in Turkey: 1992-2007. Turk J Med Sci 2009; 39: 591-7.

253. Kalaycioglu H, Korukluoglu G, Ozkul A, Oncul O, Tosun S, Karabay $O$, et al. Emergence of West Nile virus infections in humans in Turkey, 2010 to 2011. Euro Surveill 2012; 17: pii: 20182.

254. Ergunay K, Gunay F, Erisoz Kasap O, Oter K, Gargari S, Karaoglu T, et al. Serological, molecular and entomological surveillance demonstrates widespread circulation of West Nile virus in Turkey. PLoS Negl Trop Dis 2014; 8: e3028.

255. Yagci Caglayik D, Uyar Y, Korukluoglu G, Ertek M, Unal S. An imported Chikungunya fever case from New Delhi, India to Ankara, Turkey: the first imported case of Turkey and review of the literature. Mikrobiyoloji Bulteni 2012; 46: 122-8.

256. Ergunay K, Gunay F, Kar S, Oter K, Orsten S, Sarikaya Y, et al. First reporting of Chikungunya virus as well as West Nile virus and mosquito-specific flaviviruses in field-collected mosquitoes from Mediterranean, Aegean, and Thrace regions, Turkey. The 26th European Congress of Clinical Microbiology and Infectious Diseases (ECCMID); Amsterdam 2016.

257. Leblebicioglu H, Ozaras R, Irmak H, Sencan I. Crimean-Congo hemorrhagic fever in Turkey: Current status and future challenges. Antiviral Research 2016; 126: 21-34. [CrossRef]

258. Uyar Y, Aktas E, Yagci Caglayik D, Ergonul O, Yuce. An imported dengue Fever case in Turkey and review of the literature. Mikrobiyoloji Bulteni 2013; 47: 173-80. [CrossRef]

259. WHO., FAO., OIE. Report of the WHO/FAO/OIE joint consultation on emerging zoonotic diseases Geneva: WHO; 2004 (updated 3-5 May. Available from: http://apps.who.int/iris/bitstream/10665/68899/1/WHO_CDS_CPE_ZFK_2004.9.pdf.

260. Woolhouse ME, Haydon DT, Antia R. Emerging pathogens: The epidemiology and evolution of species jumps. Trends Ecol Evol 2005; 20: 238-44. [CrossRef]

261. Wang LF, Crameri G. Emerging zoonotic viral diseases. Rev Sci Tech Off Int Epiz 2014; 33: 569-81. [CrossRef]

262. Mohd HA, Al-Tawfiq JA, Memish ZA. Middle East Respiratory Syndrome Coronavirus (MERS-CoV) origin and animal reservoir. Virol J 2016; 13: 87. [CrossRef]

263. Anon. Middle East respiratory syndrome coronavirus (MERS-CoV): Summary of Current Situation, Literature Update and Risk Assessment-as of 5 February 20152017 Available from: http://www. who.int/csr/disease/coronavirus_infections/mers-5-february-2015. pdf.

264. Sarnic M. Avian influenza (kus gribi) hastaliginin Turk ekonomisi uzerine etkileri 2006 Available from: http://www.mfa.gov.tr/avian-influenza-_kus-gribi_-hastaliginin-turk-ekonomisi-uzerindeki-etkileri-. tr.mfa.

265. Oner AF, Bay A, Arslan S, Akdeniz H, Sahin HA, Cesur Y, et al. Avian influenza A (H5N1) infection in eastern Turkey in 2006. N Engl J Med 2006; 355: 2179-85. [CrossRef]

266. Gozalan A, Altas AB, Sevencan F, Akin L, Korukluoglu G, Kara S, et al. Seroprevalence following the first wave of pandemic influenza $A$ (H1N1) in Turkey, 2009. Jpn J Infect Dis 2012; 65: 13-8.

267. Ertek M, Buzgan T. An outbreak caused by hantavirus in the Black Sea region of Turkey, January-May 2009. Euro Surveill 2009; 14: pii: 19214.

268. Berk H, Öztoprak N. Hemorrhagic Fever with Renal Syndrome (Hantaviruses). Clin Microbiol Infect Dis 2014; 4.

269. Maral I, Budakoglu, II, Ceyhan MN, Atak A, Bumin MA. Hepatitis E virus seroepidemiology and its change during 1 year in primary school students in Ankara, Turkey. Eur J Clin Microbiol Infect Dis 2010; 16: 831-5. [CrossRef]

270. Cevahir N, Demir M, Bozkurt Al, Ergin A, Kaleli I. Seroprevalence of hepatitis e virus among primary school children. Pak J Med Sci 2013; 29: 629-32. [CrossRef]

271. Bayhan GI, Demioren K, Guducuoglu H. Epidemiology of hepatitis $\mathrm{E}$ virus in children in the province of Van, Turkey. Turk Pediatr Ars 2016; 51: 148-51. [CrossRef]

272. Gulen F, Cicek C, Kurugol Z, Demir E, Zeyrek D, Ozdemir R, et al. Parainfluenza type 3 outbreaks in Izmir children, Turkey. Trop Doc 2007; 37: 252-4. [CrossRef]

273. Cabalar M, Can-Sahna K. Doğu ve Guneydoğu bölgesinde süt sığırlarında Parainfluenza 3, Bovine Herpes Virus 1 ve Respiratory Syncytial Virus enfeksiyonlarının seroepidemiyolojisi. YYU Vet Fak Derg 2000; 11: 101-5. 
274. Manojkumar R, Mrudula V. Emerging viral disease of zoonotic Importance-Review. J Trop Med 2006; 1: 162-6.

275. White MK, Wollebo HS, David Beckham J, Tyler KL, Khalili K. Zika virus: An emergent neuropathological agent. Ann Neurol 2016; 80: 479-89. [CrossRef]

276. Greiser-Wilke I, Haas L. Emergence of "new" viral zoonoses. DTW Deutsche tierarztliche Wochenschrift 1999; 106: 332-8.

277. Newsom IE, Cross F. Sore Mouth in Sheep Transmissible to Man. J Am Vet Med Assoc 1934; 84: 799-802.

278. Bayindir Y, Bayraktar M, Karadag N, Ozcan H, Kayabas U, Otlu B, et al. Investigation and analysis of a human orf outbreak among people living on the same farm. New Microbiol 2011; 34: 37-43.

279. Midilli K, Erkilic A, Kuskucu M, Analay H, Erkilic S, Benzonana N, et al. Nosocomial outbreak of disseminated orf infection in a burn unit, Gaziantep, Turkey, October to December 2012. Euro Surveill 2013; 18: 20425. [CrossRef]

280. Karakas A, Oguzoglu TC, Coskun O, Artuk C, Mert G, Gul HC, et al. First molecular characterization of a Turkish orf virus strain from a human based on a partial B2L sequence. Arch Virol 2013; 158: 1105 8. [CrossRef]

281. Bayhan Gl, Tanir G, Gurkan A. Orf Disease in a Child. J Pediatr Dis 2014; 4: 271-3. [CrossRef]

282. Coetzer JAW, Guthrie AJ. African horse sickness. In Infectious Diseases of Livestock. In: Coetzer JAW, Tustin RC, editors. Cape Town: Oxford University Press Southern Africa 2004. pp. 1231-46.

283. Quan M. African Horse Sickness 2017. Available from: http://www. afrivip.org/sites/default/files/african_horse_sickness_complete.pdf.

284. Maclachlan NJ, Guthrie AJ. Re-emergence of bluetongue, African horse sickness, and other orbivirus diseases. Vet Res 2010; 41: 35. [CrossRef]

285. Wilson AJ, Mellor PS. Bluetongue in Europe: Past, present and future. Philosophical transactions of the Royal Society of London Series B. Biological Sciences 2009; 364: 2669-81. [CrossRef]

286. Ozturk F, Yavru S, Eroz S. The serological survey on Bluetongue virus infection in sheep. Eurasian J Vet Sci 1990; 6-7: 37-40.

287. Hatalski CG, Lewis AJ, Lipkin WI. Borna Disease. Emerg Infect Dis 1997; 3: 129-35. [CrossRef]

288. De La Torre JC, Gonzalez-Dunia D, Cubitt B, Mallory M, MuellerLantzsch N, Grasser FA, et al. Detection of borna disease virus antigen and RNA in human autopsy brain samples from neuropsychiatric patients. Virology 1996; 223: 272-82. [CrossRef]

289. Yilmaz H, Helps CR, Turan N, Uysal A, Harbour DA. Detection of antibodies to Borna disease virus (BDV) in Turkish horse sera using recombinant p40. Brief report. Arch Virol 2002; 147: 429-35. [CrossRef]

290. Yesilbag K, Herzog S, Kennerman E, Tuncer P, Schmid S, Kaya G, et al. Serological evidence for infections with Borna disease virus in Turkey. Berliner und Munchener tierarztliche Wochenschrift 2012; 125: 452-5.

291. Bannasch MJ, Foley JE. Epidemiologic evaluation of multiple respiratory pathogens in cats in animal shelters. J Feline Med Surg 2005; 7: 109-19. [CrossRef]

292. Dokuzeylül B, Kayar A, Or ME. Prevalence of systemic disorders in cats with oral lesions. Vet Med 2016; 61: 219-23. [CrossRef]

293. Arzt J, Baxt B, Grubman MJ, Jackson T, Juleff N, Rhyan J, et al. The pathogenesis of foot-and-mouth disease II: Viral pathways in swine, small ruminants, and wildlife; myotropism, chronic syndromes, and molecular virus-host interactions. Transbound Emerg Dis 2011; 58: 305-26. [CrossRef]

294. Prempeh H, Smith R, Muller B. Foot and mouth disease: The human consequences. The health consequences are slight, the economic ones huge. BMJ 2001; 322: 565-6. [CrossRef]

295. Parlak U, Ozyoruk F, Knowles NJ, Armstrong RM, Aktas S, Alkan F, et al. Characterisation of foot-and-mouth disease virus strains circu- lating in Turkey during 1996-2004. Arch Virol 2007; 152: 1175-85. [CrossRef]

296. Akkoyunlu Y, Ceylan B, Aslan T. Hand, foot, and mouth disease in an adult. Braz J Infect Dis 2014; 18: 227-8. [CrossRef]

297. Anon. List of FMD free member countries 2015. Available from: http://www.oie.int/fileadmin/Home/eng/Animal_Health_in_the_ World/map/A_Turkey.jpg.

298. Gould EA. Louping ill, sheep. Service MW, editor. UK: CABI Publishing; 2006. p. 517

299. Alexander DJ. Newcastle disease and other avian paramyxoviruses. Rev Sci Tech 2000; 19: 443-62. [CrossRef]

300. Akman A. Türkiye'de Newcastle hastaligi izleme programi 2015. Available from: http://docplayer.biz.tr/40537167-Turkiye-de-newcastle-hastaligi-izleme-programi.html.

301. Ngan V. Cowpox 2008. Available from: http://www.dermnetnz.org/ topics/cowpox/.

302. Ninove L, Domart Y, Vervel C, Voinot C, Salez N, Raoult D, et al. Cowpox virus transmission from pet rats to humans, France. Emerg Infect Dis 2009; 15: 781-4. [CrossRef]

303. Kallio-Kokko H, Uzcategui N, Vapalahti O, Vaheri A. Viral zoonoses in Europe. FEMS Microbiol Rev 2005; 29: 1051-77. [CrossRef]

304. Black W, Walburger MT, Baker R, Ostertag-Hill C, Reed A, Whipple $M$, et al. Identification of Pseudocowpox virus in Angus bull with failure to breed. Austin Virol Retro Virol 2014; 1: 1-5.

305. Oguzoglu TC, Koc BT, Kirdeci A, Tan MT. Evidence of zoonotic pseudocowpox virus infection from a cattle in Turkey. Virus Dis 2014 25: 381-4. [CrossRef]

306. Holmes P, Richey M, Mclnnes C, Wood A, Schock A, Wilson E, et al. Zoonotic transmission of bovine papular stomatitis virus. Vet Rec 2011; 169: 235-6. [CrossRef]

307. de Sant'Ana FJ, Rabelo RE, Vulcani VA, Cargnelutti JF, Flores EF. Bovine papular stomatitis affecting dairy cows and milkers in midwestern Brazil. J Vet Diagn Invest 2012; 24: 442-5. [CrossRef]

308. Senturk S, Catik S, Temizel E, Ozyight O. Outbreak of bovine papular stomatitis with concurrent cryptosporidiosis in a dairy herd in Turkey. BJVM 2016; 19: 78-83. [CrossRef]

309. Doro R, Farkas SL, Martella V, Banyai K. Zoonotic transmission of rotavirus: Surveillance and control. Expert Rev Anti Infect Ther 2015; 13: 1337-50. [CrossRef]

310. Heaton PM, Ciarlet M. The Pentavalent Rotavirus Vaccine: Discovery to Licensure and Beyond. Clin Infect Dis 2007; 45: 1618-24. [CrossRef]

311. Luchs A, Timenetsky Mdo C. Group A rotavirus gastroenteritis: post-vaccine era, genotypes and zoonotic transmission. Einstein 2016; 14: 278-87. [CrossRef]

312. Bozdayi G, Dogan B, Dalgic B, Bostanci I, Sari S, Battaloglu NO, et al. Diversity of human rotavirus G9 among children in Turkey. J Med Virol 2008; 80: 733-40. [CrossRef]

313. Rydell GE, Sahlgrenska akademin vid Göteborgs u. Norovirus, causative agent of winter vomiting disease, exploits several histo-blood group glycans for adhesion. Göteborg: Institute of Biomedicine, Department of Clinical Chemistry and Transfusion Medicine, University of Gothenburg; 2009

314. Erol N, Delibas SB, Ozkoc S, Erguden C, Aksoy UC. Investigation of parasitic and viral pathogens in mussels (Mytilus galloprovincialis) in the Gulf of Izmir, Turkey. Saudi Med J 2016; 37: 703-6. [CrossRef]

315. Yılmaz A, Bostan K, Altan E, Muratoglu K, Turan N, Tan D, et al. Investigations on the frequency of norovirus contamination of ready-to-eat food items in Istanbul, Turkey, by using real-time reverse transcription PCR. J Food Prot 2011; 74: 840-3. [CrossRef]

316. Sezen F, Aval E, Agkurt T, Yilmaz S, Temel F, Gulesen R, et al. A large multi-pathogen gastroenteritis outbreak caused by drinking contaminated water from antique neighbourhood fountains, Erzurum 
city, Turkey, December 2012. Epidemiol Infect 2015; 143: 704-10. [CrossRef]

317. Yilmaz H, Turan N, Altan E, Bostan K, Yilmaz A, Helps CR, et al. First report on the phylogeny of bovine norovirus in Turkey. Arch Virol 2011; 156: 143-7. [CrossRef]

318. Jeong HS, Jeong A, Cheon DS. Epidemiology of astrovirus infection in children. Korean J Pediatr 2012; 55: 77-82. [CrossRef]

319. Greger $M$. The human/animal interface: emergence and resurgence of zoonotic infectious diseases. Crit Rev Microbiol 2007; 33: 243-99. [CrossRef]

320. Bastone P, Truyen $U$, Lochelt M. Potential of zoonotic transmission of non-primate foamy viruses to humans. J Vet Med B Infect Dis Vet Public Health 2003; 50: 417-23. [CrossRef]

321. Wang J, Selleck P, Yu M, Ha W, Rootes C, Gales R, et al. Novel phlebovirus with zoonotic potential isolated from ticks, Australia. Emerg Infect Dis 2014; 20: 1040-3. [CrossRef]

322. Ausvetplan. Disease Strategy Lumpy skin disease 2009. Available from: http://www.oie.int/fileadmin/Home/eng/Animal_Health_in_ the_World/docs/pdf/LSD3_0-12FINAL_27Jan09_.pdf.

323. OIE. Lumpy skin disease aetiology epidemiology diagnosis prevention and control 2013. Available from: http://www.oie.int/fileadmin/ Home/eng/Animal_Health_in_the_World/docs/pdf/

324. Anon. Scientific Opinion on lumpy skin disease. EFSA 2015; 13 : 3986. [CrossRef]

325. Baechlein C, Fischer N, Grundhoff A, Alawi M, Indenbirken D, Postel $A$, et al. Identification of a Novel Hepacivirus in Domestic Cattle from Germany. J Virol 2015; 89: 7007-15. [CrossRef]

326. Anggakusuma, Brown RJ, Banda DH, Todt D, Vieyres G, Steinmann E, et al. Hepacivirus NS3/4A Proteases Interfere with MAVS Signaling in both Their Cognate Animal Hosts and Humans: Implications for Zoonotic Transmission. J Virol 2016; 90: 10670-81. [CrossRef]

327. Thomas DL, Mahley RW, Badur S, Palaoglu E, Quinn TC. The epidemiology of hepatitis $C$ in Turkey. Infection 1994; 22: 411-4. [CrossRef]

328. Bouloy M. Molecular biology of phleboviruses. In: Plyusnin A, Elliott RM, editors. Bunyaviridae: molecular and cellular biology. Norfolk, UK: Caister Academic Press; 2011. pp. 95-128.

329. Tuppurainen ES, Stoltsz WH, Troskie M, Wallace DB, Oura CA, Mellor PS, et al. A potential role for ixodid (hard) tick vectors in the transmission of lumpy skin disease virus in cattle. Transbound Emerg Dis 2011; 58: 93-104. [CrossRef]

330. Inci A, Yıldırım A, Duzlu O. Three emerging vector-borne diseases in Turkey. Erü Vet Fak Derg 2014; 11: 117-20.

331. Öner EB, Yeșilbağ K. Lumpy skin disease: some epidemiological datas related to the first outbreak in Turkey. Uludag Vet Fak Derg 2015; 34: 41-52.

332. Sariözkan S, Yalçin C. Estimating the total cost of bovine fasciolosis in Turkey. Ann Trop Med Parasitol 2011; 105: 439-44. [CrossRef]

333. Mas-Coma MS, Esteban JG, Bargues MD. Epidemiology of human fascioliasis: A review and proposed new classification. Bull World Health Organ 1999; 77: 340-6.

334. Saba R, Korkmaz M, Inan D, Mamikoglu L, Turhan O, Gunseren F, et al. Human fascioliasis. Clin Microbiol Infect 2004; 10: 385-7. [CrossRef]

335. Cengiz ZT, Yilmaz H, Dulger AC, Akdeniz H, Karahocagil MK, Cicek M. Seroprevalence of human fascioliasis in Van province, Turkey. Turk J Gastroenterol 2015; 26: 259-62. [CrossRef]

336. Cengiz ZT, Yilmaz H, Dulger AC, Cicek M. Human infection with Dicrocoelium dendriticum in Turkey. Ann Saudi Med 2010; 30: 15961. [CrossRef]

337. PAHO., WHO. Report: PAHO/WHO Preparatory Meeting on Epidemiological Data Needed to Plan Elimination of Schistosomiasis in the Caribbean Grenada 2007. Available from:http://www1.paho. org/hq/dmdocuments/2010/Report-of-Schistosomiasis-Eliminati on-in-the-Caribbean-Grenada-2007.pdf.
338. Uysal HK, Akgul O, Aliyev E, Tunc MH, Oner YA. A rare case of urinary schistosomiasis in Turkey. Travel Med Infect Dis 2014; 12: 283-5. [CrossRef]

339. Dhaliwal BBS, Juyal PD. Cestode Zoonoses. Parasitic Zoonoses. New Delhi: Springer India; 2013. pp. 65-82.

340. Şimşek S. Türkiye'de kistik echinococcosis: Epidemiyoloji, genotipik çeşitlilik ve veteriner halk sağlığı üzerindeki etkiler. 19 Ulusal Parazitoloji Kongresi ve Uluslarasi Katilimli Ekinokokkozis sempozyumu; 2015 5-9 Ekim; Erzurum, s.7.

341. Öztürk G. Karaciğer alveolar kistlerinin tedavisi. 19 Ulusal Parazitoloji Kongresi ve Uluslararasi katilimli ekinokokkozis sempozyumu; 2015 5-9 Ekim; Erzurum.

342. Oral A. Kuzey Doğu Anadolu bölgesinde hidatik kist bulunan çocuk hastalardaki cerrahi yaklaşimlar ve edinilen tecrübeler. 19 Ulusal Parazitoloji Kongresi ve Uluslararasi Katilimli Ekinokokkozis Sempozyumu; 2015 5-9 Ekim; Erzurum.

343. Balik AA, Basoglu M, Celebi F, Oren D, Polat KY, Atamanalp SS, et al. Surgical treatment of hydatid disease of the liver: review of 304 cases. Arch Surg 1999; 134: 166-9. [CrossRef]

344. Oral A, Yigiter M, Yildiz A, Yalcin O, Dikmen T, Eren S, et al. Diagnosis and management of hydatid liver disease in children: a report of 156 patients with hydatid disease. J Pediatr Surg 2012; 47: 528-34. [CrossRef]

345. Kantarci M, Pirimoglu B, Aydinli B, Ozturk G. A rare reason for liver transplantation: Hepatic alveoloar echinococcosis. Transpl Infect Dis 2014; 16: 450-2. [CrossRef]

346. Keser SH, Selek A, Ece D, Barisik CC, Sensu S, Gecmen GG, et al. Review of Hydatid Cyst with Focus on Cases with Unusual Locations. Turk Patol Derg 2017; 33: 30-6.

347. Laranjo-Gonzalez M, Devleesschauwer B, Gabriel S, Dorny P, Allepuz A. Epidemiology, impact and control of bovine cysticercosis in Europe: A systematic review. Parasit Vector 2016; 9: 81. [CrossRef]

348. Kus FS, Sevimli FK, Miman O. Cysticercus bovis in slaughtered cattle in the Afyonkarahisar and Burdur provinces and its importance from the point of view of public health. Turkiye Parazitol Derg 2013; 37: 262-8. [CrossRef]

349. Abera S, Wubit T, Nejash A. Cerebral Coenurosis in Small Ruminants: A Review. J Anim Sci Adv 2016; 6: 1595-608. [CrossRef]

350. Gicik Y, Kara M, Arslan MO. Prevalence of Coenurus cerebralis in sheep in Kars province, Turkey. Bull Vet Inst Pulawy 2007; 51: 37982. [CrossRef]

351. Avcioglu H, Yildirim A, Duzlu O, Inci A, Terim KA, Balkaya I. Prevalence and molecular characterization of bovine coenurosis from Eastern Anatolian region of Turkey. Vet Parasitol 2011; 176: 59-64.

352. Kozan E, Sevimli FK, Birdane FM. The occurrence of gastrointestinal cestode and nematode infections in stray dogs in Afyonkarahisar and Eskisehir provinces. Turkiye Parazitol Derg 2007; 31: 208-11.

353. Yildirim A, Ica A, Duzlu O, Yavuz A, Inci A. The prevalence of gastrointestinal helminths in dogs by coprological examination in Kayseri province. J Fac Vet Med Univ Erciyes 2007; 4: 65-71.

354. Feachem RG. Sanitation and disease: Health aspects of excreta and wastewater management. Chichester u.a.: Wiley; 1983.

355. Sadaf HS, Khan SS, Kanwal N, Tasawer BM. A Review On Diarrhoea Causing Hymenolepis nana-Dwarf Tapeworm. IRJP 2013; 4: 32-5.

356. Kilincel O, Ozturk CE, Gun E, Oksuz S, Uzun H, Sahin I, et al. A rare case of Hymenolepis diminuta infection in a small child. Mikrobiyoloji Bulteni 2015; 49: 135-8. [CrossRef]

357. Selver MM, Beyazit A. Izmir'de bir köpekte mezenterial larval cestodiosis olgusu. Turkiye Parazitol Derg 2013; 37: 292-4.

358. Tigin Y. The first case report on the occurrence of Angiostrongylus vasorum Baillet, 1866 infection in a dog. Ankara Univ Vet Fak Derg 1972; 19: 76-84. 
359. Ulukanligil M. The results of a control program carried out on school children for intestinal parasites in Sanliurfa province, Turkey between the years of 2001 and 2005. Turkiye Parazitol Derg 2006; 30: 39-45.

360. Anon. Zoonotic Hookworms: The Center for Food Security and Public Health, lowa State University; 2013. Available from: http://www.cfsph. iastate.edu/Diseaselnfo/disease .php?name=hookworms.

361. Bozkurt O, Yildirim A, Inci A, Ciloglu A, Bişkin Z, Duzlu O. Investigation of Contamination with Ascarid Species by Parasitological and Molecular Techniques in Playgrounds in Parks of Kayseri Province. Kafkas Univ Vet Fak Derg 2012; 18: A175-80.

362. Yavuzer K, Ak M, Karadag AS. A Case Report of Cutaneous Larva Migrans. Eurasian J Med 2010; 42: 40-1. [CrossRef]

363. Otkun M, Karabay O, Tugrul M, Karakurt S. A case of Dirofilaria conjunctivae in the scalp and a brief review of Turkish literature. Turkiye Parazitol Derg 1997; 21: 149-52.

364. Kutlutürk I, Tamer GZS, Karabaş L, Erbesler AN, Yazar S. A rapidly emerging ocular zoonosis; Dirofilaria repens. Eye 2016; 30: 639-41. [CrossRef]

365. Cengiz N, Savas L, Uslu Y, Anarat A. Filariasis in a child from southern Turkey: A case report. Turk J Pediatr 2006; 48: 152-4.

366. Aktas E, Taslidere N, Canoz O. Dapson tedavisine tam yanit alinan eozinofilik pannikülit; Olgu sunumu. Turk Dermatoloji Derg 2010; 4: 94-6. [CrossRef]

367. Alibasoglu M, Goksu K, Erturk E, Guler S. Türkiye'de sığırlarda görülen onchocercosis olayları (Onchocerca armillata Railliet ve Henry, 1909). Ankara Univ Vet Fak Derg 1969; 16: 50-60.

368. Otranto D, Sakru N, Testini G, Gurlu VP, Yakar K, Lia RP, et al. Case report: First evidence of human zoonotic infection by Onchocerca lupi (Spirurida, Onchocercidae). Am J Trop Med Hyg 2011; 84: 55-8. [CrossRef]

369. Ilhan HD, Yaman A, Morishima Y, Sugiyama H, Muto M, Yamasaki H, et al. Onchocerca lupi infection in Turkey: $A$ unique case of a rare human parasite. Acta Parasitol 2013; 58: 384-8. [CrossRef]

370. Singh S. Human strongyloidiasis in AIDS era: its zoonotic importance. J Assoc Physicians India 2002; 50: 415-22.

371. Ozturk G, Aydinli B, Celebi F, Gursan N. Gastric perforation caused by Strongyloides stercoralis: a case report. TJTES 2011; 17: 90-2.

372. Umur S, Bolukbas CS, Gurler AT, Acici M, Meral Y. First clinical Strongyloides stercoralis case in a dog in Turkey. Turk J Vet Anim Sci 2017; 41: 312-5. [CrossRef]

373. Ecevit C, Bag O, Vergin C, Ozturk A. Visceral larva migrans presenting with hypereosinophilia. Turkiye Parazitol Derg 2013; 37: 58-60. [CrossRef]

374. Nazli B, Inal T. The occurrence of Trichinella spiralis in domestic and wild pigs and in prepared pork products in Turkey. Berl Munch Tierarztl Wochenschr 1987; 100: 187-90.

375. Ozdemir D, Ozkan H, Akkoc N, Onen F, Gurler O, Sari I, et al. Acute trichinellosis in children compared with adults. Pediatr Infect Dis J 2005; 24: 897-900. [CrossRef]

376. Turk M, Kaptan F, Turker N, Korkmaz M, El S, Ozkaya D, et al. Clinical and laboratory aspects of a trichinellosis outbreak in Izmir, Turkey. Parasite 2006; 13: 65-70. [CrossRef]

377. Akkoc N, Kuruuzum Z, Akar S, Yuce A, Onen F, Yapar N, et al. A large-scale outbreak of trichinellosis caused by Trichinella britovi in Turkey. Zoo Pub Health 2009; 56: 65-70. [CrossRef]

378. Heper Y, Yilmaztepe F, Komitova R, Akalin H, Vutova K, Helvaci S. A trichinosis outbreak caused by wild boar meat in Turkey. Parasite 2005; 12: 191-2. [CrossRef]

379. Kuvat SV, Aydin A, Tuncer S, Kesim SN, Arinci A, Kabakas F, et al. Comparison of different prophylaxis methods to prevent infections in leech using: Preliminary report. ANKEM Derg 2006; 20: 76-80.

380. Al-Khleif A, Roth M, Menge C, Heuser J, Baljer G, Herbst W. Tenacity of mammalian viruses in the gut of leeches fed with porcine blood. J Med Microbiol 2011; 60: 787-92. [CrossRef]
381. Litwinowicz A, Blaszkowska J. Preventing Infective Complications following Leech Therapy: Elimination of Symbiotic Aeromonas spp. from the Intestine of Hirudo verbana Using Antibiotic Feeding. Surg Infect 2014; 15: 757-62. [CrossRef]

382. Michalsen A, Roth M, Dobos G, Aurich M. The Biology of Leeches. Stuttgart; New York: Thieme; 2011.

383. Arslan N, Oktener A. A general review of parasitic Annelida (Hirudinea) recorded from different habitats and hosts in Turkey. Turk J Zool 2012; 36: 141-5

384. Lok U, Bozkurt S, Okur M, Gulacti U, Hatipoglu S. A rare case of adverse effects caused by leech bite. Am J Case Rep 2013; 14: 191 3. [CrossRef]

385. Kantekin Y, Sari K, Ozkiris M, Kapusuz Gencer Z. An Unusual Cause of Bleeding on the Floor of Mouth: Leech Infestation. Turkiye Parazitol Derg 2015; 39: 323-5. [CrossRef]

386. Anon. Leishmaniasis (Cutaneous and Visceral): The Center for Food Security and Public Health, lowa state University; 2009. Available from: http://www.cfsph.iastate.edu/Factsheets/pdfs/leishmaniasis.pdf

387. Karakus M, Nasereddin A, Onay H, Karaca E, Ozkeklikci A, Jaffe CL, et al. Epidemiological analysis of Leishmania tropica strains and giemsa-stained smears from Syrian and Turkish leishmaniasis patients using multilocus microsatellite typing (MLMT). PLoS Negl Trop Dis 2017; 11: e0005538.

388. Ozkeklikci A, Karakus M, Ozbel Y, Toz S. The new situation of cutaneous leishmaniasis after Syrian civil war in Gaziantep city, Southeastern region of Turkey. Acta Trop 2017; 166: 35-8. [CrossRef]

389. Webster JP. Review of "Toxoplasmosis of Animals and Humans (Second Edition)" by J.P. Dubey. Parasit Vectors 2010; 3: 112.

390. Lehmann T, Marcet PL, Graham DH, Dahl ER, Dubey JP. Globalization and the population structure of Toxoplasma gondii. Proc Natl Acad Sci U S A 2006; 103: 11423-8. [CrossRef]

391. Inci A, Babur C, Dincer S. Investigation of anti-Toxoplasma gondi antibodies in cats using Sabin-Feldman dye test in Ankara. Turkiye Parazitol Derg 1996; 3-4: 407-11.

392. Inci A, Babur C, Kalinbacak A. Investigation of anti-Toxoplasma gondii antibodies using Sabin-Feldman dye test in dogs in a military farm in Gemlik. Turkiye Parazitol Derg 1996; 3-4: 413-6.

393. Inci A, Babur C, Karaer Z. Detection of anti-Toxoplasma gondii antibodies using Sabin-Feldman dye test in horses in a military farm in Gemlik. Turkiye Parazitol Derg 1996; 3-4: 417-9.

394. Babur C, Inci A, Karaer Z. Detection on seropositivity of Toxoplasma gondii in sheep and goats around Cankiri using Sabin-Feldman dye test. Turkiye Parazitol Derg 1997; 21: 409-12.

395. Inci A, Babur C, Dincer S, Erdal N. Detection of anti-Toxoplasma gondii antibodies using Sabin-Feldman dye test in domestic fowls in some provinces in Turkey. Turkiye Parazitol Derg 1998; 4: 420-3.

396. Inci A, Babur C, Cam Y, Ica A. Investigation of seropositivity of Toxoplasma gondii (Nicolle Ve Manceaux, 1908) in some prey birds by Sabin-Feldman dye test in Kayseri region. F U Sag Bil Derg 2002; 2: 177-9.

397. Saygi G. The epidemiology of toxoplasmosis in Turkey-A review of the literature. Wiad Parazytol 2001; 47: 19-30.

398. Fayer R, Esposito DH, Dubey JP. Human Infections with Sarcocystis Species. Clin Microbiol Rev 2015; 28: 295-311. [CrossRef]

399. Saki CE, Deger S, Ozer E. Türkiye'de Sarcosporidiosis. YYU Vet Fak Derg 2010; 21: 129-34.

400. Minetti C, Chalmers RM, Beeching NJ, Probert C, Lamden K. Giardiasis. BMJ 2016; 355: i5369.

401. Xiao L, Fayer R. Molecular characterisation of species and genotypes of Cryptosporidium and Giardia and assessment of zoonotic transmission. Int J Parasitol 2008; 38: 1239-55. [CrossRef]

402. Feng Y, Xiao L. Zoonotic potential and molecular epidemiology of Giardia species and giardiasis. Clin Microbiol Rev 2011; 24: 110-40. [CrossRef] 
403. Heyworth MF. Giardia duodenalis genetic assemblages and hosts. Parasite 2016; 23: 13. [CrossRef]

404. Ehsan AM, Geurden T, Casaert S, Parvin SM, Islam TM, Ahmed UM, et al. Assessment of zoonotic transmission of Giardia and Cryptosporidium between cattle and humans in rural villages in Bangladesh. PloS One 2015; 10: e0118239.

405. Ozmen O, Yukari BA, Haligur M, Sahinduran S. Observations and immunohistochemical detection of Coronavirus, Cryptosporidium parvum and Giardia intestinalis in neonatal diarrhoea in lambs and kids. Schweiz Arch Tierheilkd 2006; 148: 357-64. [CrossRef]

406. Bayraktar MR, Mehmet N, Durmaz R. Serum cytokine changes in Turkish children infected with Giardia lamblia with and without allergy: Effect of metronidazole treatment. Acta Trop 2005; 95: 116-22. [CrossRef]

407. Unver A, Oyur T, Kurt O, Toz SO, Turgay N. E.histolytica/dispar Cases Diagnosed in Ege University Medical Faculty Parasitology Outpatient Clinic Between January 2010 to June 2011. Kafkas Univ Vet Fak Derg 2012; 18(Suppl-A): A201-4.

408. Kurt O, Aktas N, Caliskan C, Karatuna O, Aygun H, Akyar I. Amoebic liver abscess in a patient initially diagnosed with pneumonia: case report and discussion of relevant literature. Turkiye Parazitol Derg 2015; 39: 70-4. [CrossRef]

409. Ghazy AA, Shafy SA, Shaapan RM. Cryptosporidiosis in Animals and Man: 1. Taxonomic Classification, Life Cycle, Epidemiology and Zoonotic Importance. Asian J Epidemiol 2015; 8: 48-63. [CrossRef]

410. Leitch GJ, He Q. Cryptosporidiosis-an overview. Biomed Res Int 2012; 25: 1-16.

411. Simsek AT, Inci A, Yildirim A, Ciloglu A, Biskin Z, Duzlu O. Detection of cryptosporidiosis in diarrhoeic neonatal calves in Nevsehir district by Real Time PCR and Nested PCR techniques. J Fac Vet Med Univ Erciyes 2012; 9: 79-87.

412. Yildirim A, Adanir R, Inci A, Yukari BA, Duzlu O, Ciloglu A, et al. Burdur yöresindeki sığırlarda cryptosporidiosis'in Real Time PCR yöntemi ile araştııılması ve cryptosporidium izolatlarının moleküler karakterizasyonu. 18 Ulusal Parazitoloji Kongresi; Eylül 5-Ekim 29; Denizli,Türkiye 2013. p. 149.

413. Yildirim A, Sevinc F, Inci A, Derinbay EO, Duzlu O, Isik N, et al. Molecular characterization of Cryptosporidium Isolates from calves with diarrhea in Konya Province. 2nd International Meeting on Apicomplexan Parasites in Farm Animals; 31 October-2 November; Kusadasi, Turkiye 2013. p. 75.

414. Fredricks DN, Jolley JA, Lepp PW, Kosek JC, Relman DA. Rhinosporidium seeberi: a human pathogen from a novel group of aquatic protistan parasites. Emerg Infect Dis 2000; 6: 273-82. [CrossRef]

415. Silva V, Pereira CN, Ajello L, Mendoza L. Molecular evidence for multiple host-specific strains in the genus Rhinosporidium. J Clin Microbiol 2005; 43: 1865-8. [CrossRef]

416. Prakash M, Johnny JC. Rhinosporidiosis and the pond. J Pharm Bioallied Sci 2015; 7(Suppl 1): S59-62.

417. Agirdir BV, Derin AT, Ozbilim G, Akman A. Cutaneous rhinosporidiosis presents with recurrent nasal philtrum mass in southern Turkey. Int J Dermatol 2008; 47: 700-3. [CrossRef]

418. Jeffery GM. Human Coccidiosis in South Carolina. J Parasitol 1956; 42: 491-5. [CrossRef]

419. Balcioglu IC, Kose S, Kayran E, Limoncu ME, Kurt O, Ozbilgin A. Isosporiasis in an immunocomppetent child: case report. Turkiye Parazitol Derg 2007; 31: 27

420. Cengiz ZT, Yilmaz H, Cicek M, Beyhan YE, Dulger AC. Cystoisospora sp. Infection Determined in Immunosuppressed and Immunocompetent Children: Three Cases Report. Turkiye Parazitol Derg 2016; 40: 107-9. [CrossRef]

421. Inci A, Kilic E, Canhilal R. Entomopathogens in control of urban pests. Ankara Univ Vet Fak Derg 2014; 61: 155-60.
422. Goddard J, Zhou L. Physician's Guide to Arthropods of Medical Importance, 5th Edition. Emerg Infec Dis 2007; 13: 1442. [CrossRef]

423. Robinson WH. Urban insects and arachnids Cambridge: Cambridge University Press; 2005.

424. Oguz B, Ozdal N, Deger MS, Orunc Kilinc O. Türkiyede Blattella germanica'nin vektörlük potansiyeli üzerine ilk araştırma. Ankara Univ Vet Fak Derg 2017; 64: 141-4.

425. Hood M. Handbook of small hive beetle IPM. Clemson, S.C.: Clemson University, Cooperative Extension Service; 2011.

426. Sullivan GT, Baxter G, Ozman-Sullivan SK, Lumaret JP, Zalucki MP, Zeybekoglu U. Dung beetles (Coleoptera: Scarabaeidae) utilizing water buffalo dung on the Black Sea coast of Turkey. Turk J Zool 2016; 40: 80-6. [CrossRef]

427. Hall RD, Gerhardt RR. Medical and veterinary entomology. Mullen G, Durden LA, editors. Amsterdam: AP; 2009.

428. Merdivenci A. Türkiye sivrisinekleri: Yurdumuzda varligi bilinen sivrisineklerin biyo-morfolojisi, biyo-ekolojisi, yayilisi ve saglik önemleri. Istanbul: IU Cerrahpasa Tip Fak.; 1984.

429. Yildirim A, Inci A, Duzlu O, Biskin Z, Ica A, Sahin I. Aedes vexans and Culex pipiens as the potential vectors of Dirofilaria immitis in Central Turkey. Vet Parasitol 2011; 178: 143-7. [CrossRef]

430. Sahingoz Demirpolat G. Investigation of Culex pipiens biotypes and Culex torrentium by real-time pcr in Kayseri region and molecular characterization of the isolates (Yüksek Lisans): Erciyes Üniversitesi; 2016.

431. Inci A, Yildirim A, Njabo KY, Duzlu O, Biskin Z, Ciloglu A. Detection and molecular characterization of avian Plasmodium from mosquitoes in central Turkey. Vet Parasitol 2012; 188: 179-84. [CrossRef]

432. Adler PH, Inci A, Yildirim A, Duzlu O, McCreadie JW, Kúdela M, et al. Are black flies of the subgenus Wilhelmia (Diptera: Simuliidae) multiple species or a single geographical generalist? Insights from the macrogenome. Biol J Linnean Soc 2015; 114: 163-83. [CrossRef]

433. Adler PH, Yildirim A, Onder Z, Tasci GT, Duzlu O, Arslan MO, et al. Rearrangement hotspots in the sex chromosome of the Palearctic black fly Simulium bergi (Diptera, Simuliidae). Comp Cytogenet 2016; 10: 295-310. [CrossRef]

434. Adler PH, McCreadie JW. Black flies (Simuliidae). Mullen GR, Durden LA, editors. Amsterdam, Boston, Heidelberg, London, New York, Oxford, Paris, San Diego, San Francisco, Singapore, Sydney, Tokyo: Academic Press; 2009.

435. Inci A, Yildirim A, Duzlu O, Onder Z, Ciloglu A, Seitz G, et al. Genetic Diversity and Identification of Palearctic Black Flies in the Subgenus Wilhelmia (Diptera: Simuliidae). J Med Entomol 2017; 54: 888-94. [CrossRef]

436. Onder Z, Inci A, Arslan MO, Yildirim A, Adler PH, Sari B, et al. Kuzey Dogu Anadolu yoresinde Simulium türlerinin DNA barkodlamasi ve filogenetik klasifikasyonlari. ERU Bilimsel Arastirma Projeleri (BAP) TSA-2015-6011, 2015.

437. Inci A, Yildirim A, Duzlu O. Orta Kızılırmak Havzasında sorun oluşturan karasinek (Diptera: Simuliidae) türlerinin moleküler klasifikasyonu ve vektörlük potansiyellerinin real time PCR ile araştırılması. TUBITAK Projesi, 1110426, Kayseri, 2014.

438. Arslan MO, Temur A. Simuliidlerin hayvan ve insan sagligi uzerine etkileri ve simulotoksikozis olgulari. 19 Ulusal Parazitoloji Kongresi ve Uluslararasi Katilimli Ekinokokozis Sempozyumu; 5-9 Ekim; Erzurum 2015. p. 23-6.

439. Mullen GR. Biting midges. In: Mullen GR, Durden LA, editors. Medical and veterinary entomology. Amsterdam; Boston, Heidelberg, London, New York, Oxford, Paris, San Diego, San Francisco, Singapore, Sydney, Tokyo: Elsevier ; Academic Press; 2009. p. 169-88.

440. Dik B, Yagci S, Linton YM. A review of species diversity and distribution of Culicoides Latreille, 1809 (Diptera: Ceratopogonidae) in Turkey. J Nat Hist 2006; 40: 1947-67. [CrossRef] 
441. Inci A, Yildirim A, Dik B, Duzlu O, Gursoy Ergen A. Sultan sazlığı ekosisteminde kanatlı haemosporidianlarının moleküler ekolojisi. TUBITAK PROJESI, 114 O 646, 2014. 2017.

442. Rutledge L, Gupta RK. Moth flies and Sand Flies. Mullen G, Durden LA, editors. Amsterdam, Boston, Heidelberg, London, New York, Oxford, Paris, San Diego, San Francisco, Singapore, Sydney, Tokyo: Academic Press; 2009

443. Cicek H, Yaman M, Yagci S, Karaer Z. Phlebotomus (Diptera: Psychodidae) species around Afyon province. Ankara Univ Vet Fak Derg 2005; 52: 49-51.

444. Yaman M, Yagci S. An investigation of Tabanidae pecies (Diptera) in the Hatay province. Turkiye Parazitol Derg 2004; 28: 113-7.

445. Moon RD. Muscid flies (Muscidae). In: Mullen G, Durden LA, editors. Medical and veterinary entomology. Second Edition ed. Amsterdam, Boston, Heidelberg, London, New York, Oxford, Paris, San Diego, San Francisco, Singapore, Sydney, Tokyo: Academic Press; 2009. pp. 275-95.

446. Yabas $\mathrm{C}$. Some flies belonging to the Muscidae family in Cukurova region. Turk Bit Kor Derg 1984; 8: 105-10.

447. Scholl PJ, Catts EP, Mullen GR. Myiasis (Muscoidea, Oestroidea). In: Mullen G, Durden LA, editors. Medical and veterinary entomology. Amsterdam, Boston, Heidelberg, London, New York, Oxford, Paris, San Diego, San Francisco, Singapore, Sydney, Tokyo AP; 2009. pp. 309-38.

448. Beyhan YE, Yilmaz H, Baran Al, Tas Cengiz Z, Yakan U, Ekici A. Urogenital Myiasis Caused by Psychoda albipennis (Diptera: Psychodidae) in a Woman in Siirt. Turkiye Parazitol Derg 2015; 39: 316-8. [CrossRef]

449. Dokur M, Eroglu F, Ipek DN, Ulutasdemir N. Two different myiasis cases in southeast of Turkey: Ophthalmomyiasis and cutaneous myiasis. Parasitol Res 2015; 114: 2767-70. [CrossRef]

450. Demirel-Kaya F, Orkun O, Cakmak A, Inkaya AC, Ocal M, Erguven S. A Case of Extensive Wound Myiasis Caused by Lucilia sericata (Diptera: Calliphoridae) in a Patient with Maxillary Sinus Squamous Cell Carcinoma, in Turkey. J Arthropod Borne Dis 2016; 10: 267-70.

451. Yurumez Y, Yavuz Y, Yucel M, Cetinkaya Z, Ciftci IH. Reactions and complications to bites. Neth J Med 2016; 74: 142-3.

452. Reed HC, Landolt PJ. Ants, Wasps, and Bees (Hymenoptera). Mullen GR, Durden LA, editors. Amsterdam, Boston, Heidelberg, London, New York, Oxford, Paris, San Diego, San Francisco, Singapore, Sydney, Tokyo: AP; 2009.

453. Akyildiz B, Ozsoylu S, Ozturk MA, Inci A, Duzlu O, Yildirim A. A fatal case caused by massive honey bee stings. Turk J Pediatr 2016; 57 : 611-4.

454. Inci A, Yildirim A, Duzlu O. Caterpillar-Borne abortions in pregnant mares and camels. Erciyes Univ Vet Fak Derg 2014; 11: 191-6.

455. Durden LA, Hinkle NC. Fleas (Siphonaptera). In: Mullen GR, Durden LA, editors. Medical and veterinary entomology. Amsterdam, Boston, Heidelberg, London, New York, Oxford, Paris, San Diego, San Francisco, Singapore, Sydney, Tokyo: Academic Press; 2009. pp. 115-35.

456. Dincer S. Ankara ve çevresinde kedi (Felis domesticus), köpek (Canis familiaris) ve tilki (Vulpes vulpes)'lerde bulunan pire
(Siphonaptera)'ler üzerine sistematik araştırmalar. Ankara Univ Vet Fak Yayinlari 1971; 277: 94

457. Bandi KM, Saikumar C. Sarcoptic mange: a zoonotic ectoparasitic skin disease. JCDR 2013; 7: 156-7.

458. Deger TB, Ural K. Comparable efficacy of topical eprinomectin and permethrin for treatment of sarcoptic mange in dogs. Vet Arhiv 2013; 83: 393-402.

459. Farkas R, Estrada-Peña A, Jaenson TGT, Pascucci I. Basic biology and geographical distrubition of tick species involved in the transmission of animal pathogens, including zoonoses. In: Salman M, Tarres-Call J, editors. Ticks and Tick-borne Diseases Geographical Distribution and Control Strategies in the Euro-Asia Region UK: CABl; 2013 pp. 6-26.

460. Sonenshine DE, Roe RM. Overview, ticks, people and animals. In: Sonenshine DE, Roe RM, editors. Biology of ticks: Oxford University Press; 2014. pp. 3-16.

461. Salman M, Estrada-Pena A. Emerging (Re-emerging) tick-borne infections and the dissemination of ticks. In: Salman M, Tarres-Call J, editors. Ticks and Tick-borne Diseases Geographical Distribution and Control Strategies in the Euro-Asia Region. UK: CABI; 2013. pp. $1-5$.

462. Diaz JH. Mite-transmitted dermatoses and infectious diseases in returning travelers. J Travel Med 2010; 17: 21-31. [CrossRef]

463. Turan H, Turan A, Coban G, Gonen I. Cheyletiella dermatiti: Bir olgu sunumu. Klimik Derg 2012; 25: 127-9. [CrossRef]

464. Ozlem MB, Karaer Z, Turgut K, Eren H, Irmak K, Inci A. Efficacy of long-acting oxytetracycline on bovine anaplasmosis. Ankara Univ Vet Fak Derg 1988; 35: 1-5.

465. Akman M. Streptomycin ve Aureomycin ile tedavi edilen ikinci ruam vak'amiz. Hekimlikte Yeni Göruüşler Mecmuası 1955; 9: 2346.

466. Discontools. 2017. Available from: http://www.discontools.eu/.)

467. O'Nell J. Tackling drug-resistant infections globally: Final report and recommondations, A review on antimicrobial resistance 2016. Available from: https://amr-review.org/sites/default/files/160518_ Final\%20paper_with\%20cover.pdf

468. MacGuire RA, Coelho PRP. Parasites, pathogens, and progress: Diseases and economic development. Cambridge, MA: MIT Press; 2011.

469. Parola P, Paddock CD, Raoult D. Tick-borne rickettsioses around the world: emerging diseases challenging old concepts. Clin Microbiol rev 2005; 18: 719-56. [CrossRef]

470. Madder M, Pascucci I. Factors influencing the spread and distribution of ticks. In: Salman M, Tarres-Call J, editors. Ticks and TickBorne Diseases Geographical Distribution and Control Strategies in The Euro-Asian Region. UK: CABI; 2013. pp. 27-32.

471. Revich B, Tokarevich N, Parkinson AJ. Climate change and zoonotic infections in the Russian Arctic. Int J Circumpolar Health 2012; 71 18792. [CrossRef]

472. Anon. Global Early Warning and Response System for Major Animal Diseases, including Zoonoses (GLEWS) 2006. Available from: http:// www.acu-sy.org/en/early-warning-alert-and-response-network/?gclid=COPJh_vTwdMCFYoQOwodsaONZg 